\title{
Prototype SDC Muon Alignment-Position Monitoring Concepts
}

\author{
D. Eartly \\ Fermi National Accelerator Laboratory \\ P.O. Box 500, Batavia, Illinois 60510 \\ P. Johnson \\ Hutchinson Career Center \\ Fairbanks, Alaska
}

March 1992 


\section{Disclaimer}

This report was prepared as an account of work sponsored by an agency of the United States Government. Neither the United States Government nor any agency thereof, nor any of their employees, makes any warranty, express or implied, or assumes any legal liability or responsibility for the accuracy, completeness, or usefulness of any information, apparatus, product, or process disclosed, or represents that its use would not infringe privately owned rights. Reference herein to any specific commercial product, process, or service by trade name, trademark, manufacturer, or otherwise, does not necessarily constitute or imply its endorsement, recommendation, or favoring by the United States Government or any agency thereof. The views and opinions of authors expressed herein do not necessarily state or reflect those of the United States Government or any agency thereof. 
Fermilab

MARCH 16, 1991

FERMILAB TM 1770

\section{PROTOTYPE SDC MUON ALIGNMENT-POSITION MONITORING CONCEPTS}

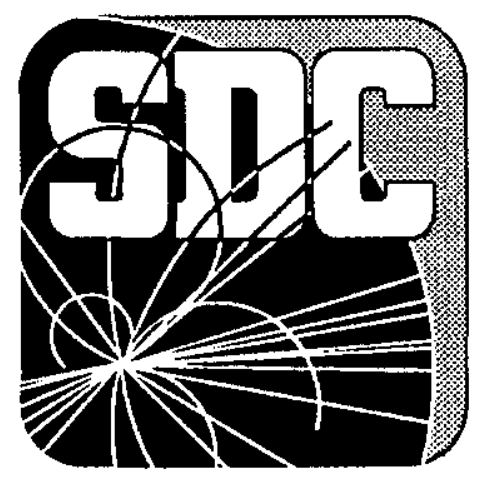

DAVID P. EARTLY, FERMILAB

PAUL T. JOHNSON,

HUTCHINSON CAREER CENTER, FAIRBANKS, ALASKA

*DOE-TRAC TEACHER RESEARCH ASSOCIATE 
ABSTRACT: We have developed and tested some prototype ideas, components, and systems for monitoring the relative planar orientations, spacings between, transverse positions and rotations of the multi Muon supermodule layers in a given SDC Muon chamber projective tower. These are described and parameterized from measurements. Their resolutions are given, and long term stabilities have been determined.

The SDC (Solenoidal Detector Collaboration) is now doing technical design studies for a general purpose, high luminosity detector at the SSC. The Central/Intermediate Muon system for this detector is visioned to be made up of a large number of proportional drift chamber supermodules grouped in three layer (inner+outer) projective towers on a $28 \mathrm{~m}$ long conventional barrel toroid magnet. The Forward systems are to be made up of five supermodule layers on the inside, inbetween, and outside the two layer Forward toroids in each end of the barrel toroid. Because of possible deflections and movements (mechanical and thermal) of the magnets, supermodules and system subassemblies, we must develop stable relative and absolute remote alignment-position monitoring schemes for the supermodules. Here we first address alignment monitoring schemes in the context of the Central system; an independent BW1 supermodule layer on the inside of the toroid, and BW2+BW3 supermodule layers connected by a box on the outside of the toroid in an octant tower configuration with in-plane kinematic mounts as shown in Figures 1a, 1b. We propose to have a matrix of boreholes through the magnet at four to six locations around the perimeter of each tower to allow us to monitor corner/edge positions of each supermodule layer. Some boreholes will be used for other purposes.

A number of prototype alignment concepts for the boreholes are being studied. The first is a mechanical wire/target/proximity sensor scheme. The test wire is fixed at one end and guided through a locating iris at the other. The wire is stretched in the horizontal plane under approximately constant tension by a compression spring at the iris end. Cylindrical metal targets are mounted along the wire 
at fixed reference locations. Three orthogonal proximity sensors $(x, y, z)$ are grouped on a common support and positioned to monitor their distances to the corresponding reference target surfaces. $X, Y$ transverse coordinates are sensed from the curved surface while the $Z$ radial coordinate is sensed from a flat endcap. Measurements have demonstrated that square targets are rotationally too unstable and would require a two wire system. Cylindrical targets do generate a coupling between the two transverse coordinate measurements. However, by using a small parabolic correction in iteration, we can derive each transverse coordinate. Table 1 illustrates some measured versus derived $x, y$ coordinates. As applied to the SDC muon system, the wire would be stretched between the inside of the BW1 supermodule and the outside of the BW3 supermodule in a tower.

Table 1. $X, Y$ Measurements on a 1.5" Dia. S.Steel Tube Target

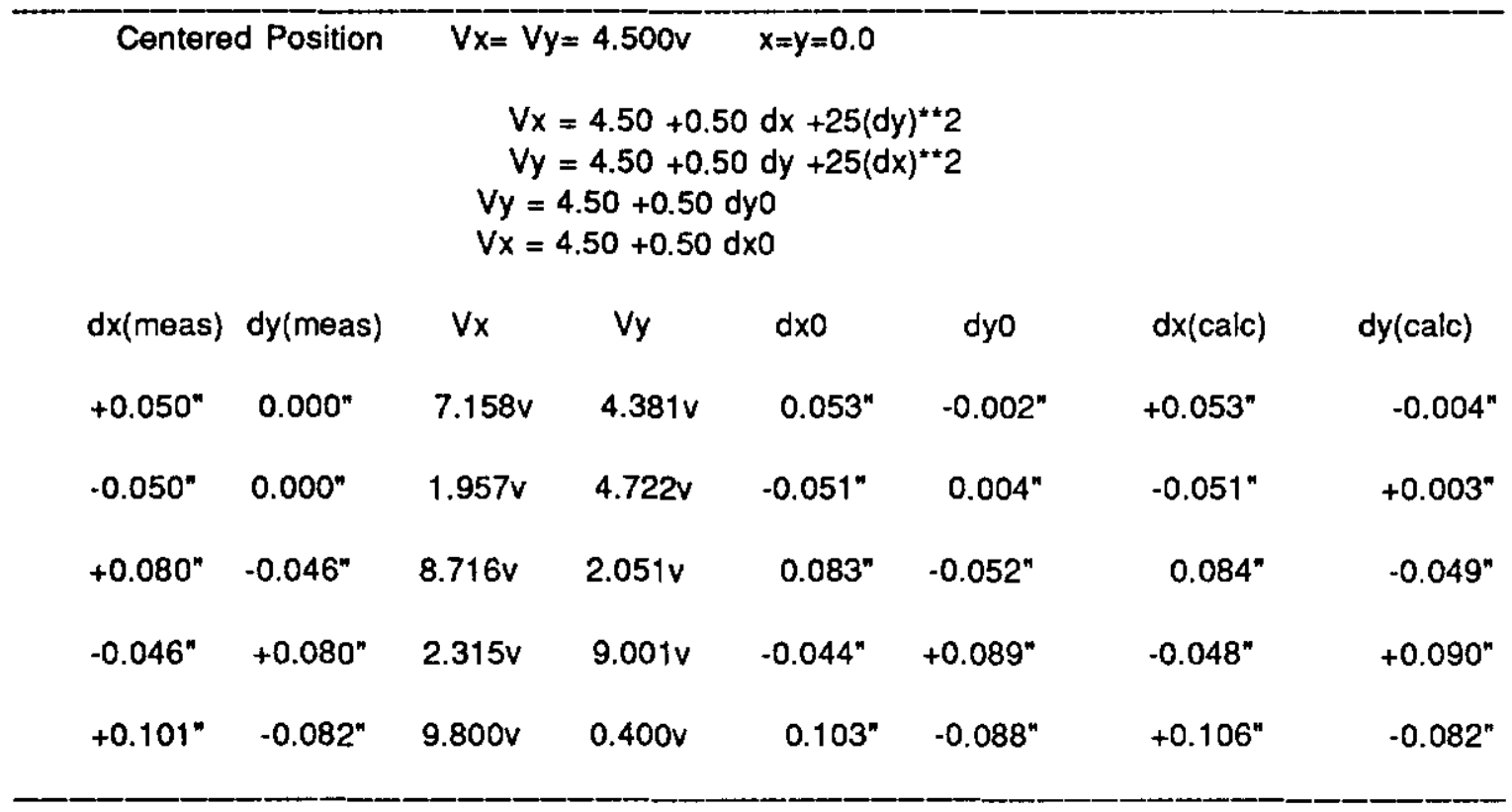

Then the $x, y, z$ position of the intermediate BW2 is determined (from the target position) relative to the outer layers. Because of fringe magnetic fields, the wire would have to be tungsten (rather than invar) and the BW2 targets non magnetic. By averaging a cluster of sensor readings, we have demonstrated that we can eliminate any effects of wire vibrations. An adaptation of this scheme (1) is to support the wire system independently inside a perforated (target areas) metal tube extending from the inside of $\mathrm{BW} 1$ to the outside of BW3. This allows position sensing by all chamber layers to the wire system. However, it requires a knowledge of the position of both ends of the wire support tube. The chosen alternate prototype of this 
scheme is the replacement of the wire and targets with a removable continuous two piece stainless steel tube with ears which projects through the magnet. On the detector, the tubes would have a $3 \mathrm{~m}$ projection outside the magnet and a $1 \mathrm{~m}$ projection inside. To use the tubes as the targets, the deflected shape of these cantilevered elements in all orientations would have to be known. Both ends of the tubes would have survey targets. The outside end could be surveyed at any time, and the inside whenever the detector end(s) is open. As these tubes project through the gaps between adjoining supermodules, we describe them as fenceposts. We (2) propose to monitor the shape and orientation of the tubes ("fenceposts") with precision narrow range inclinometers and a cascaded optics axis measurement system inside the tubes. $X, Y, Z$ linear analog proximity sensors for a supermodule would be installed in a fixture ("castle") which is aligned and calibrated in a test fixture. Fenceposts would be calibrated in a test bench setup, installed on the open magnet, and surveyed. They would be removed for tower installation and then be reinstated. Muon supermodule towers would be linked to each other by referencing to common fenceposts. Initial survey measurements of chamber and fencepost positions would be done in an assembly alignment fixture (in a surface facility) which holds the tower in its final detector equivalent position.

Capacitive proximity sensors are electrostatic and sense a change in the surrounding dielectric created by a nearby target. These sensors are relatively target metal independent. Inductive sensors (high frequency field emitters) sense an absorption of energy from an oscillator by eddy currents induced in the surface of a metal target. Magnetic targets also have magnetization flip absorption effects. Inductive sensors have the best linear response range to these targets. We are studying some self contained capacitive sensors that are relatively linear. A number of inductive proximity sensors and non magnetic metal targets have been studied in order to optimize the linear displacement sensing range. Figures $2 a, 2 b, 2 c, 2 d$ show comparative response curves for Microswitch and Turck inductive sensors of $18 \mathrm{~mm}$ and $30 \mathrm{~mm}$ head dimensions. The response of a Rechner (KAS-80-30-IL-M32) long range capacitive sensor has also been measured. These units can be adjusted to constrain the end of the near linear part of the response curve to pass through a given calibration point as shown in Figure $2 \mathrm{e}$. In good approximation this can lead to a standard approximate non linear calibration. These would be essentially target metal independent as shown in Figure $2 f$. As sensors in a high magnetic field, we are evaluating the stability of these Rechner sensors. However, they are affected by relative 
humidity fluctuations and electronic drifts greater than the thermal drifts.

The best non magnetic ranging targets for inductive sensors are stainless steel tubes or a thin skin (25-50 micron) aluminum foil on a plastic tube. The effect of a fringe magnetic field (120 gauss) oriented in different directions relative to the sensor is minimal. There is only a small shift effect for axial fields as shown in Figures 3a, 3b. Measurement of the voltage out versus distance slope (0.050v/25 micron) of a sample of six Microswitch sensors (924AB4WL2P) resulted in a sample variation of $=1 \%$ (= 2.5 micron). Deadband thresholds varied by $=250$ microns. Thus each sensor threshold would have to be measured. The sensor output was measured to be invariant to supply voltage variation between 12 and 30v DC.

Using a pair of adjacent $38 \mathrm{~mm}$ diameter stainless steel targets suspended near the middle of a $6 \mathrm{~m}$ long horizontal steel wire, we began long term stability tests on positions and proximity sensor readings over a five month period. Two fixed position reference sensors and temperature sensors (LM34) were also monitored. To provide thermal effects measurements, we allowed temperature variations of 20 deg F. All sensors provide analog outputs which are digitized by a Keithly scanning DVM ( 705 scanner, 196 DMM ) through an 10488 MacSCSI bus controller into a database on a MAC computer. Using the computer clock, we define the scanning cycle and the number of samples for averaging into a datapoint. Typically readings were taken every minute and averaged into a datapoint every fifteen minutes or half hour. We do see tracking variations (in phase/reverse phase) of all sensor readings with temperature as given in Figures $4 a, 4 b, 4 c, 4 d$. Raw data readings reflect thermal motions. When small, simple temperature corrections are made, proximity sensor readings are very stable over long time periods. In summations of extended runs, we have established limits on the uncorrected and corrected fluctuations of sensor readings over time intervals of 1000 to 3000 hours. Table 2 illustrates our results for wire supported targets where $Z$ is the gap along the wire, $Y$ is the vertical gap, and $X$ is the horizontal gap between the target and the sensor. The $Y$ fluctuations indicate a small real movement of the test steel wire (sag) with temperature. These results indicate a reasonably stable system, especially for along the wire measurements. All data include temperature effects. Microswitch sensors (MSxx) have small temperature effects but some hysteresis. Turck sensors (TKyy) have larger temperature effects but little hysteresis, so they can be corrected with small linear parametric terms. 
Table 2. Measured properties of fixed proximity sensors on two wire targets: resolution, average value, deviation, extreme data values.

DBASE SENSOR M DVIDX RES $\langle V\rangle$ STDEV <T> DT DVMAX DVMIN

I. Transverse and Longitudinal Fencepost Proximity Sensors

\begin{tabular}{|c|c|c|c|c|c|c|c|c|}
\hline $\begin{array}{l}\text { Sum3 MS30 } \\
\text { Raw Data }\end{array}$ & XwN & $\begin{array}{l}0.0500 \\
\mathrm{v} / \mathrm{mil}\end{array}$ & $\begin{array}{l}0.25 \\
\mu \mathrm{m}\end{array}$ & $\begin{array}{c}3.8622 \\
v\end{array}$ & $\begin{array}{l}0.0087 v \\
(4.4 \mu)\end{array}$ & $\begin{array}{cc}77.56 & +4.45 \\
\operatorname{deg} F & -4.2\end{array}$ & $\begin{array}{c}+0.0267 v \\
(13.6 \mu)\end{array}$ & $\begin{array}{r}-0.0202 v \\
(-10.3 \mu)\end{array}$ \\
\hline $\begin{array}{l}\text { um3 TK30 } \\
\text { aw Data }\end{array}$ & ZwN & $\begin{array}{l}0.0573 \\
\mathrm{v} / \mathrm{mil}\end{array}$ & $\begin{array}{r}0.25 \\
\mu m\end{array}$ & $\begin{array}{c}7.9368 \\
v\end{array}$ & $\begin{array}{l}0.0228 v \\
(10.1 \mu)\end{array}$ & & $\begin{array}{l}+0.0520 \mathrm{~V} \\
(23.1 \mu)\end{array}$ & $\begin{array}{l}-0.0659 \mathrm{v} \\
(29.2 \mu)\end{array}$ \\
\hline $\begin{array}{l}\text { um3 MS30 } \\
\text { aw Data }\end{array}$ & $Y w N$ & $\begin{array}{c}0.0500 \\
\mathrm{v} / \mathrm{mil}\end{array}$ & $\begin{array}{c}0.25 \\
\mu \mathrm{m}\end{array}$ & $\begin{array}{c}5.8799 \\
\vee\end{array}$ & $\begin{array}{l}0.0877 v \\
(44.5 \mu)\end{array}$ & $\begin{array}{l}\text { Wire } \\
\text { Sag }\end{array}$ & $\begin{array}{l}+0.1337 v \\
(67.9 \mu)\end{array}$ & $\begin{array}{l}-0.3233 v \\
(164.3 \mu)\end{array}$ \\
\hline $\begin{array}{l}\text { Sum3 MS30 } \\
\text { Raw Data }\end{array}$ & ZwS & $\begin{array}{r}0.0500 \\
\mathrm{v} / \mathrm{mil}\end{array}$ & $\begin{array}{l}0.25 \\
\mu \mathrm{m}\end{array}$ & $\begin{array}{c}4.7644 \\
v\end{array}$ & $\begin{array}{c}0.0039 \mathrm{v} \\
(2.0 \mu)\end{array}$ & & $\begin{array}{c}+0.0109 \mathrm{v} \\
(5.5 \mu)\end{array}$ & $\begin{array}{l}-0.0154 v \\
(-7.8 \mu)\end{array}$ \\
\hline $\begin{array}{l}\text { Sum3 MS30 } \\
\text { Raw Data }\end{array}$ & XwS & $\begin{array}{r}0.0500 \\
\mathrm{v} / \mathrm{mil}\end{array}$ & $\begin{array}{r}0.25 \\
\mu \mathrm{m}\end{array}$ & $\begin{array}{c}4.3070 \\
v\end{array}$ & $\begin{array}{l}0.0074 v \\
(3.8 \mu)\end{array}$ & & $\begin{array}{l}+0.0216 \mathrm{v} \\
(11.0 \mu)\end{array}$ & $\begin{array}{l}-0.0214 v \\
(10.9 \mu)\end{array}$ \\
\hline $\begin{array}{l}\text { Sum3 Ms30 } \\
\text { Paw Data }\end{array}$ & YwS & $\begin{array}{l}0.0500 \\
\mathrm{v} / \mathrm{mil}\end{array}$ & $\begin{array}{l}0.25 \\
\mu \mathrm{m}\end{array}$ & $\begin{array}{c}7.0795 \\
v\end{array}$ & $\begin{array}{l}0.0656 \mathrm{v} \\
(33.3 \mu)\end{array}$ & $\begin{array}{l}\text { Wire } \\
\text { Sag }\end{array}$ & $\begin{array}{c}+0.1061 v \\
(53.9 \mu)\end{array}$ & $\begin{array}{c}-0.2420 v \\
(123.0 \mu)\end{array}$ \\
\hline
\end{tabular}

Two fixed sensors looking at the support base of the wire system vary in reverse phase with temperature (Figures $4 e, 4 f)$ and provide limits on fluctuations for sensors looking at a "fencepost" as given in Table 3. Sensor head thermal motions dominate over support motions.

Table 3. Measured properties of fixed table proximity sensors in long dat summaries: resolution, average value, deviation, temperature range, extreme data values.

DBASE SENSOR M DV/DX RES <V> STDEV <T> DT DVMAX DVMIN

I. Transverse and Longitudinal Fencepost Proximity Sensors

\begin{tabular}{|c|c|c|c|c|c|c|c|c|}
\hline $\begin{array}{l}\text { Sum7 MS18 } \\
\text { Raw Data }\end{array}$ & d $\begin{array}{c}0.0627 \\
\mathrm{v} / \mathrm{mil}\end{array}$ & $\begin{array}{l}0.11 \\
\mu \mathrm{m}\end{array}$ & $6.7585 \mathrm{v}$ & $\begin{array}{l}0.0035 v \\
(1.4 \mu)\end{array}$ & $\begin{array}{l}77.56 \\
\operatorname{deg} F\end{array}$ & $\begin{array}{l}+4.45 \\
-4.2\end{array}$ & $\begin{array}{c}+0.0071 \mathrm{v} \\
(2.9 \mu)\end{array}$ & $\begin{array}{r}-0.0110 \mathrm{v} \\
(-4.5 \mu)\end{array}$ \\
\hline $\begin{array}{l}\text { Sum6 TK18 d } \\
\text { Raw Data -Tdep }\end{array}$ & $\begin{array}{l}0.0681 \\
\mathrm{v} / \mathrm{mil}\end{array}$ & $\begin{array}{l}0.21 \\
\mu \mathrm{m}\end{array}$ & $7.1009 v$ & $\begin{array}{l}0.0132 \mathrm{v} \\
(5.8 \mu)\end{array}$ & $\begin{array}{l}78.31 \\
\operatorname{deg} F\end{array}$ & $\begin{array}{l}+7.09 \\
-6.98\end{array}$ & $\begin{array}{r}+0.0285 v \\
(12.4 \mu)\end{array}$ & $\begin{array}{r}-0.0455 v \\
(-19.8 \mu)\end{array}$ \\
\hline $\begin{array}{l}\text { Sum6 TK18 d } \\
\text { Parametric Tcorr }\end{array}$ & $\begin{array}{l}0.0681 \\
\mathrm{v} / \mathrm{mil}\end{array}$ & & & $\begin{array}{l}0.0084 \mathrm{v} \\
(3.7 \mu)\end{array}$ & & & $\begin{array}{c}+0.0148 \mathrm{v} \\
(6.5 \mu)\end{array}$ & $\begin{array}{r}-0.0228 v \\
(-10.0 \mu)\end{array}$ \\
\hline
\end{tabular}


As another method to monitor the relative transverse positions of chamber supermodules etc, we have developed light emitting diode and optics unit assemblies which could mount on BW3 bulkheads etc, and provide a focus at an $X, Y$ position sensing photodiode mounted on BW2, BW1 bulkheads etc as indicated in Figure 5 . In this scheme, we assume that the source and lens assembly pointing angle is relatively stable and that changes in the $X$ and $Y$ difference outputs reflect $a$ motion of the photodiode. Figures $6 a, 6 b$ illustrate a typical sensor readout circuit and response curve respectfully.

We had some concern over the stability of pulsed LED outputs. So rather than modulating the source and doing synchronous detection, we have concentrated on testing the DC luminous output and stability of a large sample of near and far infrared emitting diodes as measured by different photodiodes masked with various longpass optical filters. In this process, we have suppressed the effect of ambient light background (including sunset infrared) on the system, for wavelength cutoffs at $630 \mathrm{~nm}$ and above. Large photodiodes $(25 \mathrm{~mm})$ were best stabilized with cutoffs around $760 \mathrm{~nm}$.

Quadrant Photodiode detectors like United Detector Technologies (UDT) Spot 9D and Silicon Detector Corporation (SDC) SD 197-23-21041(98) provide a sharp but very limited range of light spot position measurement about a null as indicated in Figure 7. As we want to track position excursions of several millimeters, we must trade sensitivity for range by using continuous differential position sensing diodes. Our linear range goal was $+-5 \mathrm{~mm}$. Using precision $X, Y$ micrometer stages supporting the diode assembly, we measured the response of UDT SC10D, DL10, and SC25D continuous position sensing photodiodes to calibrated diode motions in different optical configurations. Some response curves are shown in Figures $8 \mathrm{a}, 8 \mathrm{~b}$. Using a pinhole mask $(0.33 \mathrm{~mm})$, we could also measure optical focus profiles (nominally Gaussian) as shown in Figure 9. A number of optical source diodes were evaluated in given optical configurations as shown in Figure 10.

The initial round of testing and optimization resulted in the selection of the MARKTECH MTE108CL LED $(940 \mathrm{~nm})$, the UDT SC25D photodiode for range rather than sensitivity, and a two glass lens optics configuration for the BW3 to BW1 path $(f 63 \mathrm{~mm}, f 400 \mathrm{~mm}$, $780 \mathrm{~nm}$ longpass filter) and for the BW3 to BW2 path (f50, f340, $630 \mathrm{~nm}$ longpass filter). Alternate possible lens and filter configurations will be evaluated. A series of long term stability tests were initiated with the above configurations. For each configuration, we set the diodes with large $X$ displacements of the 
light spot on the photodiode and small (null) $\mathrm{Y}$ displacements. These tests indicated a temperature variation of VXdiff (left-right) difference voltage and VYdiff (up-down) difference voltage which track local temperature fluctuations as shown in Figures 11a, 11b, 11c, 11d superposed on some long term drifts. We have not tried to uncouple LED, photodiode, amplifier, or structural thermal effects. The tests have established limits on the thermally uncorrected and corrected resolutions, fluctuations, and drifts which are given in Table 4. These are dominated by the long term drifts. We will continue to try to improve and optimize these results with sum output normalization of the source and electronics fluctuations. We have not experimented with laser diode sources because of safety and access considerations. In more limited detector applications, the LED/optics system can be replaced with an enclosed Laser system and future tests will be made to evaluate beam stability. We are also testing a short path, short optics configuration for transverse position linking between the Forward and Intermediate Muon systems (IW2-FW2) with much smaller pointing fluctuations.

Table 4. The measured properties of the BW3 to BW1 and BW3 to BW2 optical transverse displacement sensor systems under study; resolution, average value, deviation, extreme data values.

DBASE SENSOR M DV/DX RES $\langle V\rangle$ STDEV $<T>$ DT DVMAX DVMIN

II. Transverse Optics ( $25 \mathrm{~mm}$ Continuous position sensing photodiodes)

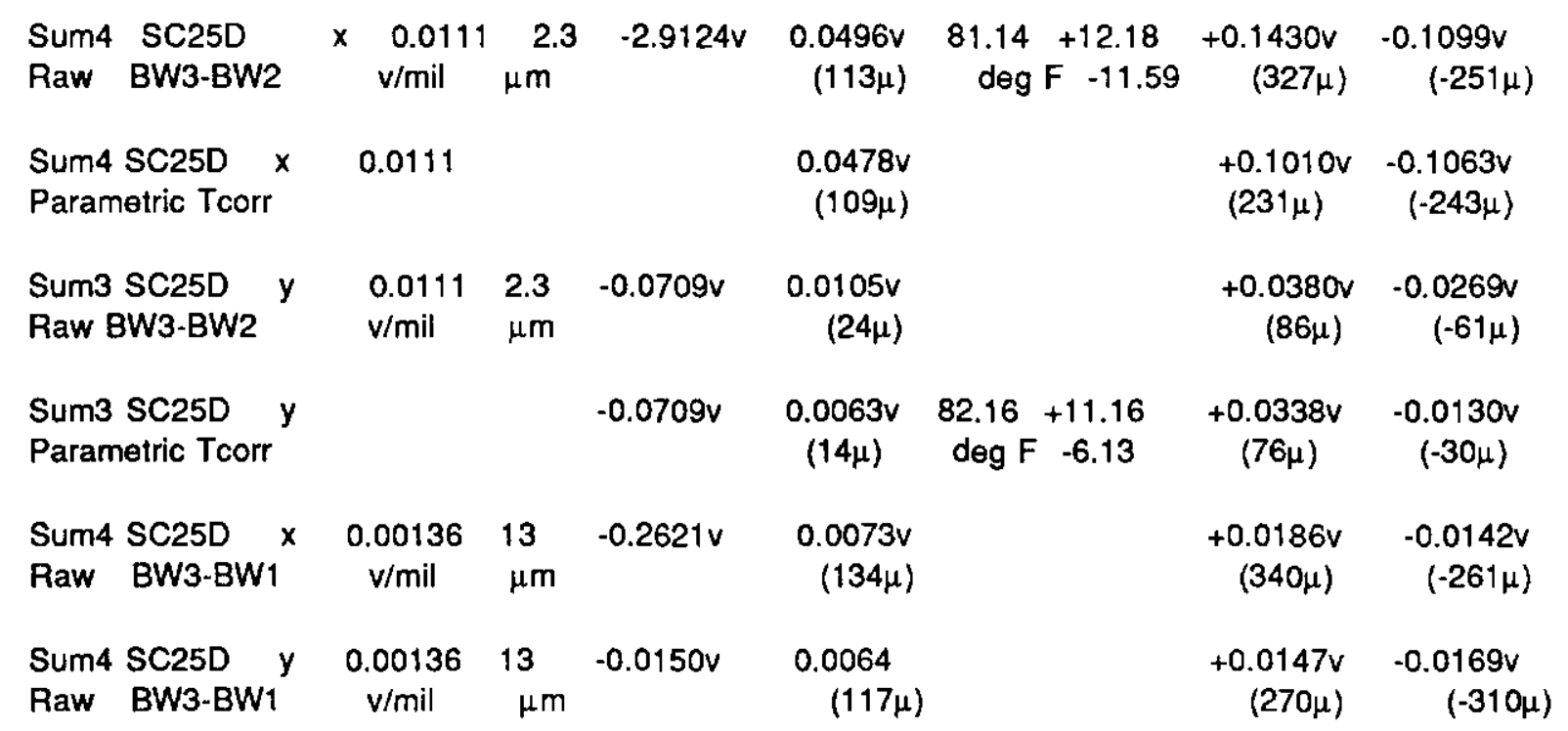


There are spacings (distances) between parts of the detector that must be measured and cannot be connected by physical rulers. One idea we have been investigating is Ultrasonic ranging. Intrinsically, there are serious thermal (propagation velocity) and air current effects. Also the transmitted and reflected beam burst profiles are large in cross section and can be influenced by transmitter/target surroundings. There can be interfering reflections and modifications of the propagation velocity by compression effects.

To initiate the study, we measured the properties of a self contained $200 \mathrm{Khz}$ transmitter-receiver from SELECTRON (Selprox UA-ASP4002/K) which has an analog output proportional to the passive relective target distance $(30-200 \mathrm{~cm})$ with a gradient of $0.010 \mathrm{v} / \mathrm{mm}$ as shown in Figure 12 The inverse temperature dependence is $3.3 \mathrm{mv}(0.33 \mathrm{~mm}) /$ deg $F$. It has a short term corrected stability of $+-0.02 \mathrm{v}$. Typical hysteresis sets a resolution limit of +$0.01 \mathrm{v}$. Long term tests indicate a stability of measurement of only $+-0.20 \mathrm{v}$ or $20 \mathrm{~mm}$. We then tested the effects of boundaries. With the sensor centerline $5 \mathrm{~cm}$ above a smooth metal surface, there were no reflections or detected compression effects. Likewise, we were able to transmit through a $76 \mathrm{~mm}$ square $O D, 70 \mathrm{~mm}$ ID tube to a reflection target with a small compression effect i.e., a $1.15 \%$ decrease in the apparent target distance. Typically, we could withdraw the unit from the start of the tube by $15 \mathrm{~cm}$ before beam reflections occured from the tube leading edges. Similar studies were performed on a Migatron (RPS-401A-72) self contained sensor with poorer results on resolution. This unit had a gradient of $0.005 \mathrm{v} / \mathrm{mm}$ with a hysteresis up to $0.01 \mathrm{v}$ and a short term stability of $+-0.01 \mathrm{v}$. Finally, we compared the performance of a self contained, temperature compensated Microswitch (945-L4Y-2D-1CO) analog ultrasonic position sensor with a gradient of $0.01 \mathrm{v} / \mathrm{mm}$. Figures $13 \mathrm{a}, 13 \mathrm{~b}$ indicate the linearity and resolution of this unit. Instantaneous stability is $200 \mu$. Extended testing of the sensor on a fixed target indicates small in phase temperature fluctuations of measurements as shown in Figure 14. A simple parametric temperature correction can improve the long term resolution to that for a short period measurement (resolution).

As another version of an Ultrasonic distance measuring system, we are testing the Migatron RPS -8800 unit. This is an 8 channel device operated by a microprocessor. The system transmits and receives back (from a passive target) on each of the transducers in sequence at a defined rate and creates adjustable stack average readings for each transducer. The system sends out the stack 
average data in an RS232 protocol. This serial read in was added to our monitoring system at a MAC serial port.(3) With a target at a fixed, defined distance, one channel (T3) is used as a temperature (velocity) correction measurement. Also this unit attempts to improve the system resolution by gain controlling the receiving amplifier (reflection burst amplitude) and triggering on a fixed threshold corresponding to the fourth oscillation in the reflection burst. In our experience, we found it necessary to capacitively phase shift one transducer (T3) in order to keep all transducer reflections within the proper trigger bounds. Otherwise, there were fluctuations in measurements of fixed targets of $+-1 \mathrm{~mm}$ even in the short term. The best short term resolution measured over a hour was $+-0.1 \mathrm{~mm}$. As with all other sensors, we were able to take a sample of readings over a defined interval and create another average of readings. Typically this was 30 minutes. Figure 15 illustrates the long term fluctuations of corrected system readings (T3) on a very distant target over an open path as compared to the measured temperature distribution. There is a small thermal structure but the system reflects calibration instabilities in temperature excursions. There are calibration shift fluctuations as large as $1.5 \mathrm{~mm}$. However, there have been extended periods of time when the system exhibits +$0.2 \mathrm{~mm}$ stability on an extreme fixed target distance of $1258 \mathrm{~mm}$. A new microprocessor with modified programming has been installed to attempt to eliminate the shifts. Tests on shorter fixed target distances (lowered amp gain) are underway. Figure 16a illustrates the precise inverse tracking of temperature by the calibration channel. Figure $16 \mathrm{~b}$ illustrates long term readings on a fixed target at comparable distance. It reflects a tracking thermal dependence with a periodic well defined instablity. Finally Figure 16c demonstrates a more confused thermal fluctuation. Measured properties of the ultrasonic distance measurement systems are summarized in Table 5.

Since we need to provide accurate distance measurements between major parts of the SDC Muon system, we choose to test a short range, high resolution reflected laser light beam device

KEYENCE LB11 sensor + LB70 Controller which is schematically illustrated in Figure 17. Its measured resolution and linearity is shown in Figure 18. Long term measurements on a fixed target are shown in Figure 19. These indicate small tracking temperature fluctuations which can be reduced by a parametric correction. Resultant stabilities on the order of +-60 microns can be achieved for distances of $130 \mathrm{~mm}$. 
Table 5. The measured properties of some ultrasonic distance measuring sensor systems under study. Resolution, average value, deviation, and extreme data values are given.

DBASE SENSOR M DV/DX RES $\langle V\rangle$ STDEV $<T\rangle$ DT DVMAX DVMIN

I. Long and Short Range Ultrasonic Distance

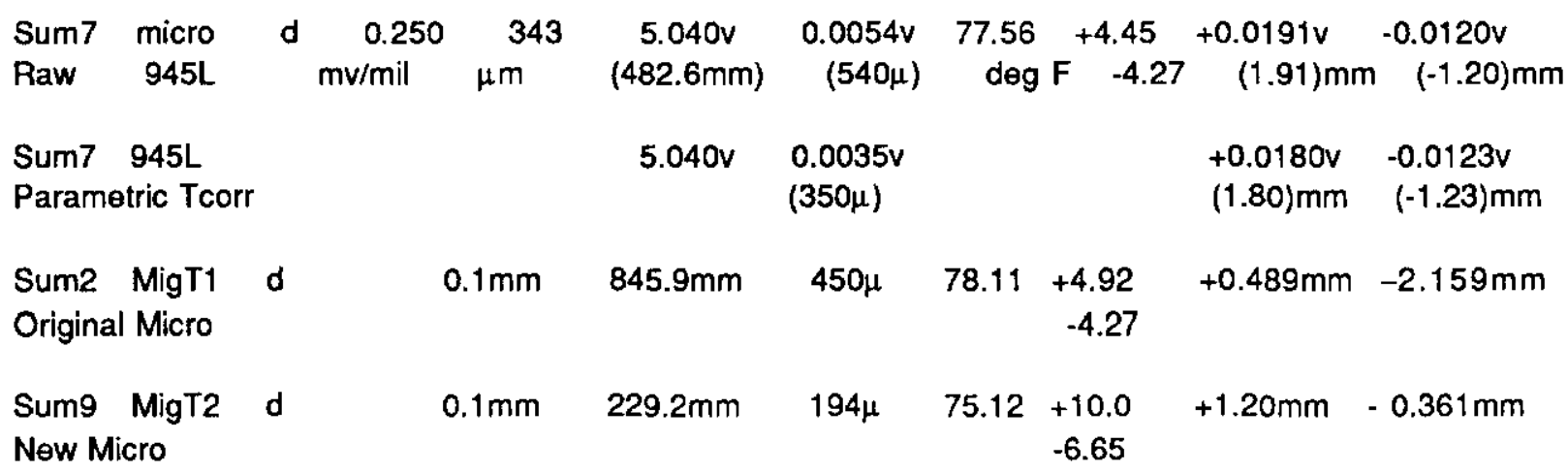

With such laser diode systems measuring the gaps between the Barrel and Forward chamber systems we can link these radially with the required resolution. Measured properties without and with a simple parametric temperature correction are given in Table 6.

Table 6. The measured properties of a LED-photodiode distance measuring sensor system under study. Resolution, average value, deviation, and extreme data values are given.

DBASE SENSOR M DV/DX RES $<V>$ STDEV $<T>$ DT DVMAX DVMIN

II. Laser Distance Device (Keyence LB11+LB70)

\begin{tabular}{|c|c|c|c|c|c|c|c|c|}
\hline $\begin{array}{l}\text { Sum7 LB11 } \\
\text { Raw Data }\end{array}$ & $\begin{array}{c}2.457 \\
\mathrm{mv} / \mathrm{m}\end{array}$ & $\begin{array}{l}0.4 \\
\mu \mathrm{m}\end{array}$ & $2.994 \mathrm{v}$ & $\begin{array}{l}0.0121 v \\
(125 \mu)\end{array}$ & $\begin{array}{l}77.56 \\
\operatorname{deg} F\end{array}$ & $\begin{array}{l}+4.45 \\
-4.27\end{array}$ & $\begin{array}{c}+0.0273 v \\
(282 \mu)\end{array}$ & $\begin{array}{r}-0.0280 v \\
(-289 \mu)\end{array}$ \\
\hline $\begin{array}{l}\text { Sum7 LB11 } \\
\text { Parametric Tcorr }\end{array}$ & & & $2.994 \mathrm{v}$ & $\begin{array}{l}0.0056 \mathrm{v} \\
(58 \mu)\end{array}$ & & & $\begin{array}{c}+0.0105 v \\
(108 \mu)\end{array}$ & $\begin{array}{c}-0.0161 v \\
(-166 \mu)\end{array}$ \\
\hline
\end{tabular}

Because of possible shape changes of the SDC Barrel toroid resulting from changes in its support; muon system elements will pitch, yaw, and roll. Thermal distortions and magnet load changes may also result in these rotations and in changes in element shape. As a consequence, we have the need for precision inclinometers to measure local orientations of supermodules and Muon subassemblies 
as well as local regions of all magnet faces. To that end, we have been studying some sample electrolytic bubble tilt meters built for the D0 detector at Fermilab.(4) The sensors are mounted in pairs on thermally insulated aluminum blocks with a heater circuit that holds their temperature stable; nominally to $0.1 \mathrm{deg} C$, as illustrated in Figure 20. In our initial test setup two blocks are mounted on a common baseplate supported at three points on a simply supported beam sitting on a thin concrete slab. The system is subject to vibrations in the building. For our tests we have both sensors in each block in the same transverse orientation and two sets (blocks 1,2) in the same orientation (along the axis of our support bench) for redundancy and relative tracking tests. Figure 21 illustrates the readings of one of the bubble circuits $(B)$ of the two bubble meters in block 1 for an extended period of time as compared to the ambient background temperature distribution. We observe some real physical motion of the bubble with temperature. The relative alignment of the two bubbles $(1 \mathrm{~B}, 1 \mathrm{D})$ in the block is very good. When we compare the difference of readings for circuits $B$ and $D$ in block 1 , there is essentially no structure but only small long term drifts as shown in Figure 22. They have a nearly linear response to tilt angle with a $0.00125 \mathrm{v} / \mathrm{sec}$ gradient. The two channels track each other in long term runs to typically 2 parts in $10^{* *} 4$ (less than $2 \mu \mathrm{rad}$ ). The variation of their readings with the temperature variations indicate that our support base wiggles with temperature changes. The corresponding long term readings of a bubble in block 2 is illustrated in Figure 23. The fluctuations are comparable to block 1 and the variations in the two bubble meters in block 2 follow those in block 1 but with larger deviations. We do not have the calibrations of the microstructure (differential gradients) of each bubble at this time. The raw, relative typical fluctuations of these two bubble meters is more like $0.075 \mathrm{v}$ or 30 microradians. To monitor $7 \mathrm{~m}$ objects to $0.15 \mathrm{~mm}$, the tilt meter long term drift must be limited to 20 microradians. We will test a larger sample of sensors under more controlled conditions and complete microstructure calibrations of each unit involved. Data from long term stability tests which include two bubble differences on the same block are given in Table 7 .

As another relative transverse position measurement scheme which could be used away from the magnets, especially at the Intermediate region ends, we are experimenting with a prototype wire current $(3 \mathrm{Khz})$ differential leakage flux transformer scheme (5). A crossing grid of vertical wire currents could define a reference plane for the Intermediate region supermodules. Transformers on the outside of these supermodules would measure their local relative 
Table 7. The measured properties of the bubble inclinometer angle sensor system under study; resolution, average value, deviation, extreme data values.

DBASE SENSOR M DVIDX RES <V $\quad$ STDEV $<T>$ DT DVMAX DVMIN

IV. Two Degree Inclinometers-Tilt angles

\begin{tabular}{|c|c|c|c|c|c|c|c|c|}
\hline $\begin{array}{l}\text { Sum2 INC1,B } \theta \\
\text { Raw }\end{array}$ & $\begin{array}{r}1.25 \\
\mathrm{mv} / \mathrm{sec}\end{array}$ & $\begin{array}{l}26.8 \\
\mu \mathrm{rad}\end{array}$ & $-0.0190 \mathrm{v}$ & $\begin{array}{l}0.1322 v \\
(512 \mu \mathrm{rad})\end{array}$ & $\begin{array}{r}77.56 \\
\operatorname{deg} F\end{array}$ & $\begin{array}{l}+4.92 \\
-4.27\end{array}$ & $\begin{array}{c}+0.3692 \mathrm{v} \\
\text { (real) }\end{array}$ & $\begin{array}{r}-0.4240 \mathrm{v} \\
\text { (real) }\end{array}$ \\
\hline $\begin{array}{l}\text { Sum2 INC1,B } \\
\text { Parametric T corr }\end{array}$ & & & $-0.0190 \mathrm{v}$ & $\begin{array}{l}0.1195 v \\
(463 \mu)\end{array}$ & & & $\begin{array}{c}+0.3748 v \\
\quad \text { (real) }\end{array}$ & $\begin{array}{c}-0.3653 \mathrm{v} \\
\text { (real) }\end{array}$ \\
\hline $\begin{array}{l}\text { Sum2 INC1,B-INC1,D } \\
\text { Raw }\end{array}$ & & & $\begin{array}{l}+0.0003 \mathrm{v} \\
(1.1 \mu \mathrm{rad})\end{array}$ & $\begin{array}{l}0.0004 \mathrm{v} \\
(1.6 \mu \mathrm{rad})\end{array}$ & & & $\begin{array}{l}+0.0013 \mathrm{v} \\
(4.9 \mu \mathrm{rad})\end{array}$ & $\begin{array}{r}-0.0008 \mathrm{v} \\
(-3.1 \mu \mathrm{rad})\end{array}$ \\
\hline $\begin{array}{l}\text { Sum2 INC2,H } \\
\text { Raw }\end{array}$ & 1.25 & & $+0.0512 v$ & $\begin{array}{c}0.1133 v \\
(438 \mu \mathrm{rad})\end{array}$ & & & $\begin{array}{l}+0.2750 \mathrm{~V} \\
\text { (real) }\end{array}$ & $\begin{array}{c}-0.3761 \mathrm{v} \\
\text { (real) }\end{array}$ \\
\hline
\end{tabular}

displacements with respect to the wire plane which can be surveyed. Different prototype transformer configurations are being tested. Two $(2 \mathrm{~cm} \times 2 \mathrm{~cm}$ ID, $3 \mathrm{~cm} \times 3 \mathrm{~cm}$ ID) thin, square, tape wound permaloy transformers are being evaluated.(6) Also two $(4 \mathrm{~cm} \times 4 \mathrm{~cm}$ ID) quadrant segmented, square, single layer transformers are also being evaluated. At present, each transformer has one pair of leftright bucking pickup coils with about seventy turns in the vertical aperture. All initial measurements indicate a linear differential output with horizontal displacement of the wire from the center of the transformer as shown in Figure 24 for the $15 \mathrm{~cm}$ long $2 \mathrm{~cm} \times 2 \mathrm{~cm}$ ID unit. Variation of the output with vertical motion of the wire is very small and reflects minor coil assymmetries and is shown in Figure 25. Figure 26 illustrates the temperature dependence of the output in a short thermal cycle of running and demonstrates an inverse thermal dependence. The first long term summation of running is illustrated in Figure 27. There are some current input and amplifier output instabilities that need to be eliminated as evidenced by the mid run discontinuity and current monitoring. We are going to implement commercial LVDT electronics into the system in an attempt to eliminate source current and gain shifts. On the average, the transformers demonstrate stable behavior. The initial results of long term tests in progress are given in Table 8.

With a model transformer that allows variation in core thickness, we will attempt to optimize the differential signal for a given geometry and aperture. 
Table 8. The measured properties of the current carrying wire-pickup transformer displacement system under study; resolution, average value, deviation, extreme data values.

DBASE SENSOR M DV/DX RES $\langle\mathrm{V}\rangle$ STDEV $<T>$ DT DVMAX DVMIN

III. Wire -Leakage Flux Transformers-Transverse position or distance

\begin{tabular}{|c|c|c|c|c|c|c|c|c|c|}
\hline $\begin{array}{lc}\text { Fair1 } & \text { HJ } \\
\text { Raw } & 22 / 66 / 2\end{array}$ & $x$ & $\begin{array}{c}0.0232 \\
\mathrm{v} / \mathrm{mil}\end{array}$ & $\begin{array}{c}3.3 \\
\mu \mathrm{m}\end{array}$ & $-4.530 \mathrm{v}$ & $\begin{array}{l}0.0561 \mathrm{v} \\
(60 \mu)\end{array}$ & $\begin{array}{l}84.34 \\
\operatorname{deg} F\end{array}$ & $\begin{array}{r}+4.40 \\
-3.20\end{array}$ & $\begin{array}{c}+0.1140 v \\
(123 \mu)\end{array}$ & $\begin{array}{r}-0.1151 \mathrm{v} \\
(124 \mu)\end{array}$ \\
\hline $\begin{array}{l}\text { Fair1 HJ } \\
\text { Parametric Tcorr }\end{array}$ & & & & $-4.530 \mathrm{v}$ & $\begin{array}{l}0.0457 v \\
(50 \mu)\end{array}$ & & & $\begin{array}{l}+0.0870 \mathrm{v} \\
(95 \mu)\end{array}$ & $\begin{array}{c}-0.0 .914 v \\
(100 \mu)\end{array}$ \\
\hline
\end{tabular}

\section{Conclusions}

We are continuing long term stability tests on various systems. The inclinometers will be studied on an optical bench in a controlled environment to understand their true resolution and stability. Inductive proximity sensing has been demonstrated to be an appropriate system $(5 \mu \mathrm{m}$ corrected stability) for muon supermodule position monitoring outside the strong solenoid field. The capacitive sensors we studied can be used in the high field regions but need calibration curves and humidity monitoring. A self monitoring prototype "fencepost" will be built and tested with a prototype supermodule. Sample far IR LED-25mm continuous position sensing photodiode systems have been shown to be an appropriate relative transverse position sensing $(100 \mu \mathrm{m}$ corrected stability) for large relative displacement ranges of $+-6 \mathrm{~mm}$. For smaller ranges like +$3 \mathrm{~mm}, 10 \mathrm{~mm}$ position sensing diodes would provide $50 \mu$ stability while quadrant photodiodes (+- $1.5 \mathrm{~mm}$ range) might provide $20 \mu$ stability. They can function in the open detector ambient background. Stable 60 to $150 \mathrm{~mm}$ high precision $(50 \mu)$ distance measurements have been demonstrated with a laser diode-optics-position sensing photodiode system. At least one Ultrasonic system we have studied can yield $350 \mu \mathrm{m}$ resolution on a $500 \mathrm{~mm}$ distance measurement. The precision inclinometers we have studied appear to be of adequate resolution (30 microradians) for our application and can potentially have a few microradian resolution using bubble difference data. The source wire-pickup transformer system is capable of $50 \mu \mathrm{m}$ 
resolution with good input current regulation and output amplifier gain. High quality LVDT electronics is needed.

\section{References}

(1) Originally suggested by J. J. Cherwinka, Physical Sciences Laboratory at the University of Wisconsin, Madison

(2) SDC Technical Design report-muon alignment section by D. Eartly, C. Grinnell, J. Govignon, D. Veal and R. Davisson, SSCL report

(3) Software additions by D. Shea, Fermilab

(4). Hans Jostlein, The electronic alignment system at the Fermilab DO detector, D0 Technical note 999, Fermilab, Batavia, Illinois

(5). Hans Jostlein, Unpublished study, Fermilab Physics Department, Fermilab, Batavia, Illinois

(6). Measurements being taken by the students of the Electronics and Technology classes of Hutchison Career Center, Fairbanks, Alaska

\section{Acknowledgements}

We want to thank Hans Jostlein for his valuable comments, review, and guidance, for the loan of a computer and scanning readout system, and for the loan of sample inclinometers, etc. Likewise, we wish to thank A. Lathrop, T. Mantsch for their help in getting us set up. We thank the Fermilab Physics Department for their help and support, loans of equipment, provision of facilities for the long term tests, etc. Finally, we wish to thank R. Maly for his work in developing and building our many "widgets". 


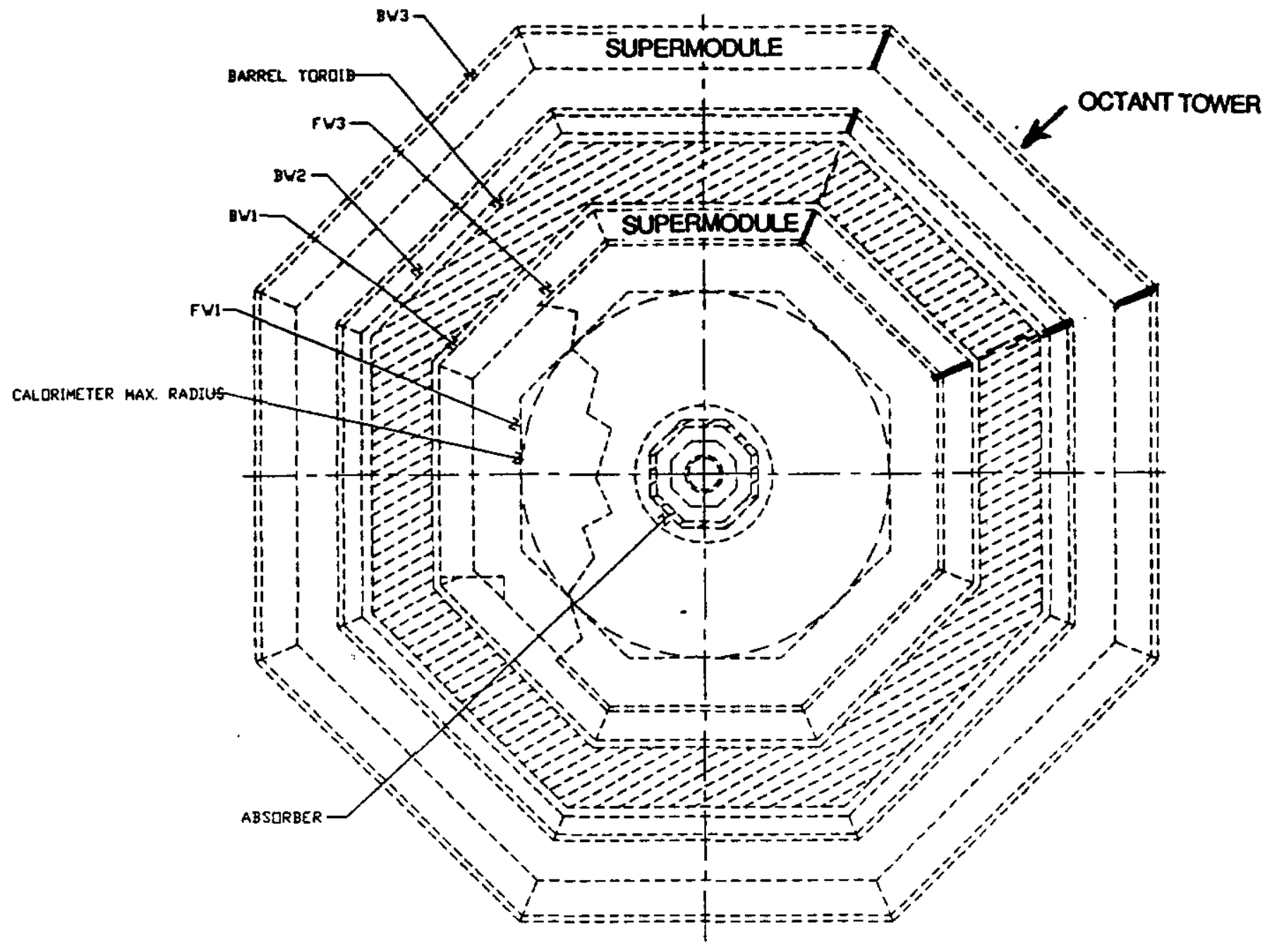

Figure 1a. Schematic SDC Barrel Octant cross section view with BW1, BW2, BW3 projective towers. 


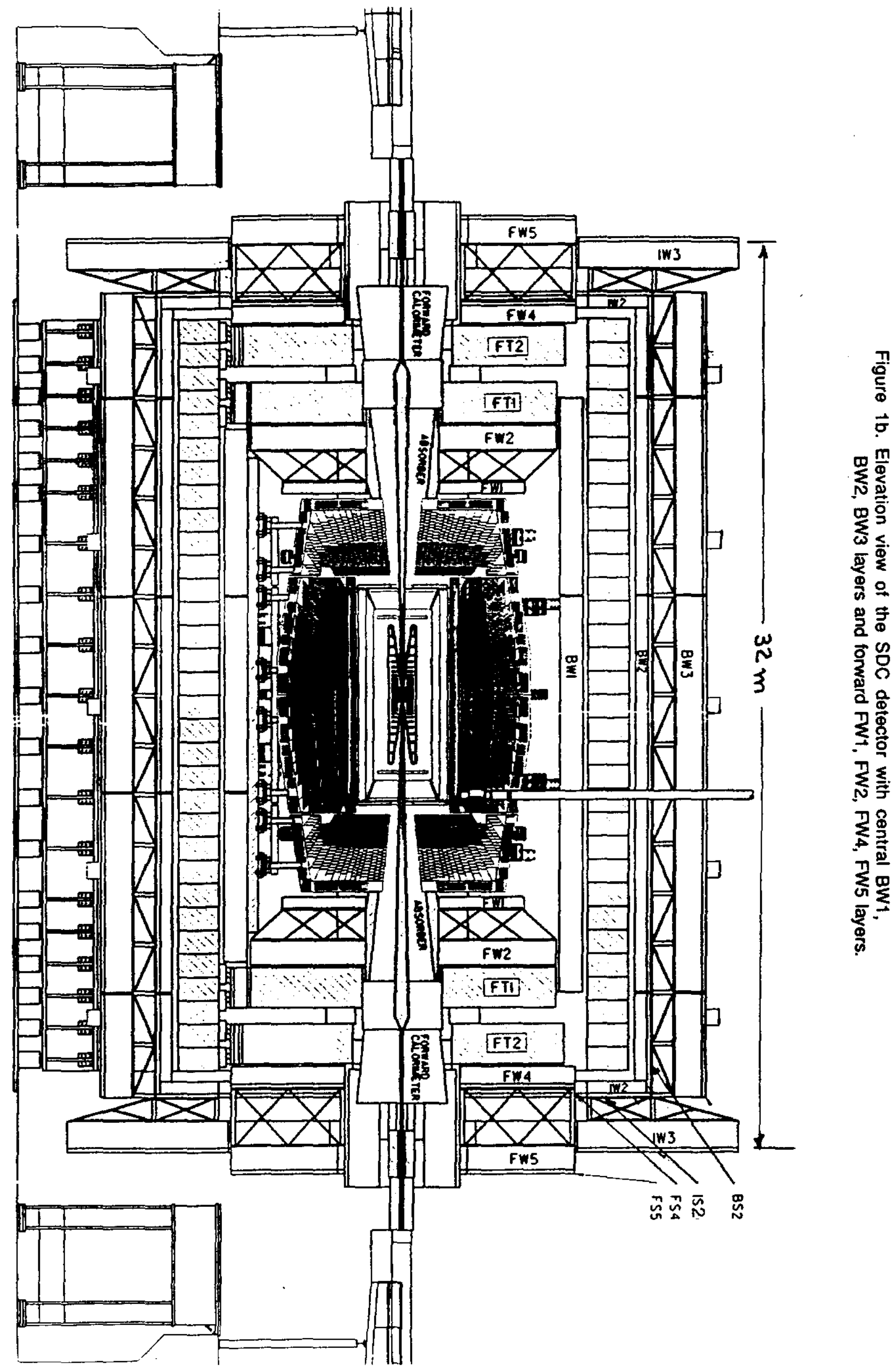


. Figure 1c. Longitudinal Quadrant of the SDC detector with supermodule segments, position monitoring, and detector subsystem linkings.

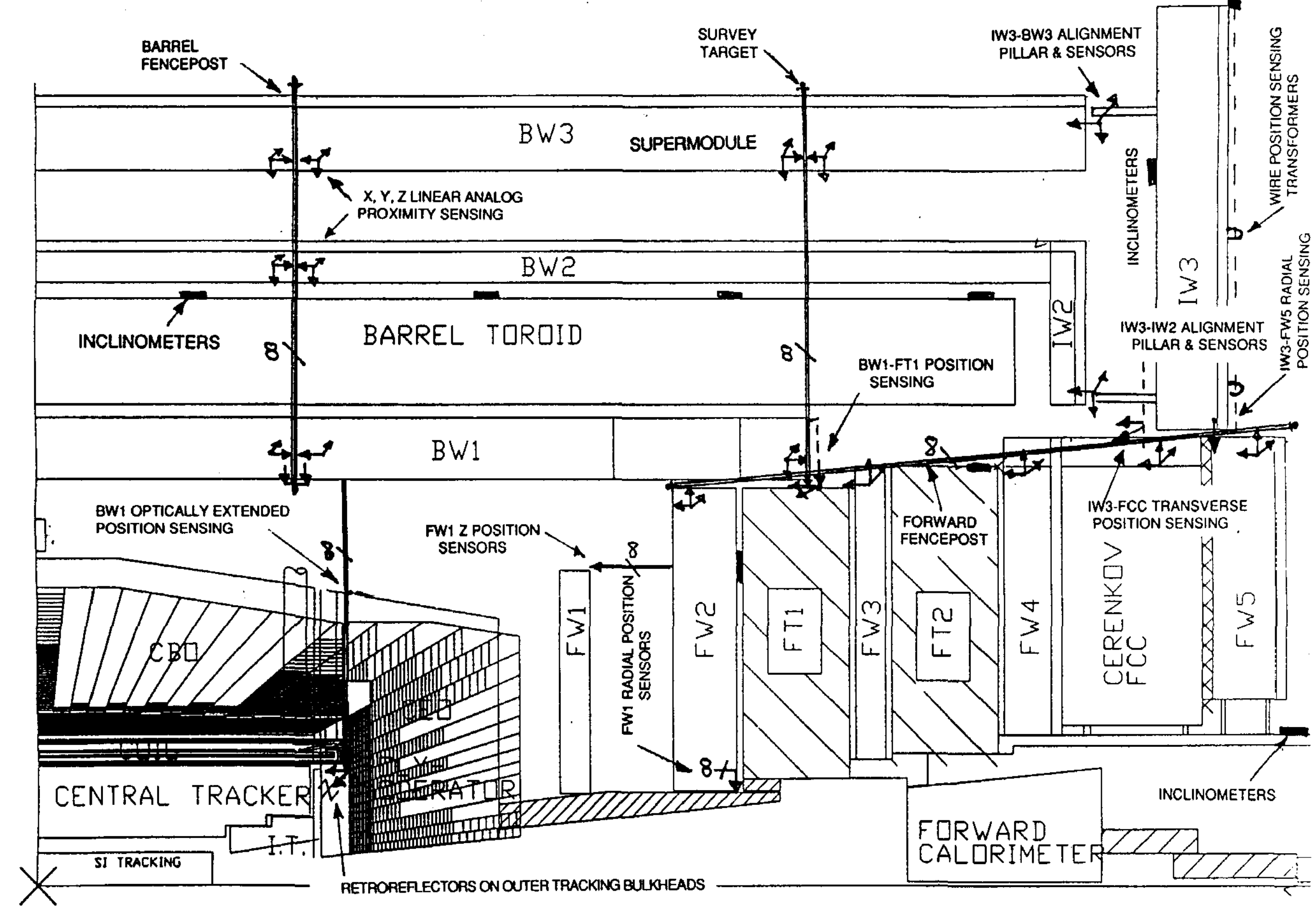




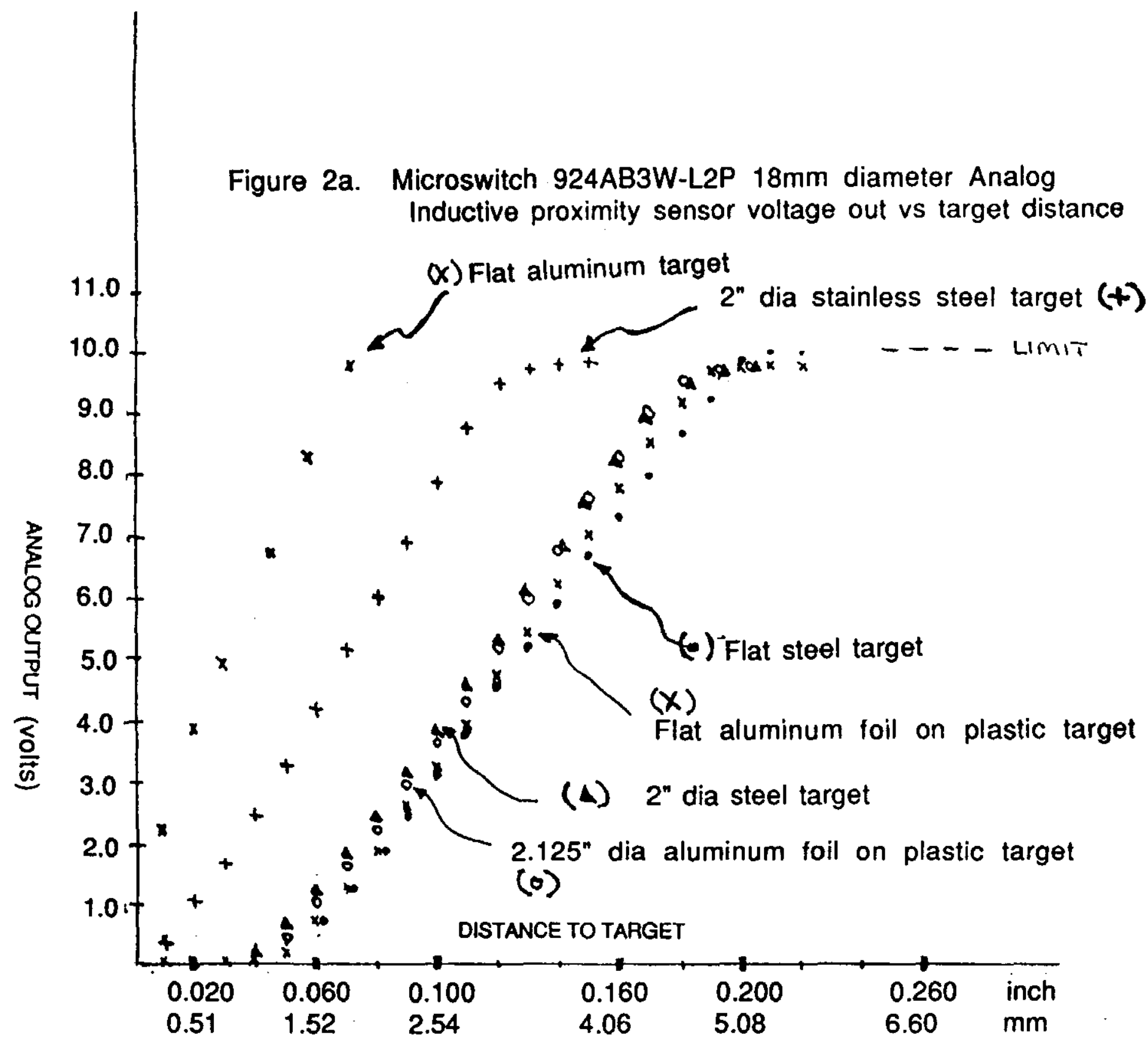

$L 1,12$

L1, 95

L1, 105

L1, 193 
Figure 2b. Microswitch 924AB4W-L2P $30 \mathrm{~mm}$ diameter Analog

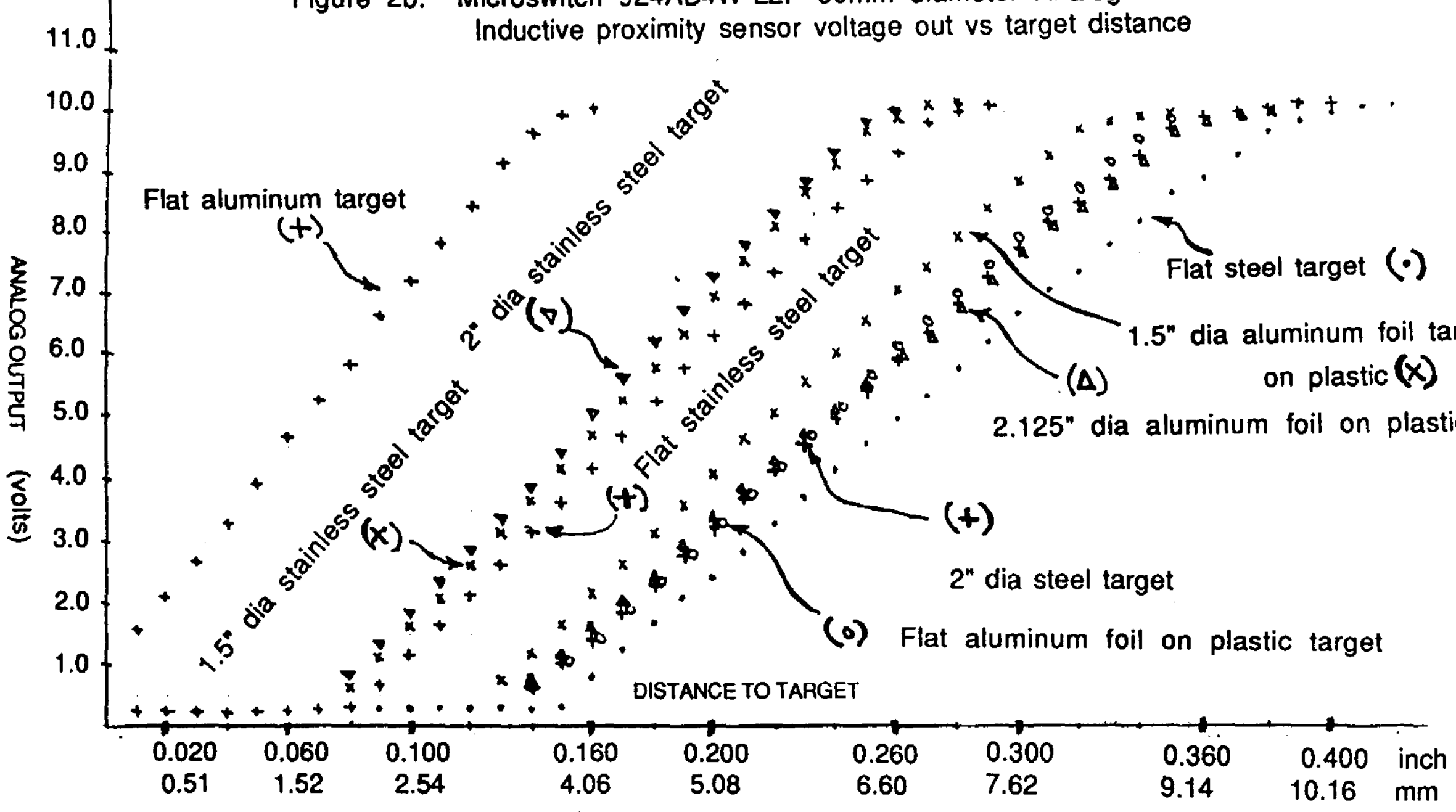




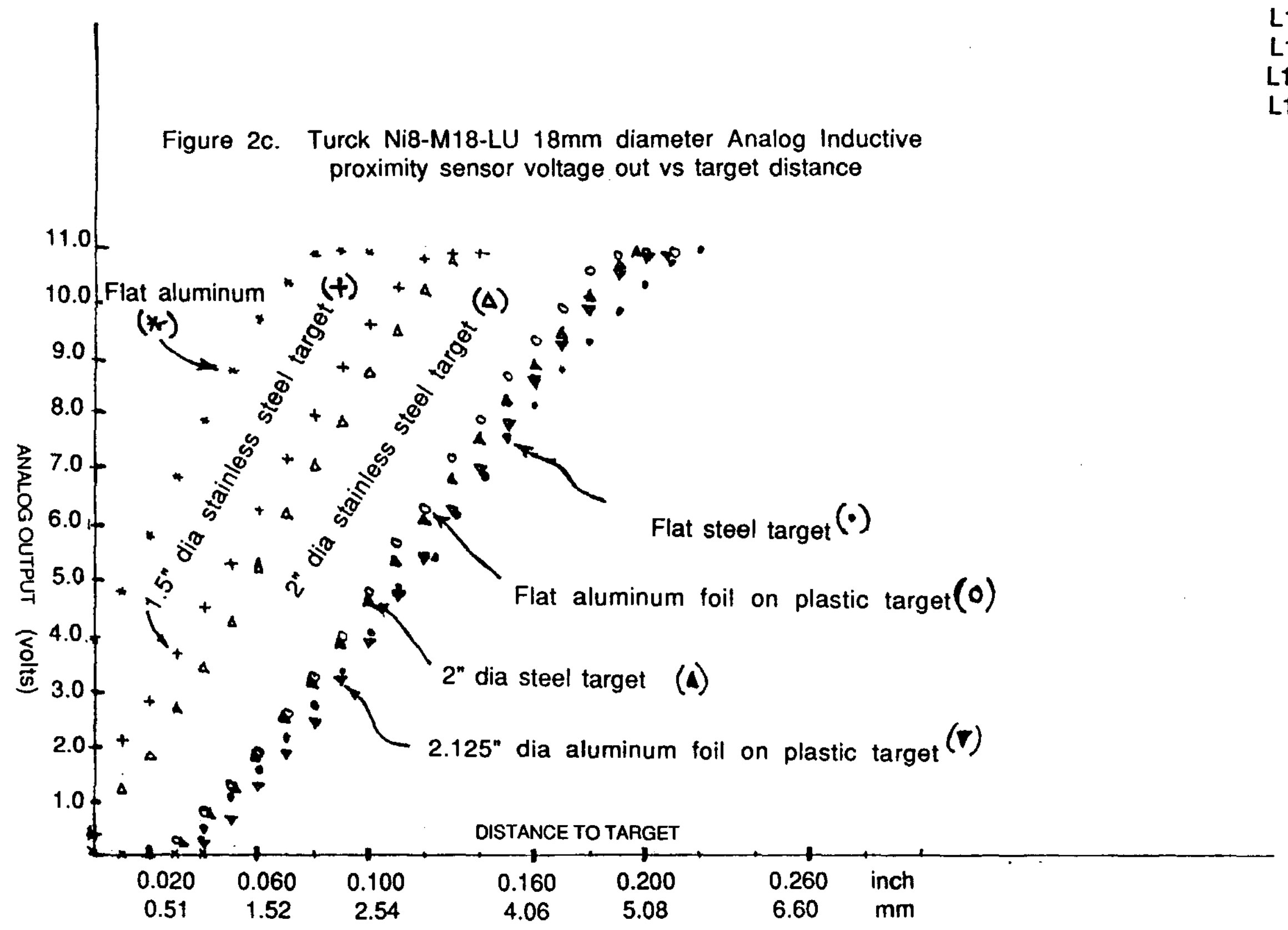

$L 1,84,86$

L1, 91,95

L1, 105

L1,194

Figure 2c. Turck Ni8-M18-LU 18mm diameter Analog Inductive proximity sensor voltage out vs target distance

Flat steel target $(\bullet)$ 


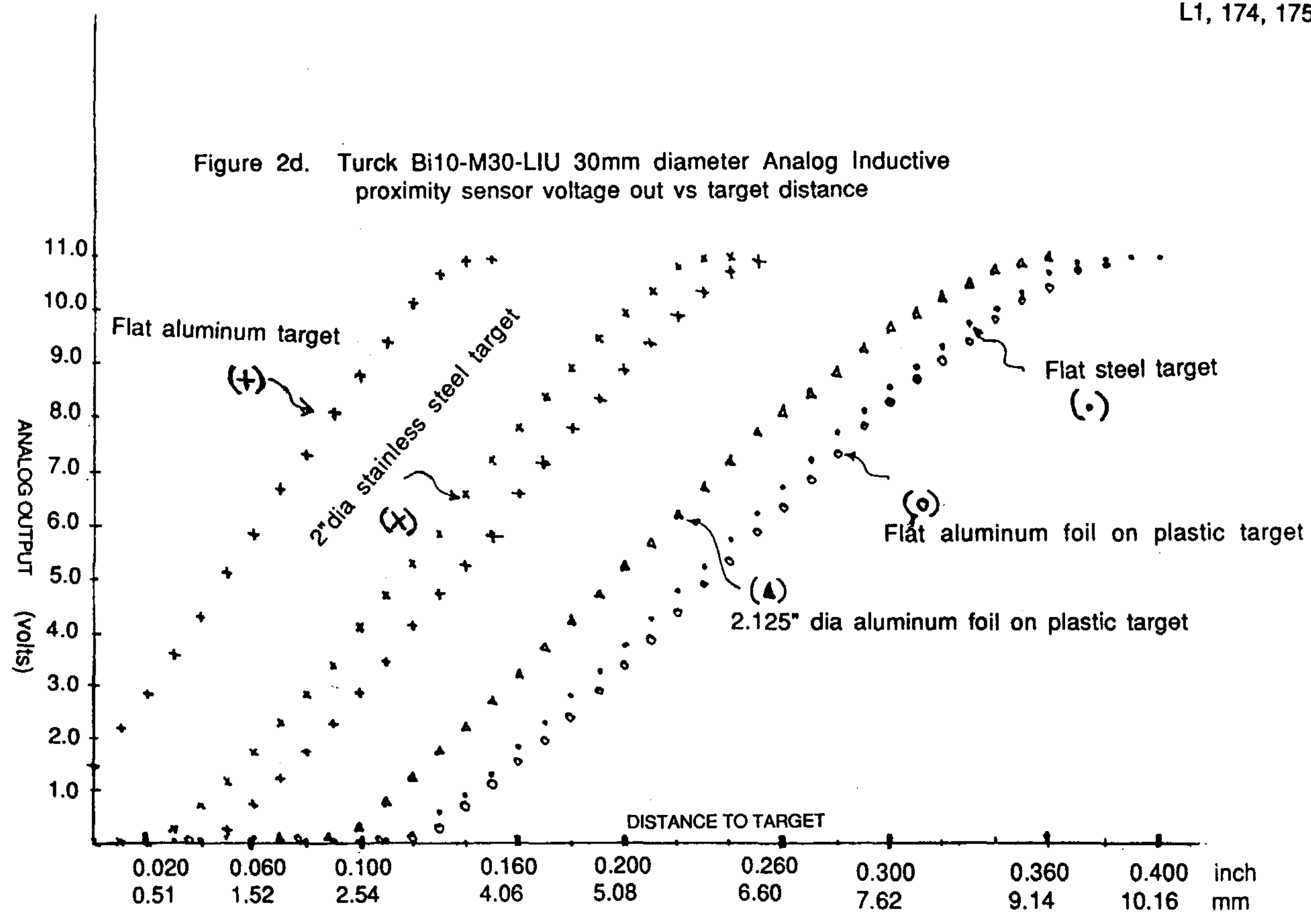




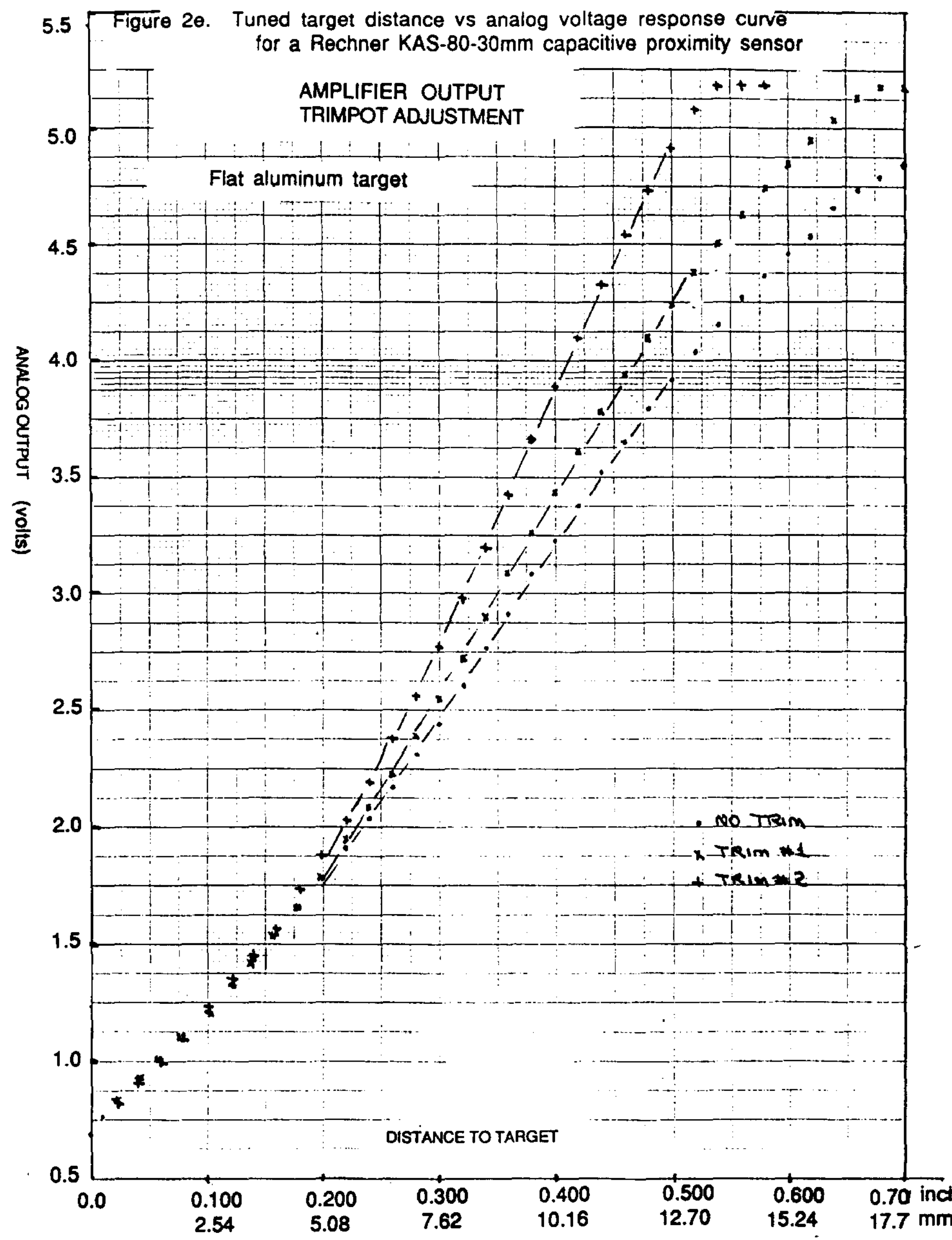




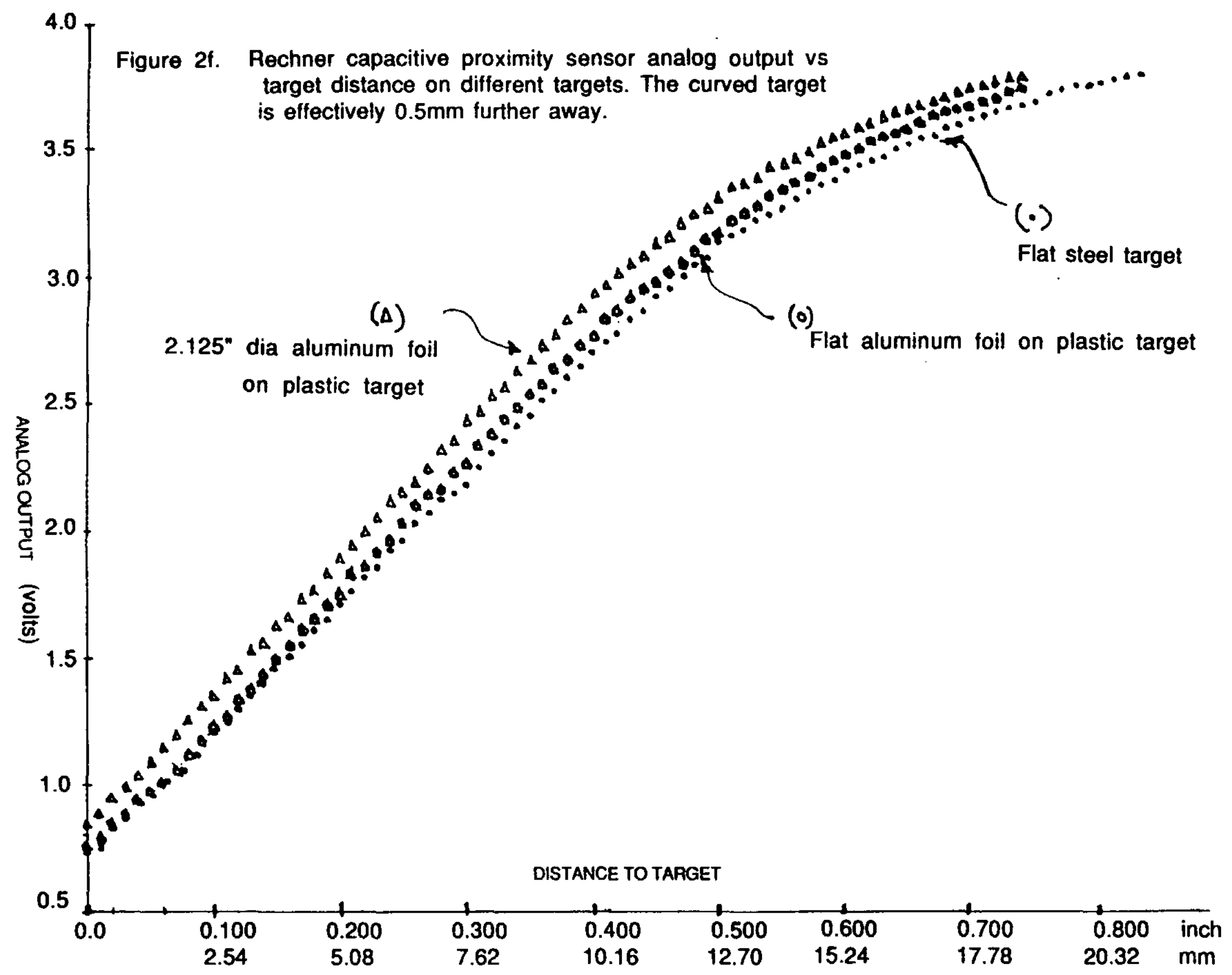


Figure 3a. 120 gauss fringe field effects on the $18 \mathrm{~mm}$ Microswitch and Turck Inductive proximity sensors
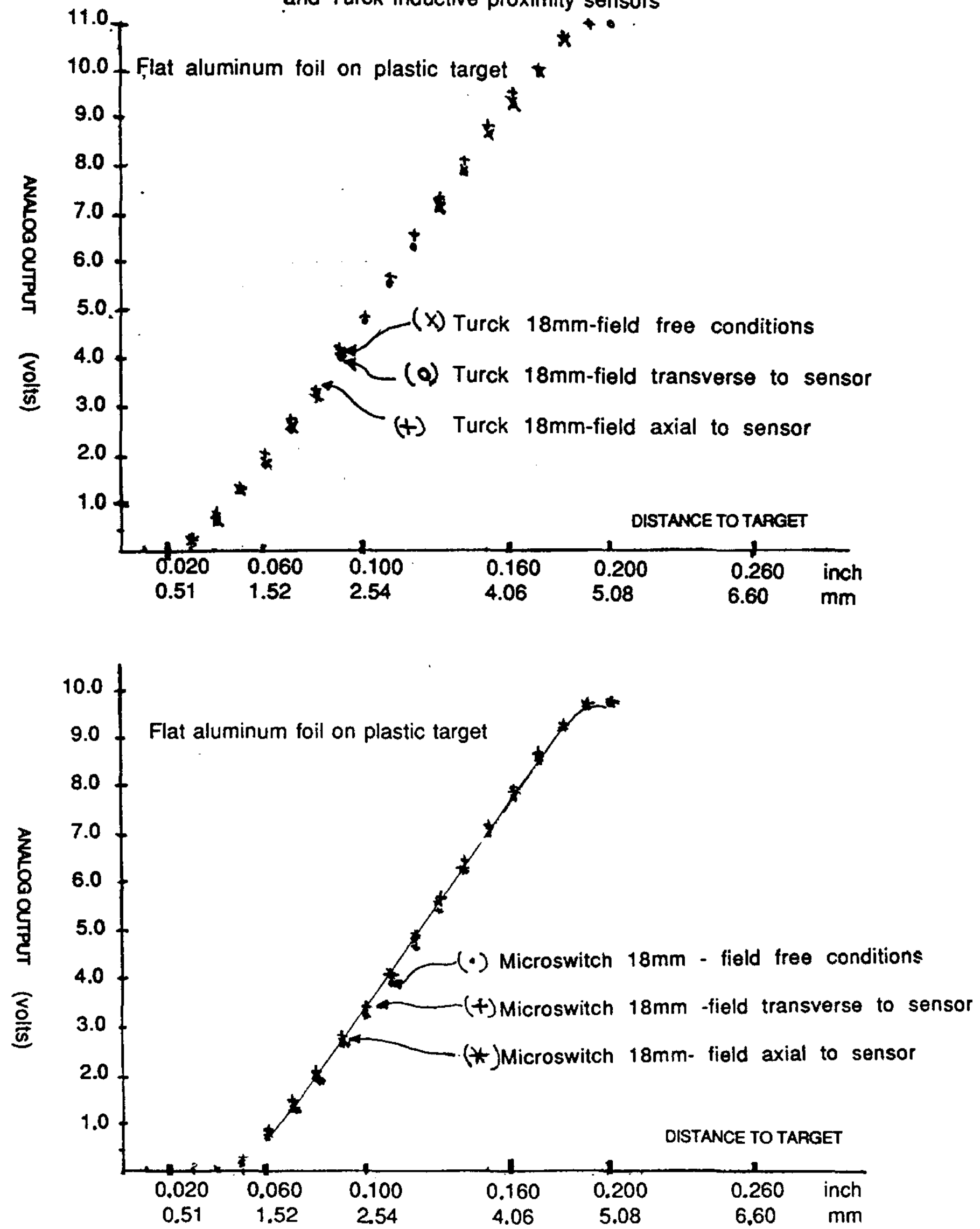
Figure 3b. 120 gauss fringe field effects on the $30 \mathrm{~mm}$ Microswitch
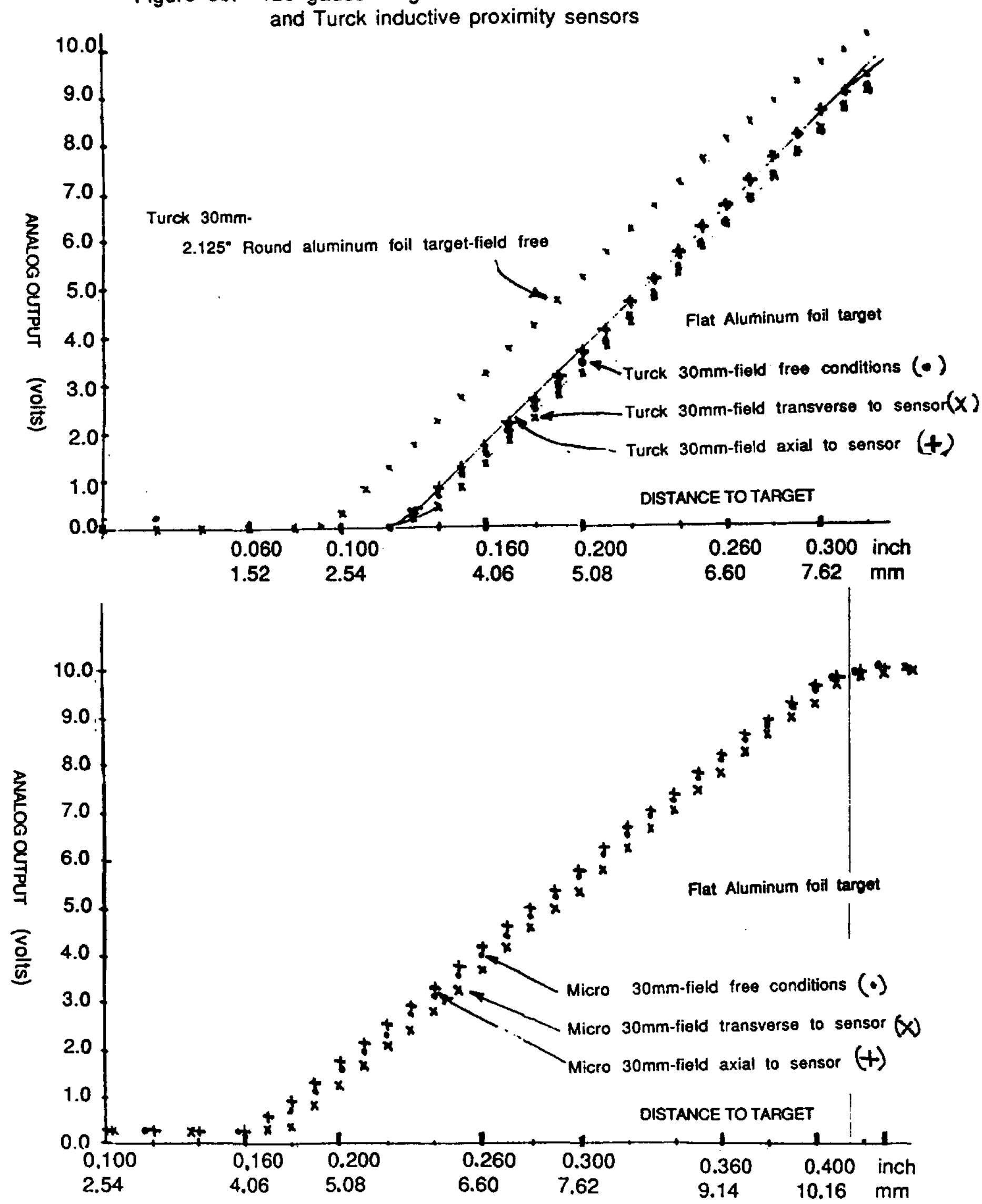


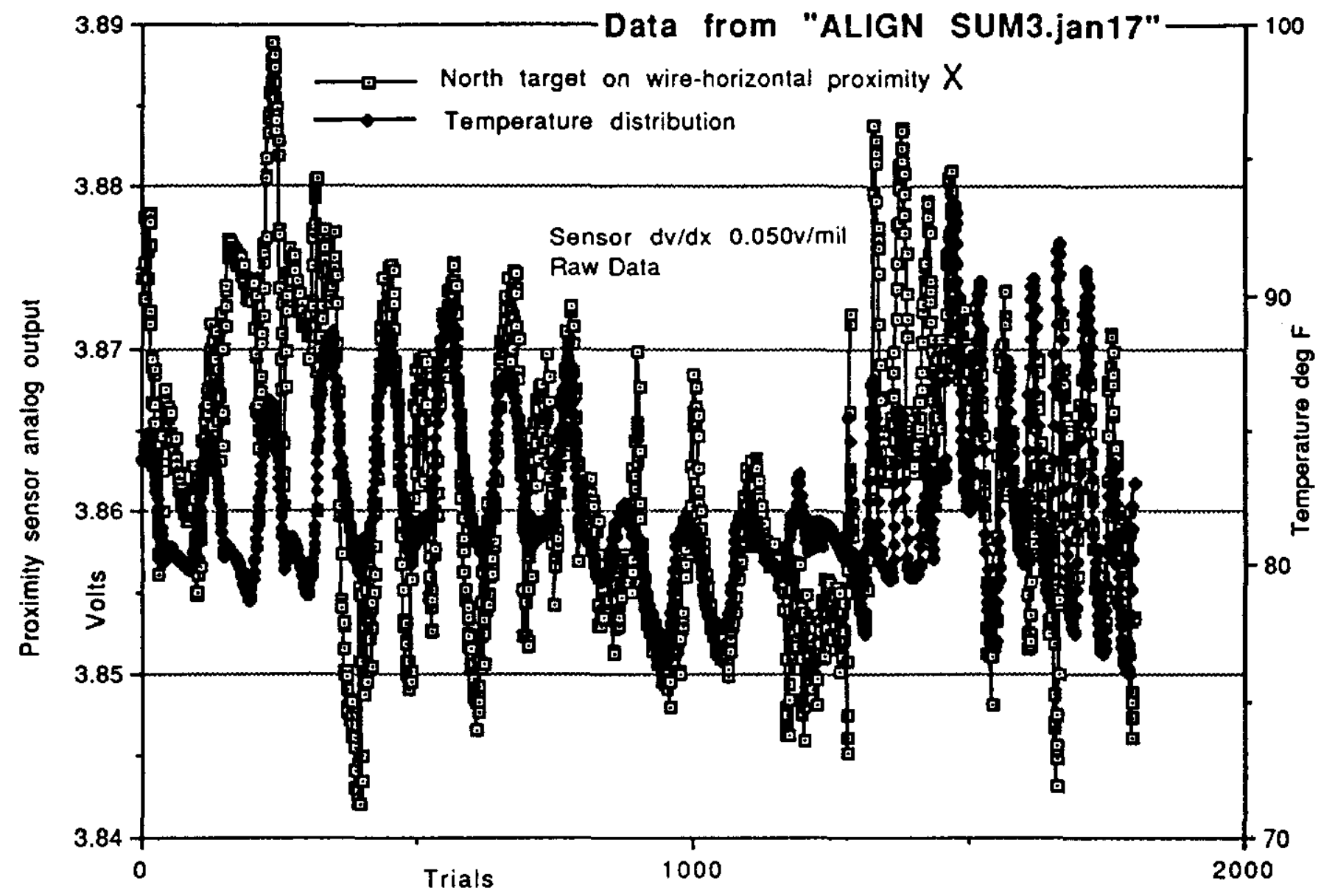

Figure 4a. Analog output voltage vs time of a stationary proximity sensor measuring a "fixed" horizontal gap to the north cylindrical ss target suspended on a $6 \mathrm{~m}$ long horizontal wire. There are small variations in phase with temperature changes. Each data point is an average of twenty five equally spaced readings in 15 minutes or 30 readings in 30 minutes. MS30 sensor output varies as $0.050 \mathrm{v} / \mathrm{mil}$. 


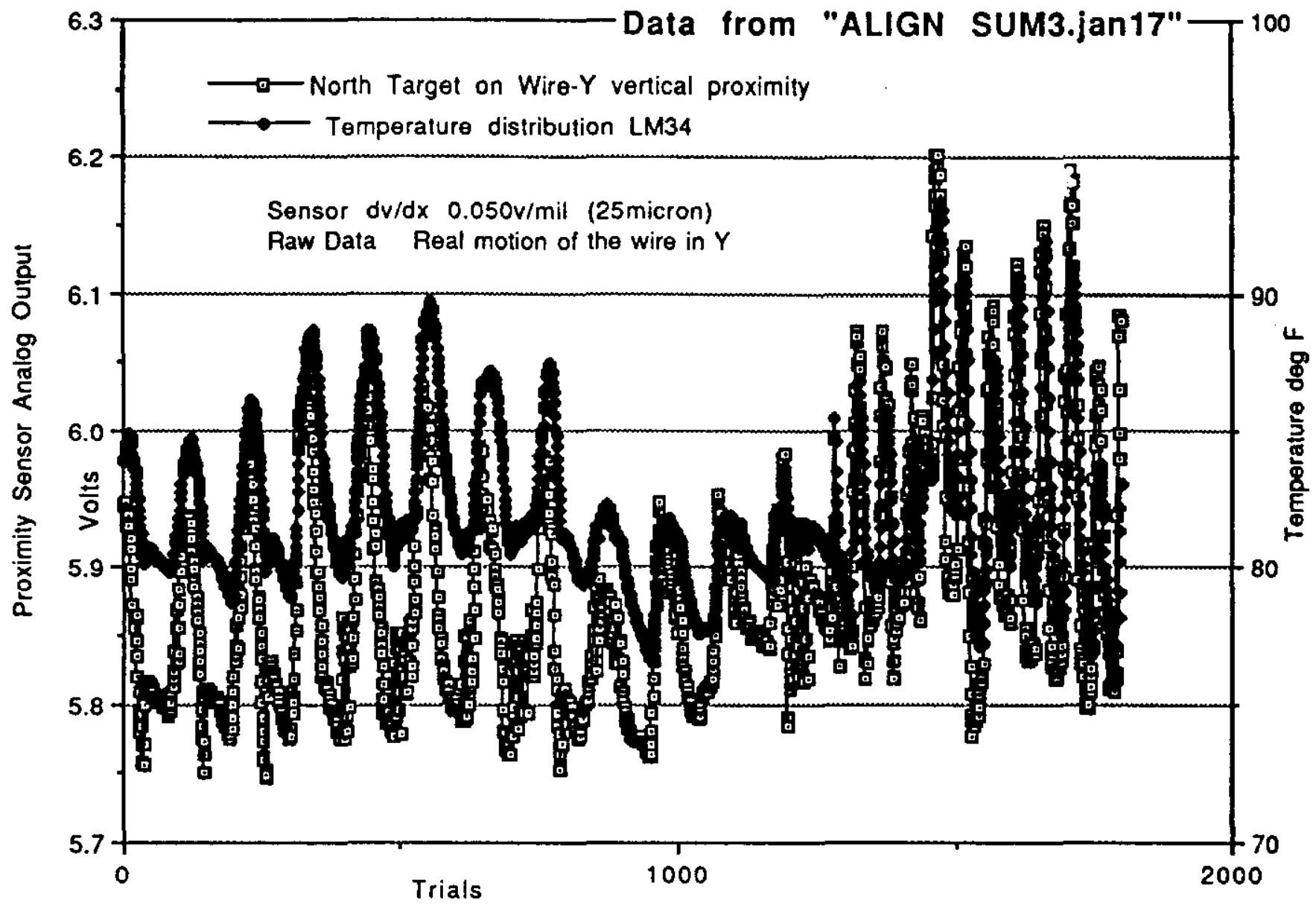

Figure $4 \mathrm{~b}$. Analog output voltage vs time of a stationary proximity sensor measuring a "fixed" vertical gap to the north cylindrical ss target suspended on a $6 \mathrm{~m}$ long horizontal wire. This variation is large due to wire/target motion and is in phase with temperature changes. MS30 sensor output varies as $0.050 \mathrm{v} / \mathrm{mil}$. 


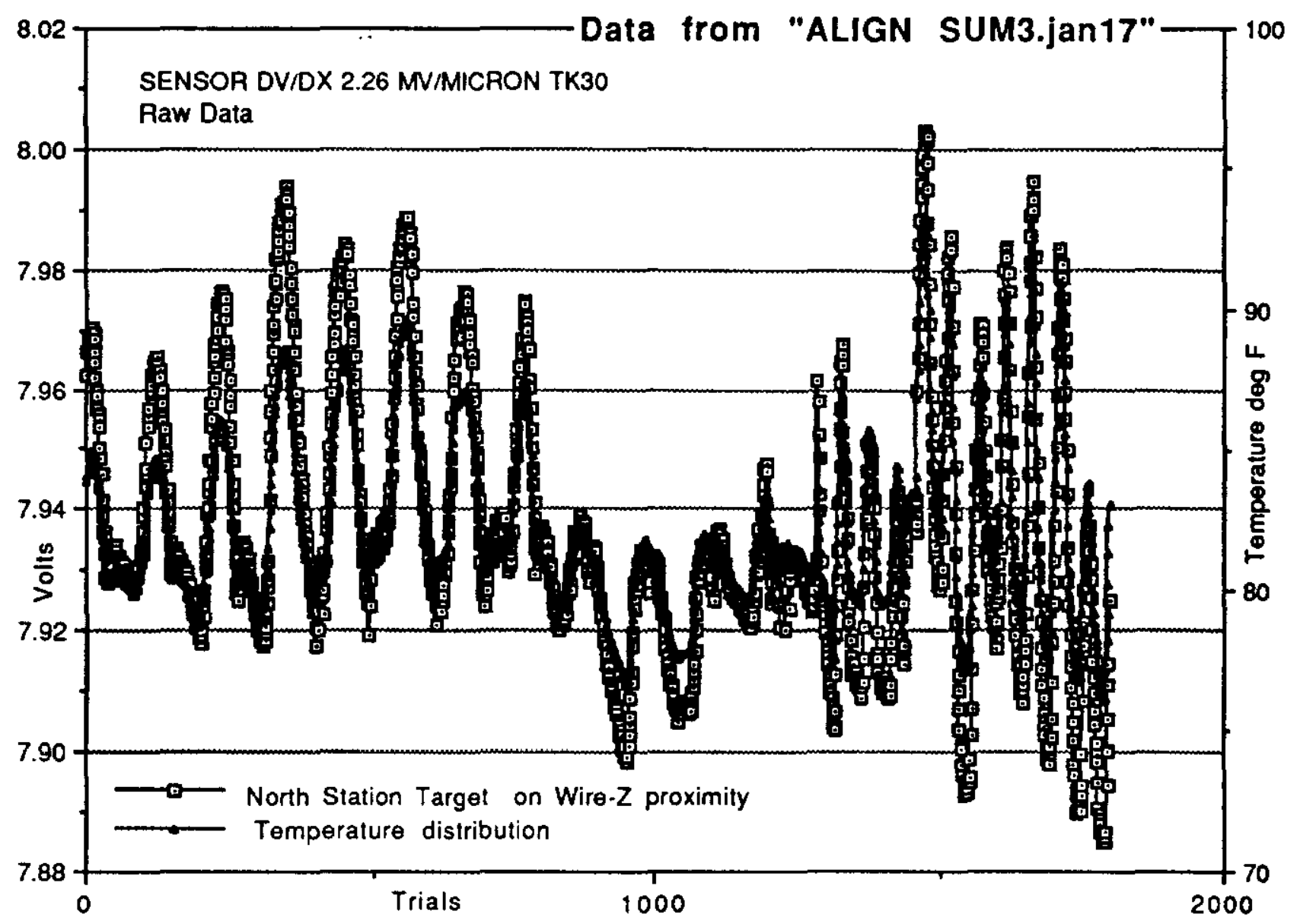

Figure 4c. Analog output voltage vs time of a stationary proximity sensor measuring a "fixed" gap along the wire to the flat end of the north target suspended on a $6 \mathrm{~m}$ long horizontal wire. This sensor has larger but precisely tracking variations with temperature changes. TK30 sensor output varies as $0.0573 \mathrm{v} / \mathrm{mil}$. 


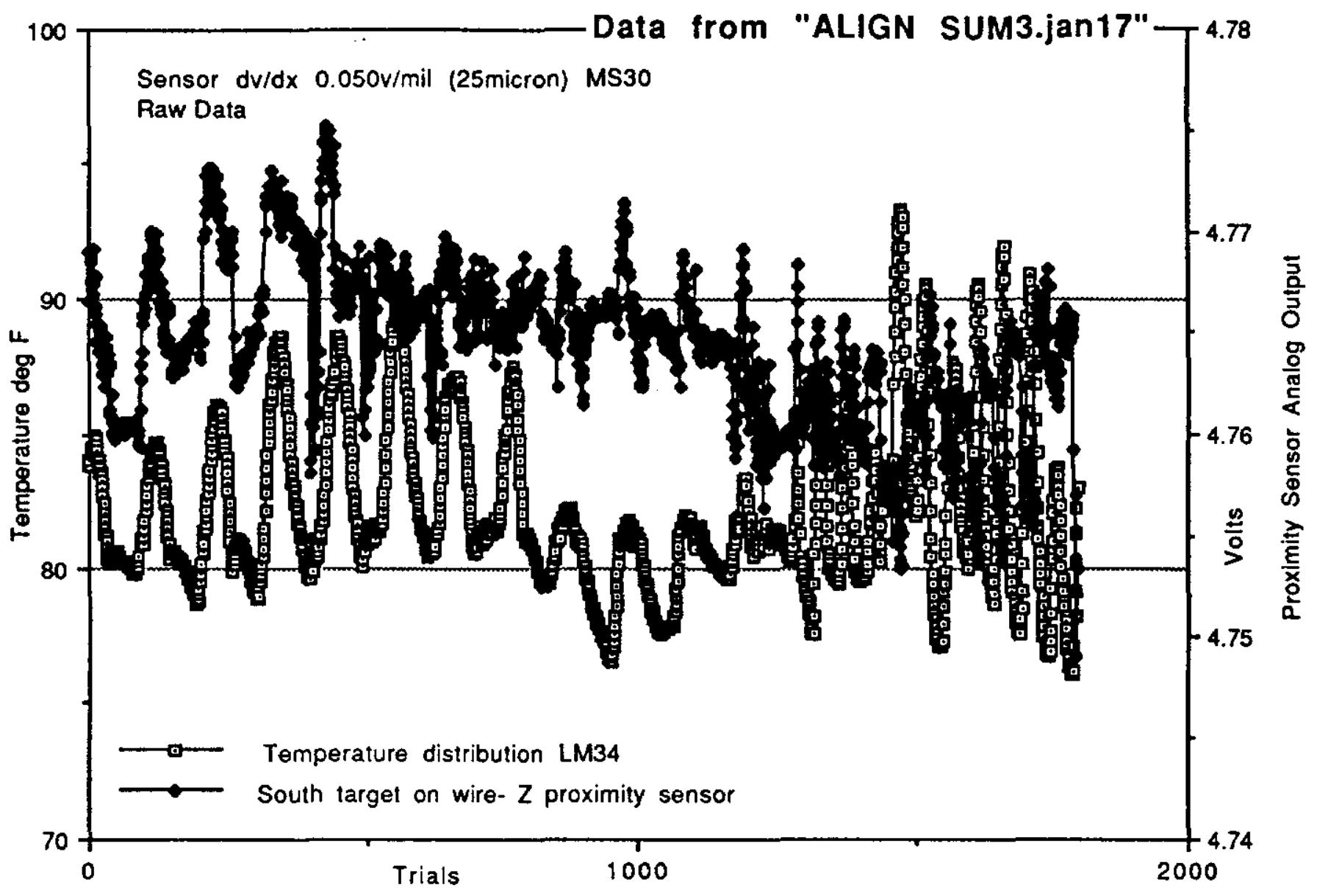

Figure 4d. Analog output voltage vs time of a stationary proximity sensor measuring a "fixed" gap along the wire to the flat end of the south ss target suspended on a $6 \mathrm{~m}$ long horizontal wire. MS30 sensor output varies as $0.050 \mathrm{v} / \mathrm{mil}$. 


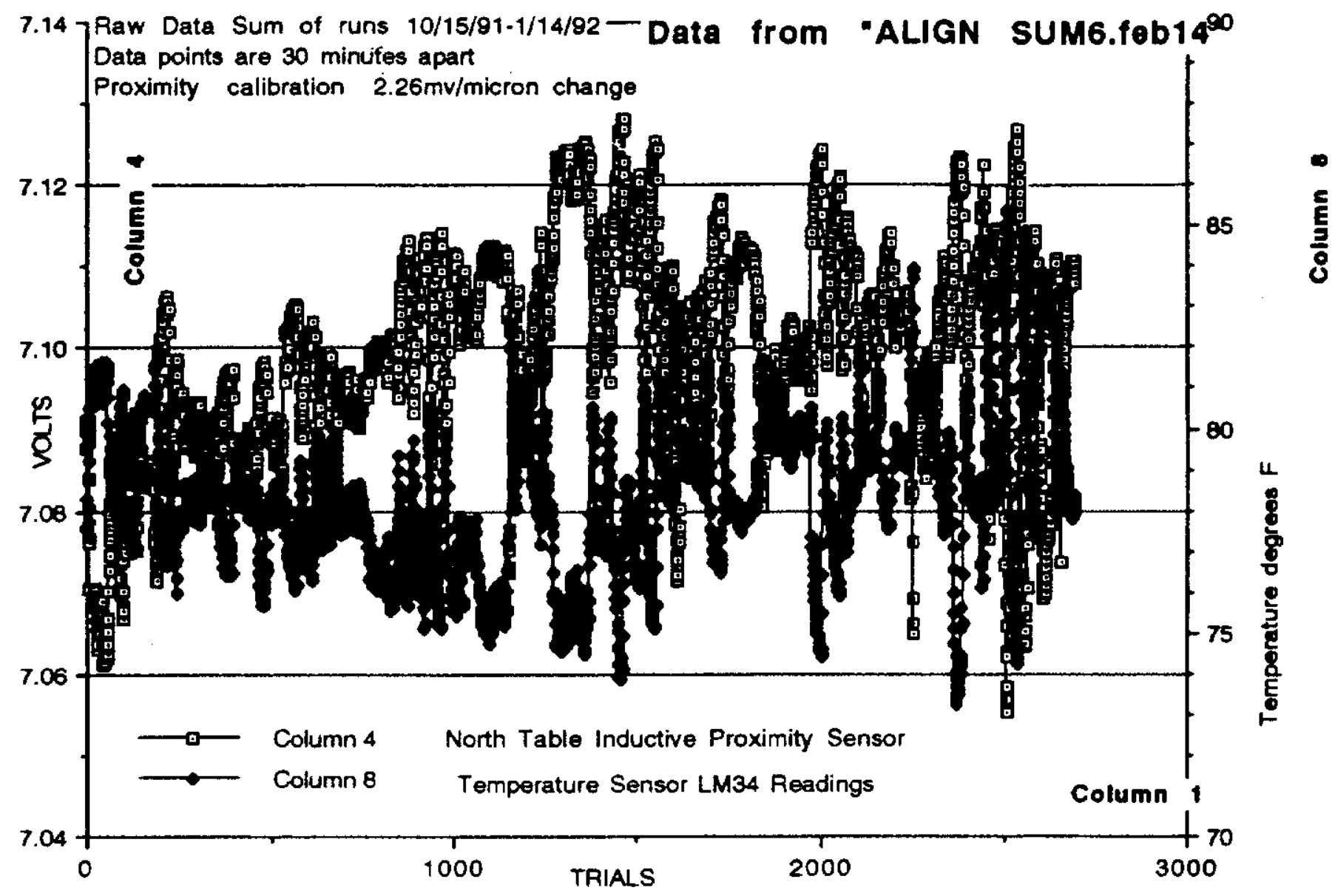

Figure 4e. Analog output voltage vs time of a stationary proximity sensor measuring a mechanically "fixed" vertical gap at the north sensor station. Data points are 30 minutes apart and the temperature variation of the output is now inverse. TK18 sensor output varies as $0.0681 \mathrm{v} / \mathrm{mil}$. 


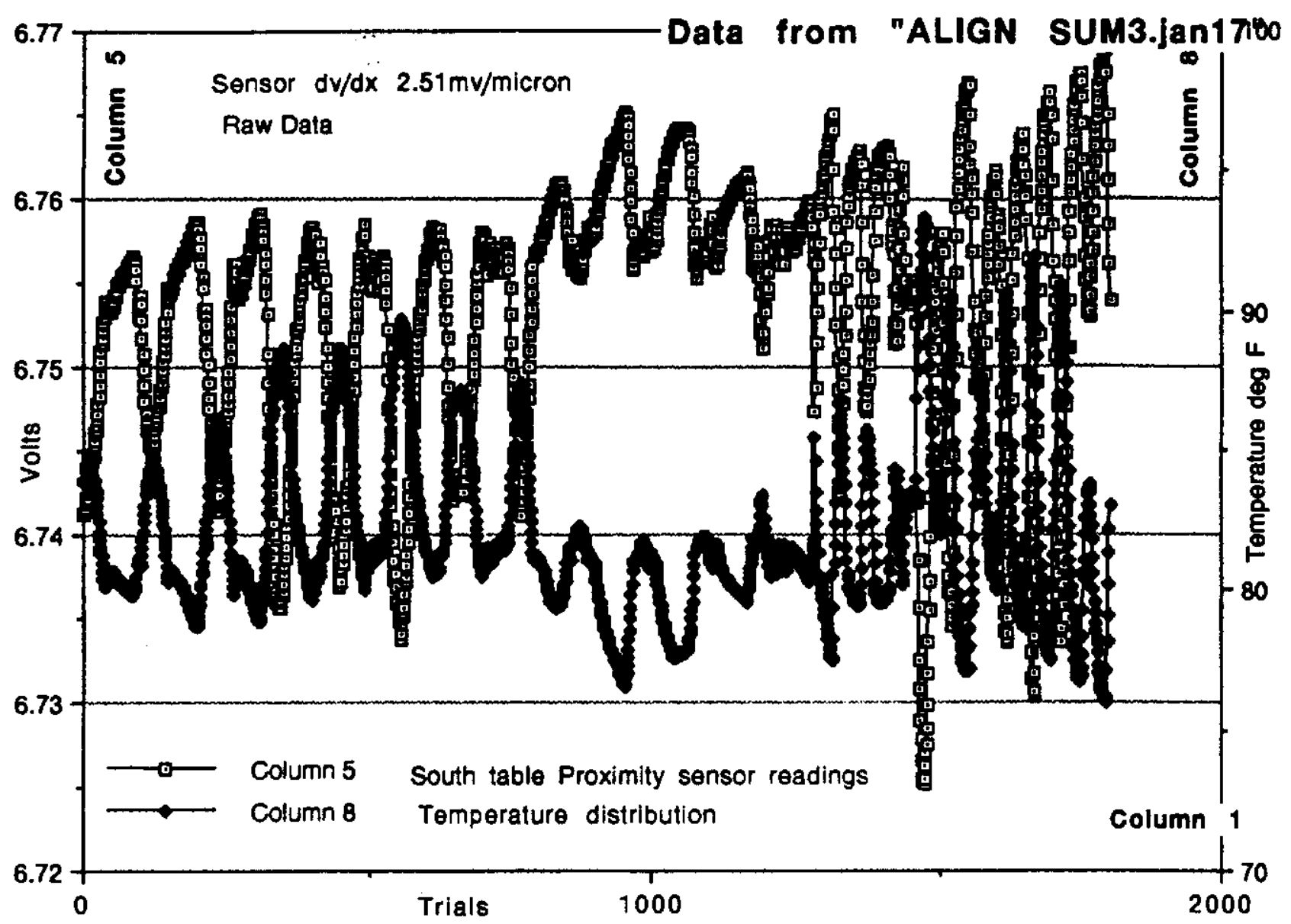

Figure 4f. Analog output voltage vs time of a stationary proximity sensor measuring a mechanically "fixed" gap at the south sensor station. MS18 sensor output varies as $0.0627 \mathrm{v} / \mathrm{mil}$. 


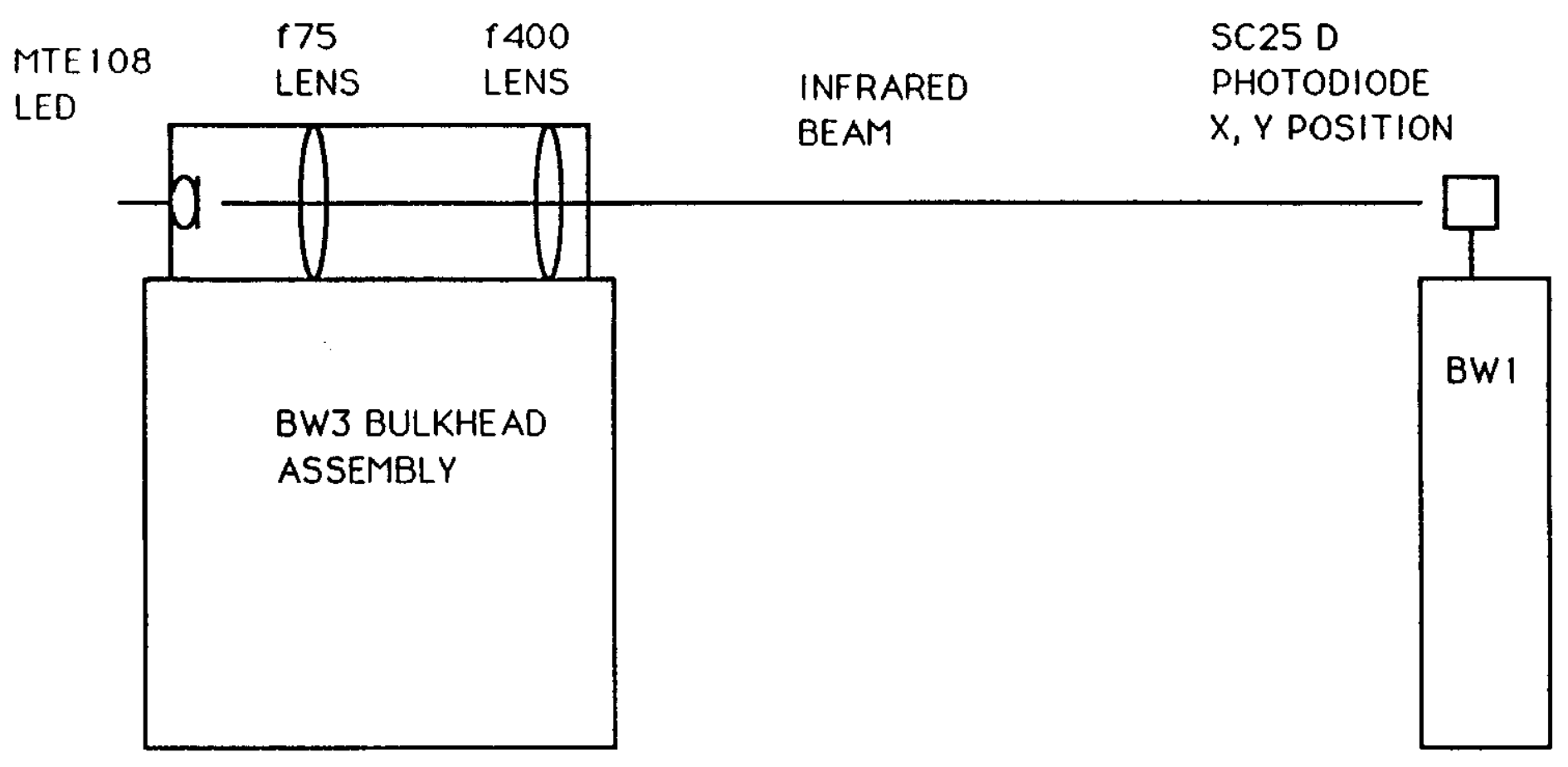

Figure 5. Diagram of the sample BW3 to BW1 optical $X, Y$ relative transverse coordinate monitoring system. 
Figure 6a. Typical coordinate difference output circuit for position sensing diodes.

\section{TYPICAL APPLICATION CIRCUIT FOR SINGLE AXIS OF A QUADRANT DETECTOR}

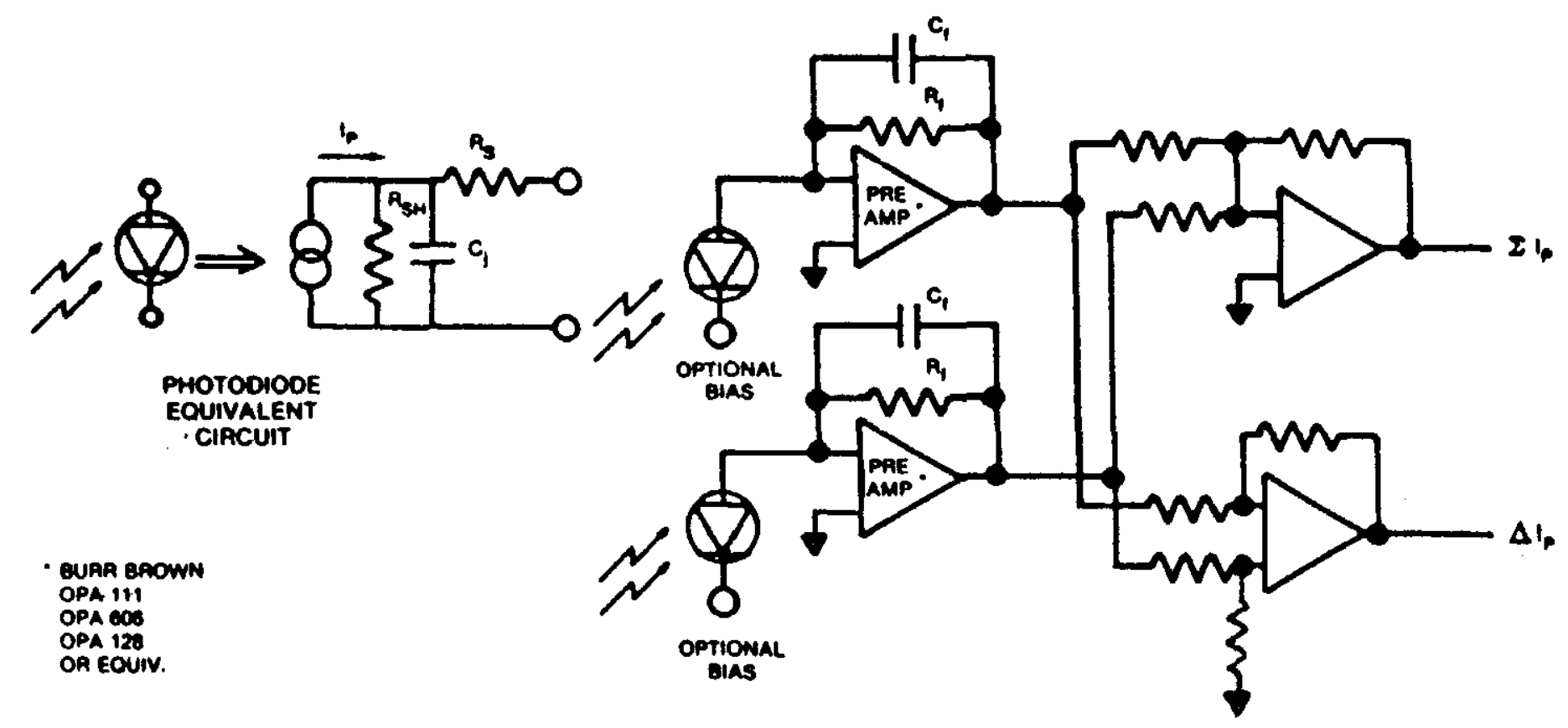




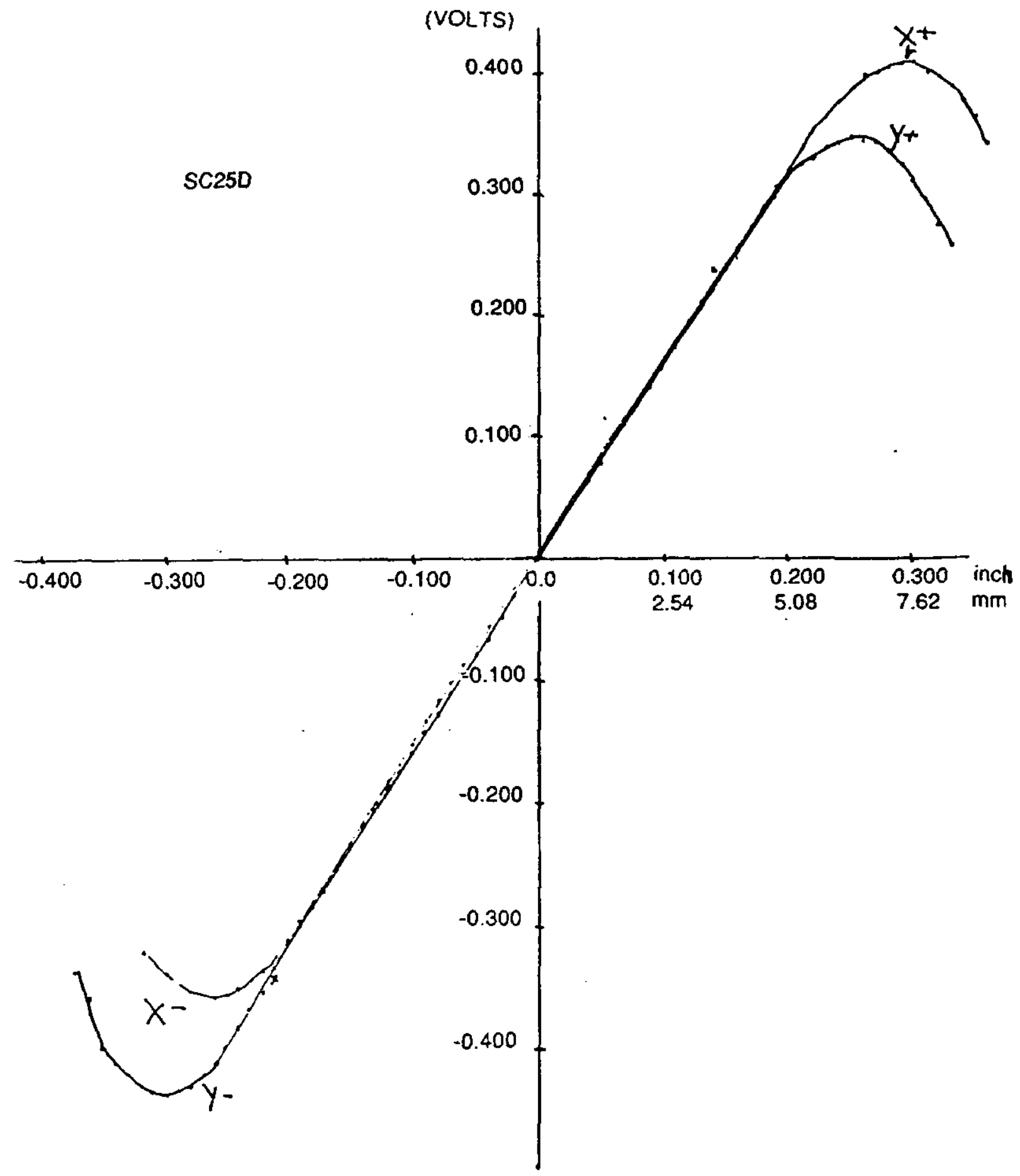

Figure 6b. UDT SC25D continuous position sensing diode current difference (transamp voltage) in the BW3-BW1 optics configuration vs diode transverse position. 


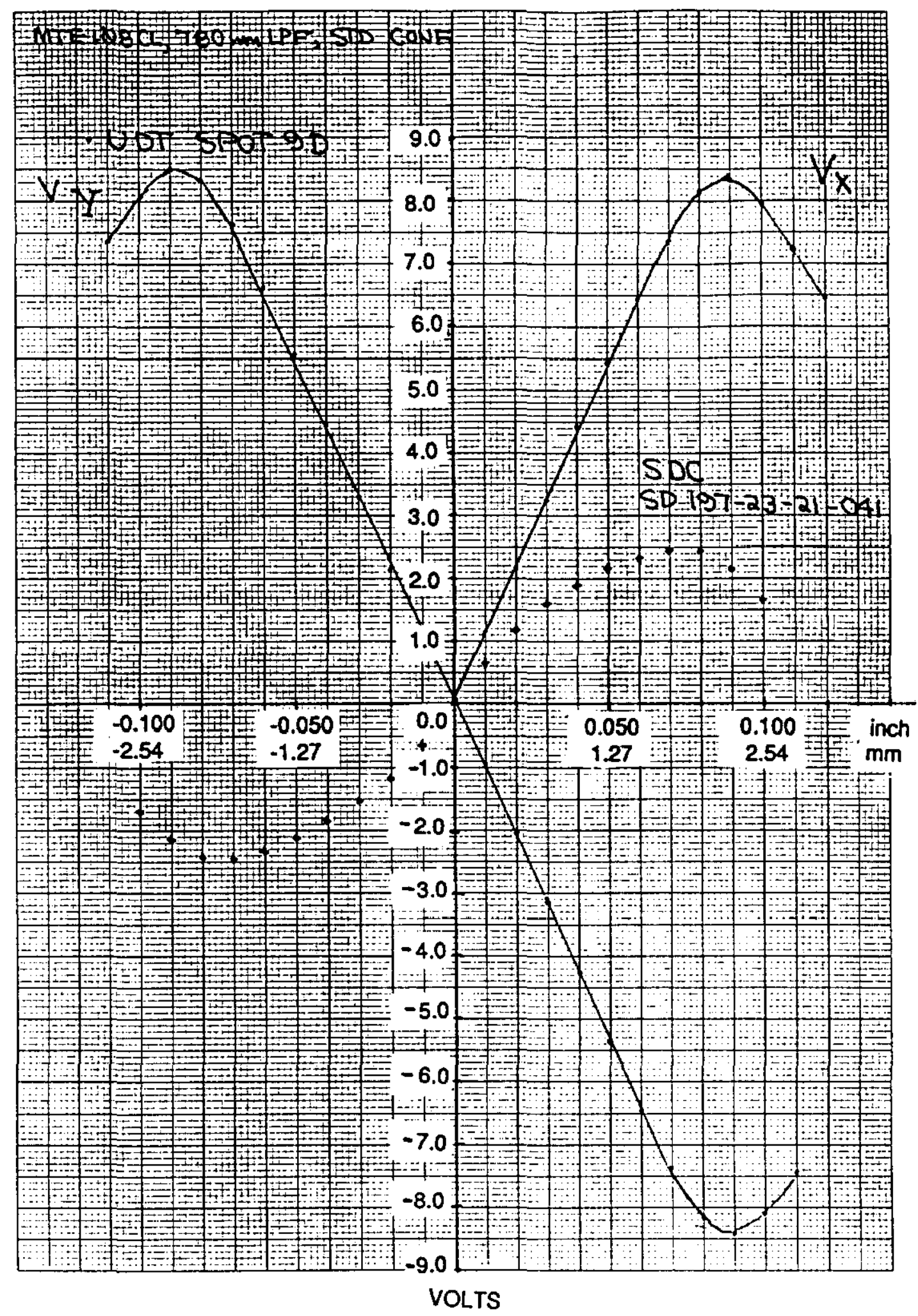

Figure 7. Quadrant photodiode voltage output response curves vs the movement of a focused infrared light spot across the photodiode for sample UDT and SDC detectors. 


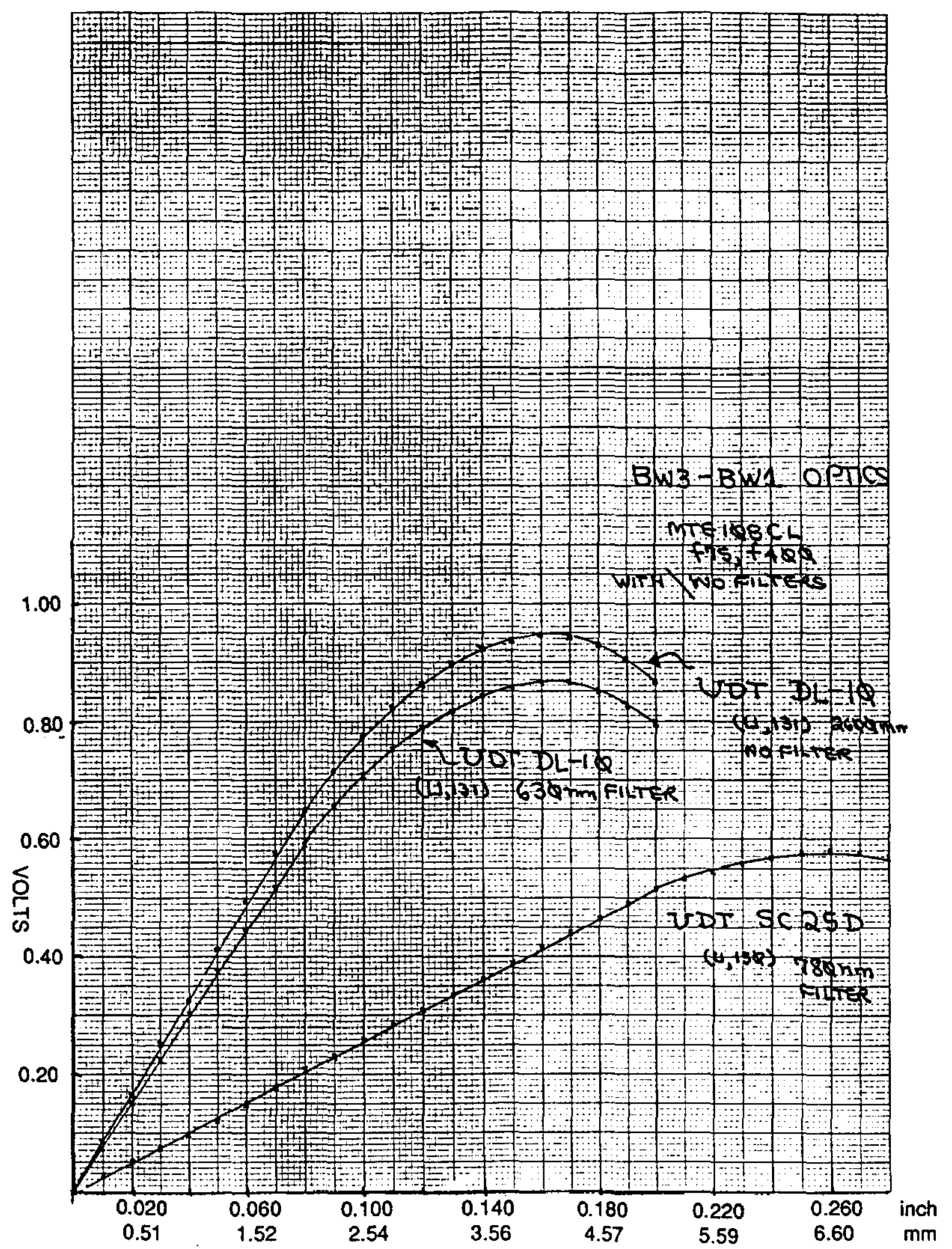

Figure $8 \mathrm{a} .10 \mathrm{~mm}$ and $25 \mathrm{~mm}$ UDT continuous light spot position sensing photodiode axis output voltage vs the movement of a focused infrared light spot across the photodiodes in the BW3 to BW1 optics configuration. 


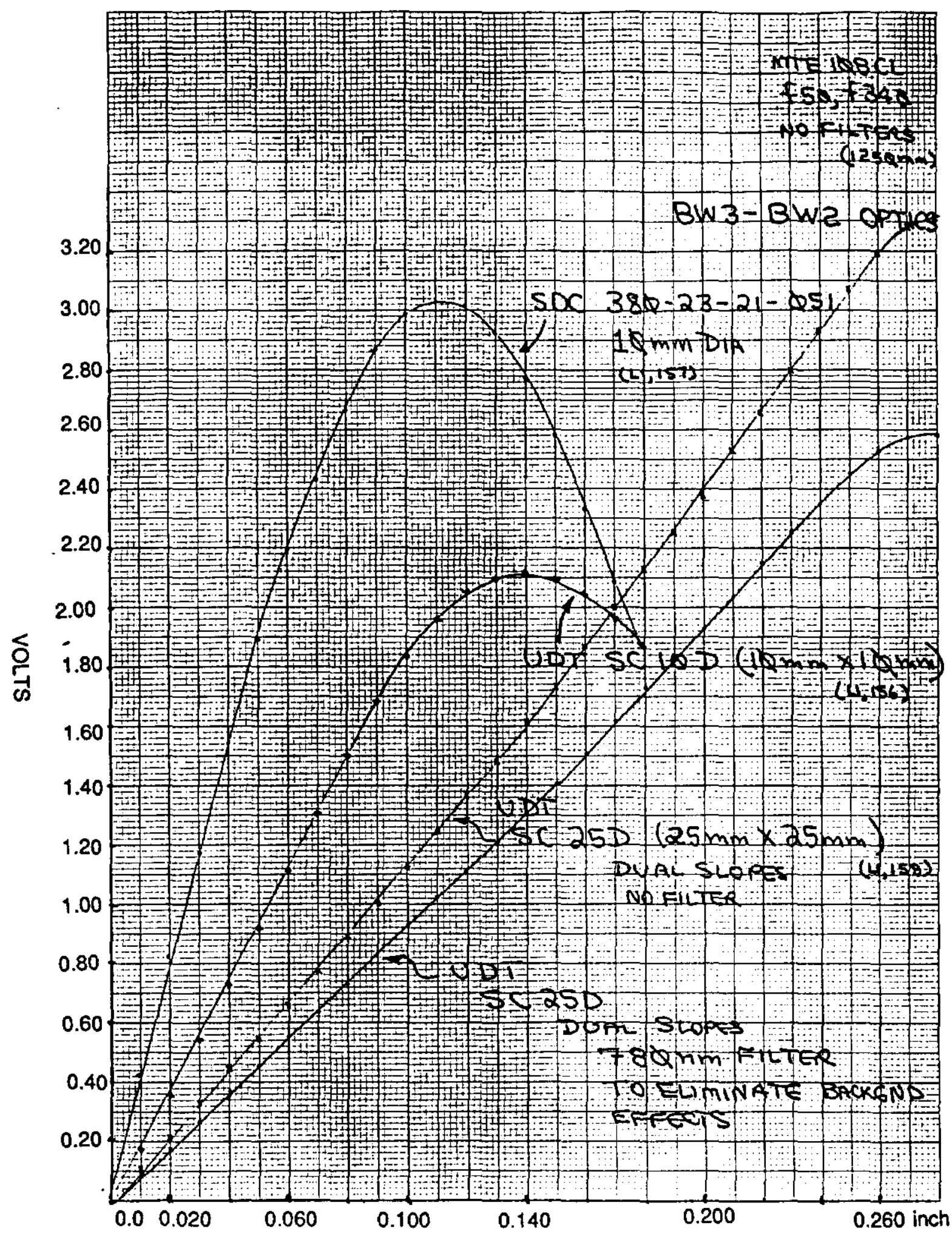

Figure $8 \mathrm{~b} .10 \mathrm{~mm}$ and $25 \mathrm{~mm}$ continuous light spot position sensing photodiode axis output voltage vs the movement of a focused infrared light spot across the photodiodes in the BW3 to BW2 optics configuration. 


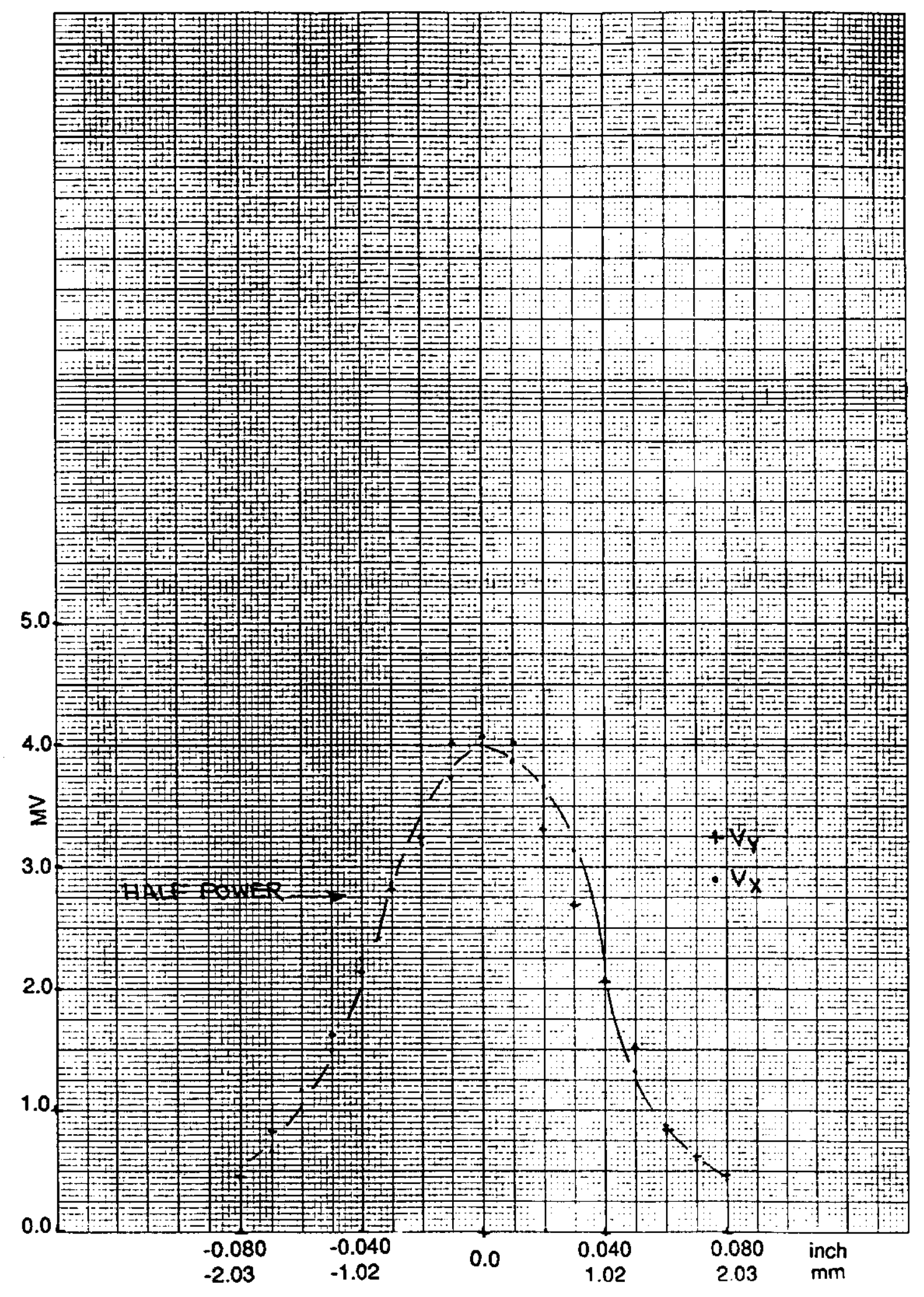

Figure 9. An infrared beam spot profile on a DL10 photodiode in the BW3 to BW2 optics configuration as measured with a pinhole mask. 
Figure 10. $25 \mathrm{~mm}$ UDT continuous position sensing photodiode axis voltage vs the movement of the light spot in a fixed BW3 to BW1 optics for different light emitting diodes.

BW3- BW1 OPTICS CONFIGURATION

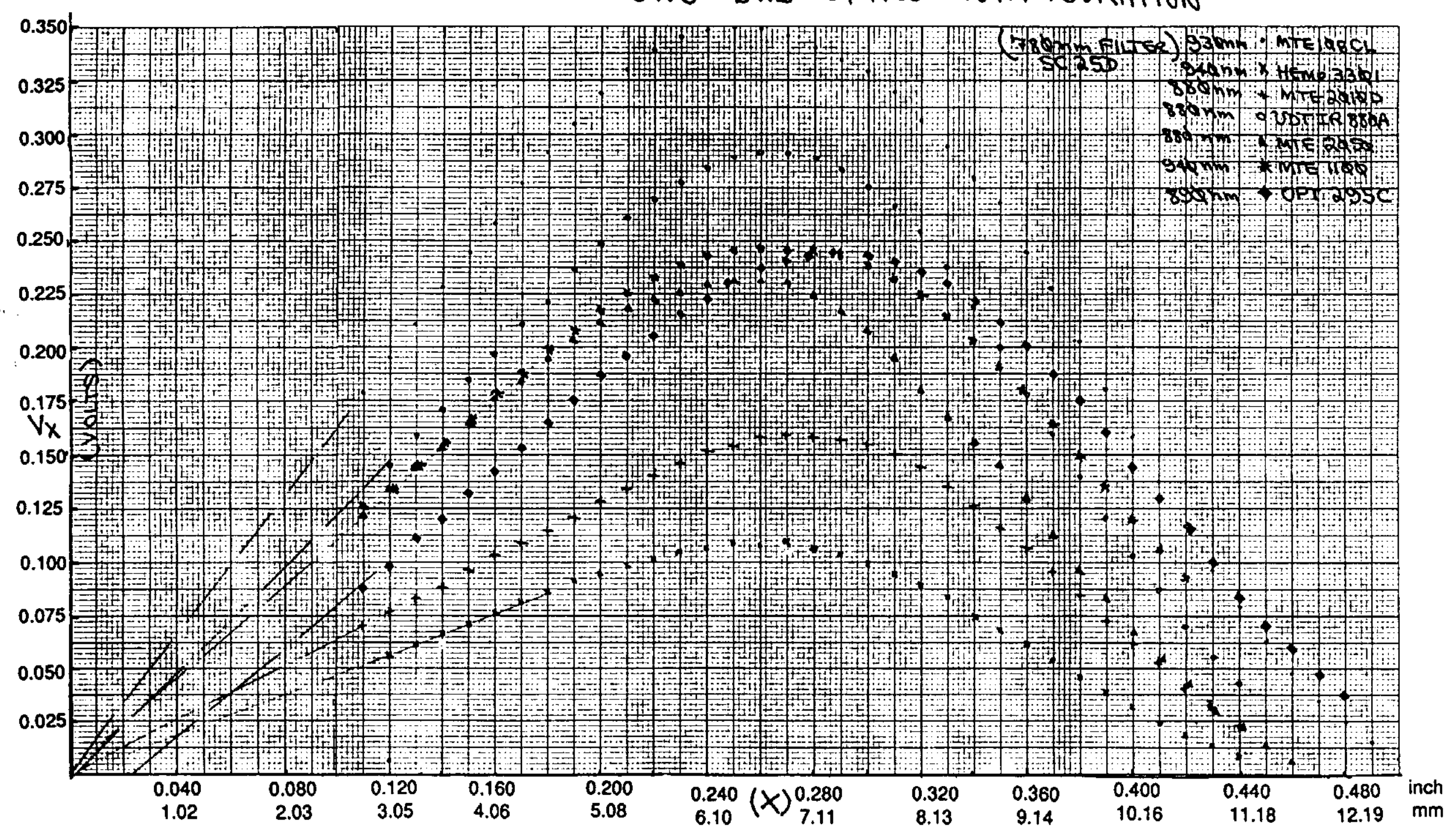




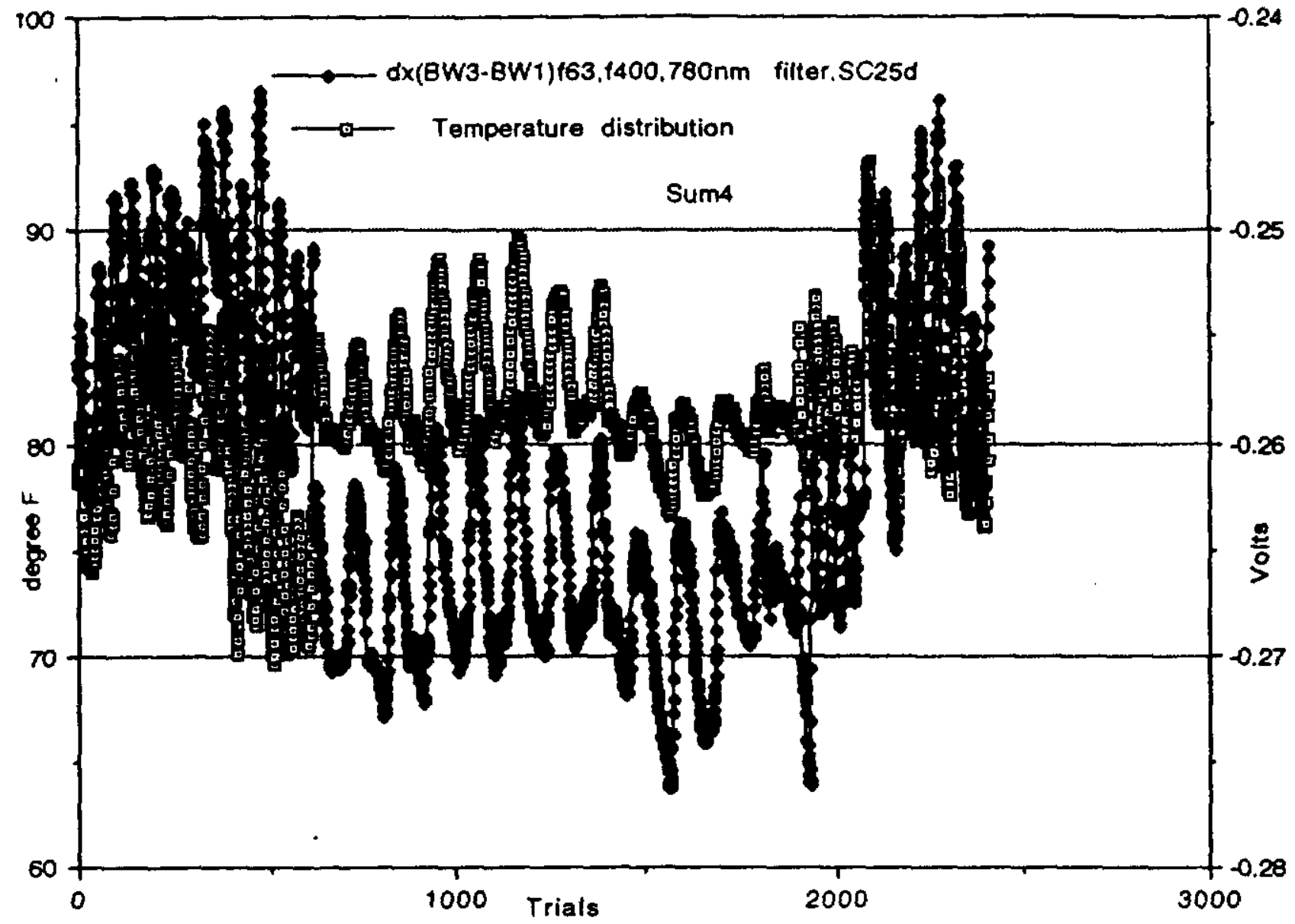

Figure 11a. $X$ axis difference voltage output of a SC25d photodiode in a fixed BW3 to BW1 optics configuration vs the temperature variation over a sum of long term periods. The output tracks temperature variation but the shifts of the average output in different periods is evident. 


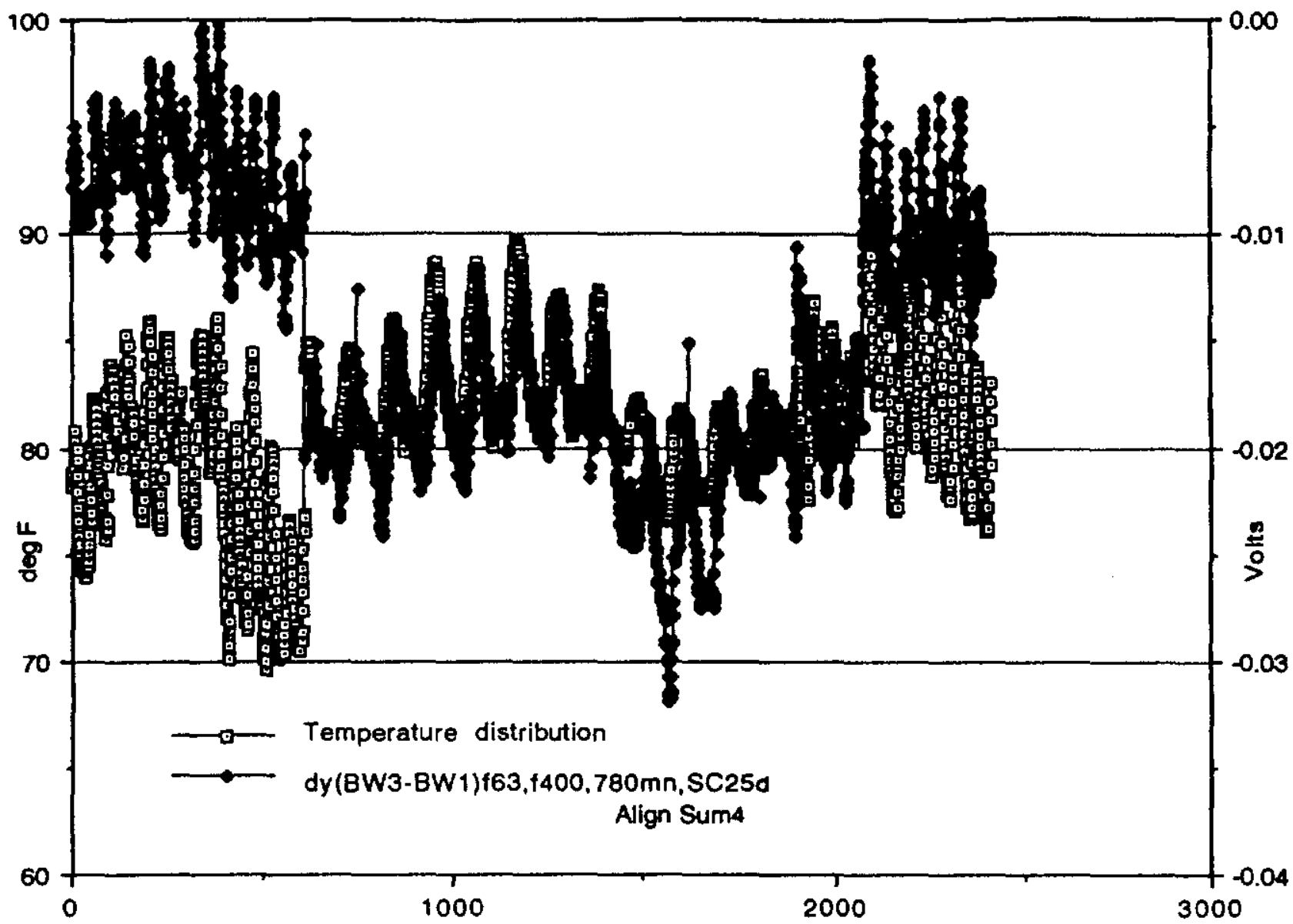

Figure 11b. $Y$ axis difference voltage output of a SC25d photodiode in a fixed BW3 to BW1 optics configuration vs temperature variation.over a sum of long term periods. The output tracks temperature variation but the shifts of the average output in different periods is evident. 


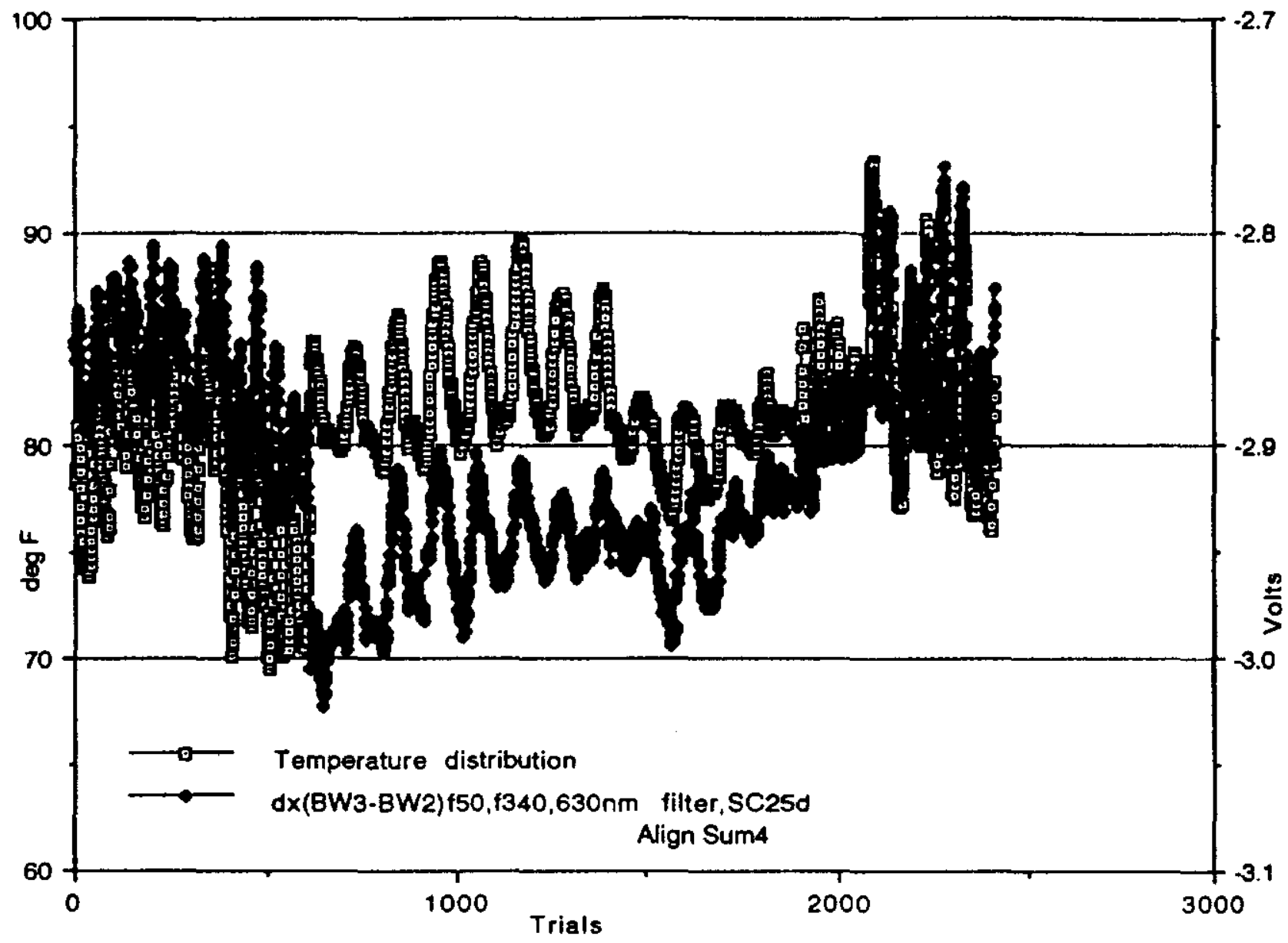

Figure 11c. $X$ axis difference voltage output of a SC25d photodiode in a fixed BW3 to BW2 optics configuration vs the temperature variation over a sum of long term periods. The output tracks temperature variation but the shifts of the average output in different periods is evident. 


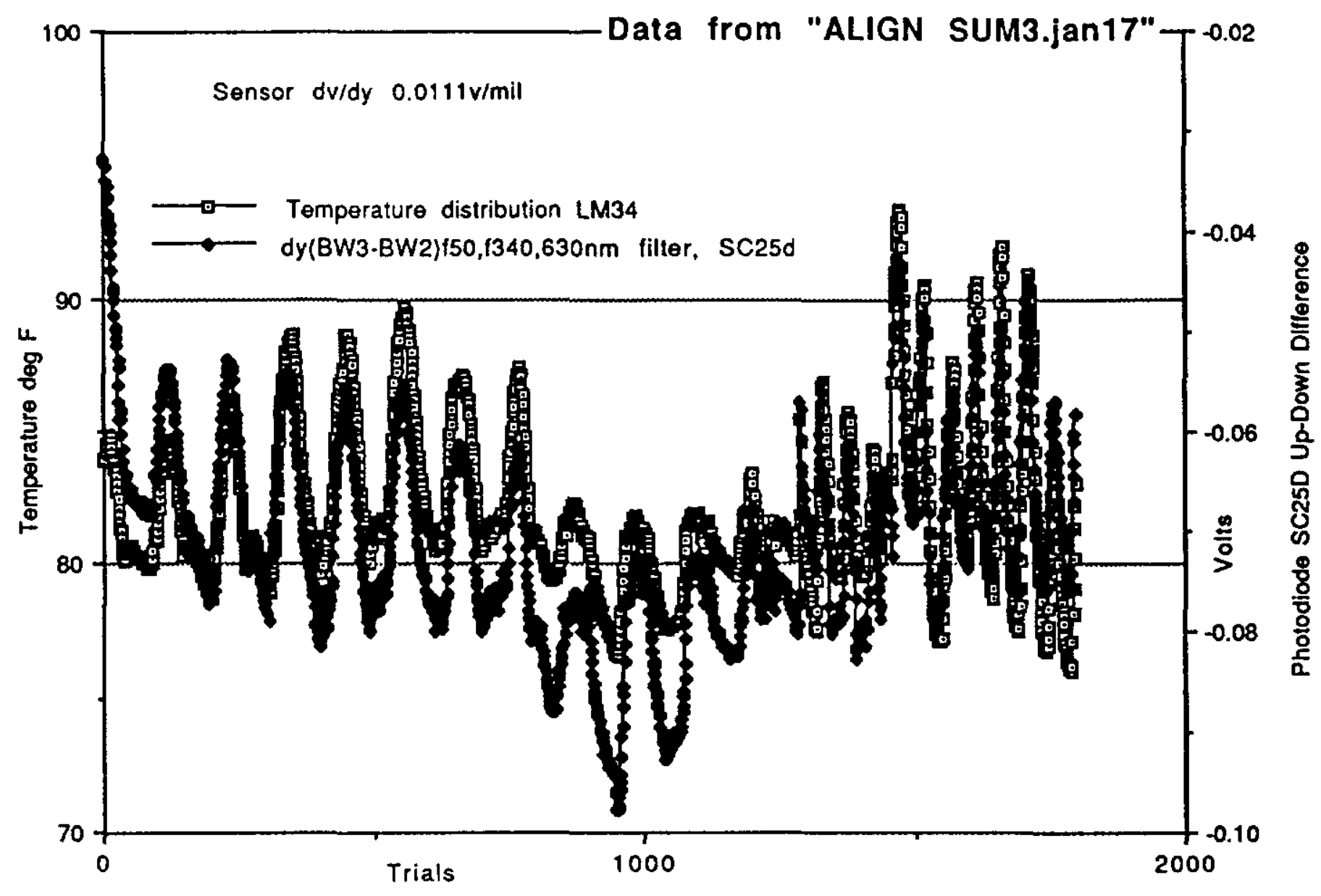

Figure 11d. $Y$ axis difference voltage output of a SC25d photodiode in a fixed BW3 to BW2 optics configuration vs temperature variation.over a sum of long term periods. The output tracks temperature variation but the shifts of the average output in different periods is evident. 


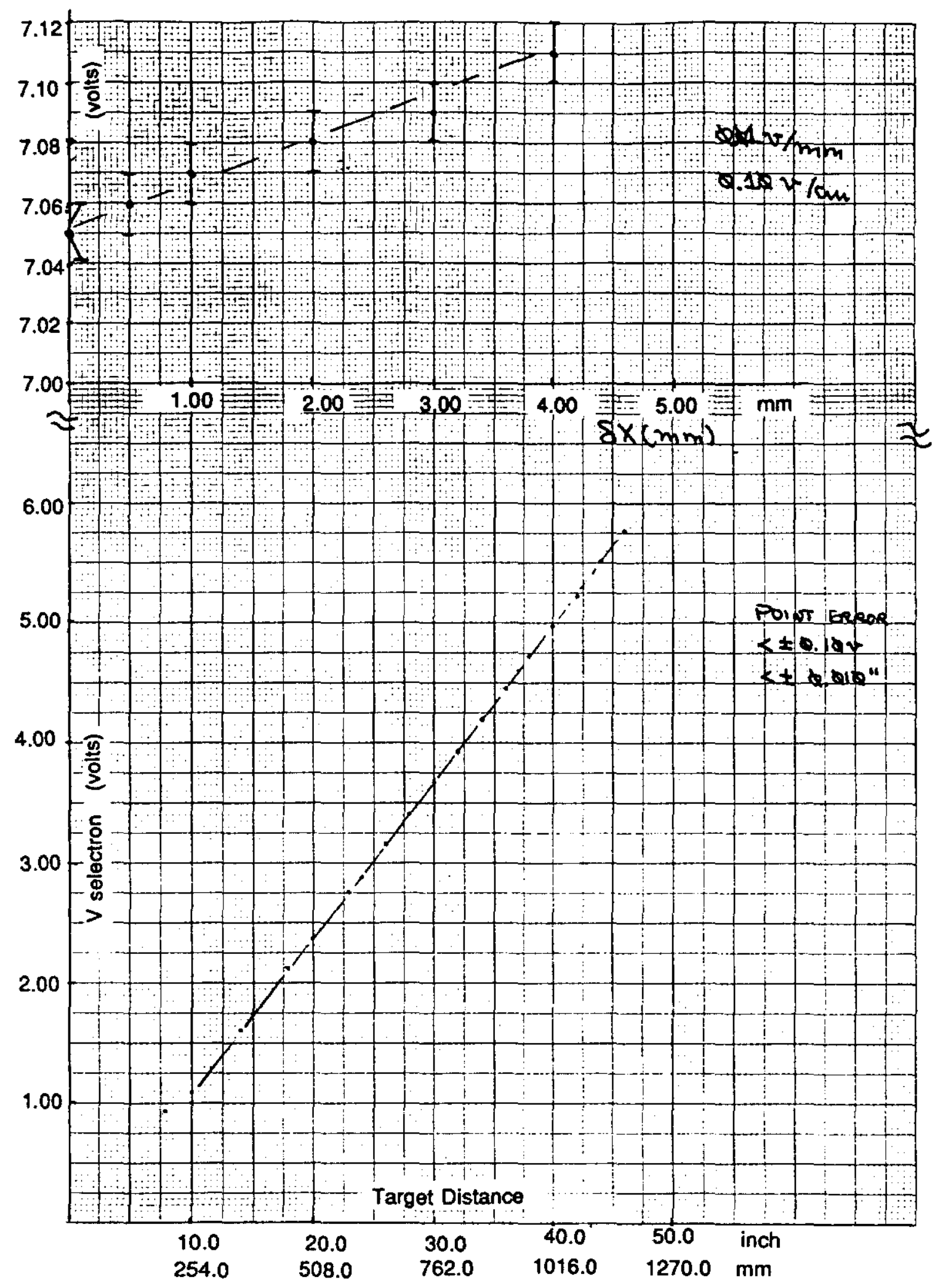

Figure 12. Selectron analog output ultrasonic distance detector resolution and range curves. 


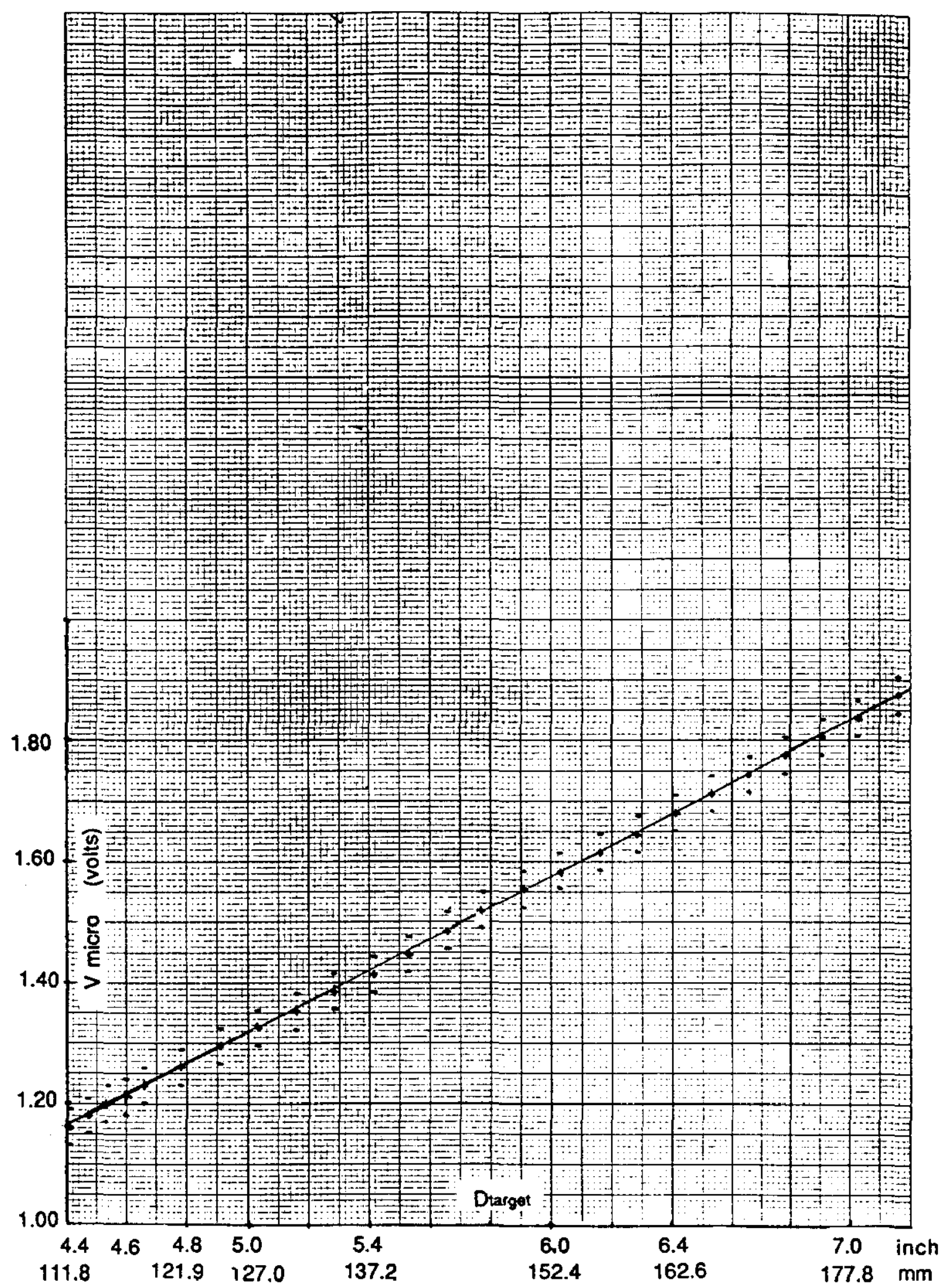

Figure 13a. Microswitch 945L analog output ultrasonic distance detector resolution curve. 
Figure 13b. Microswitch 945 $\mathrm{L}$ analog output ultrasonic distance detector linearlty and range curve.

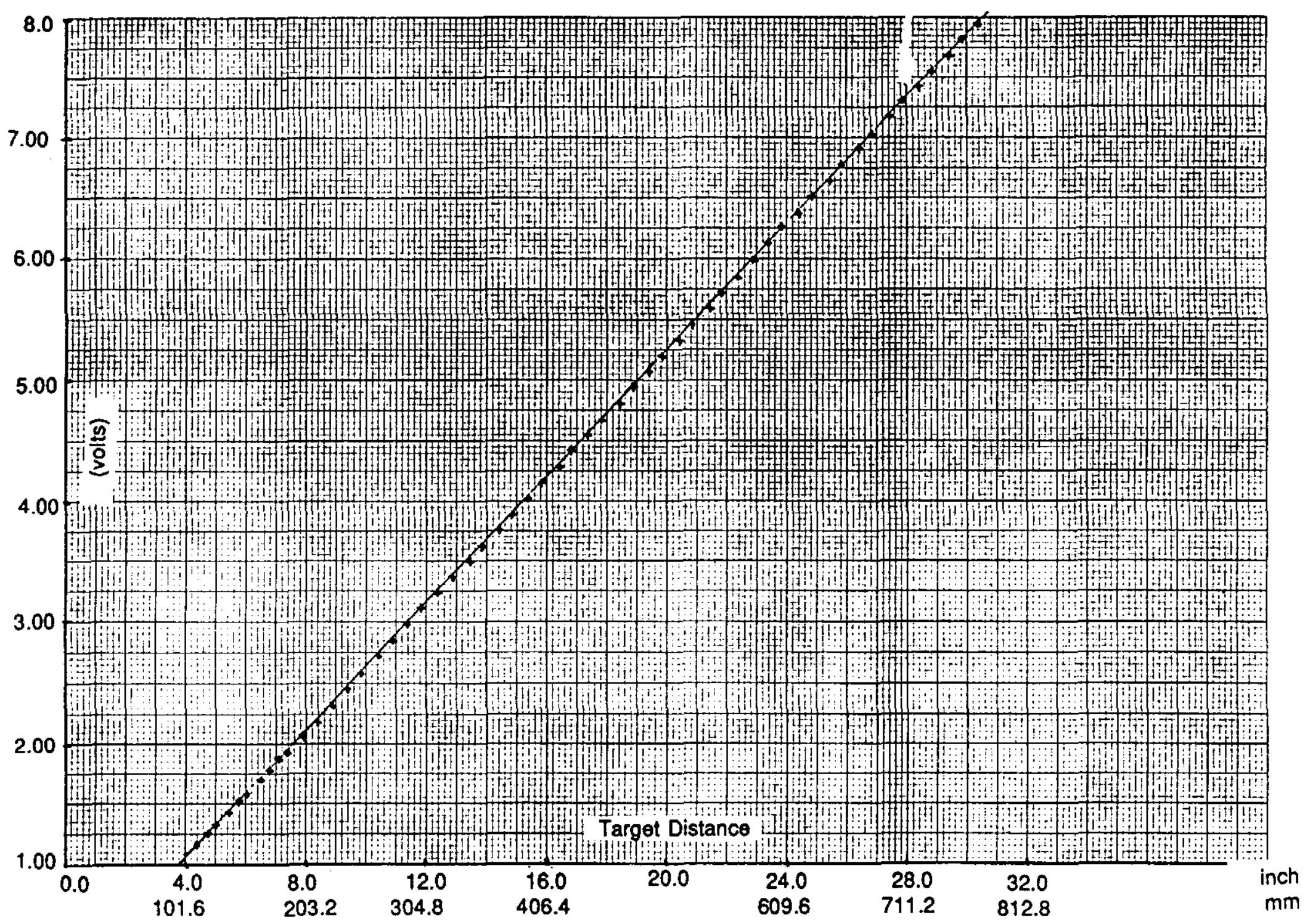




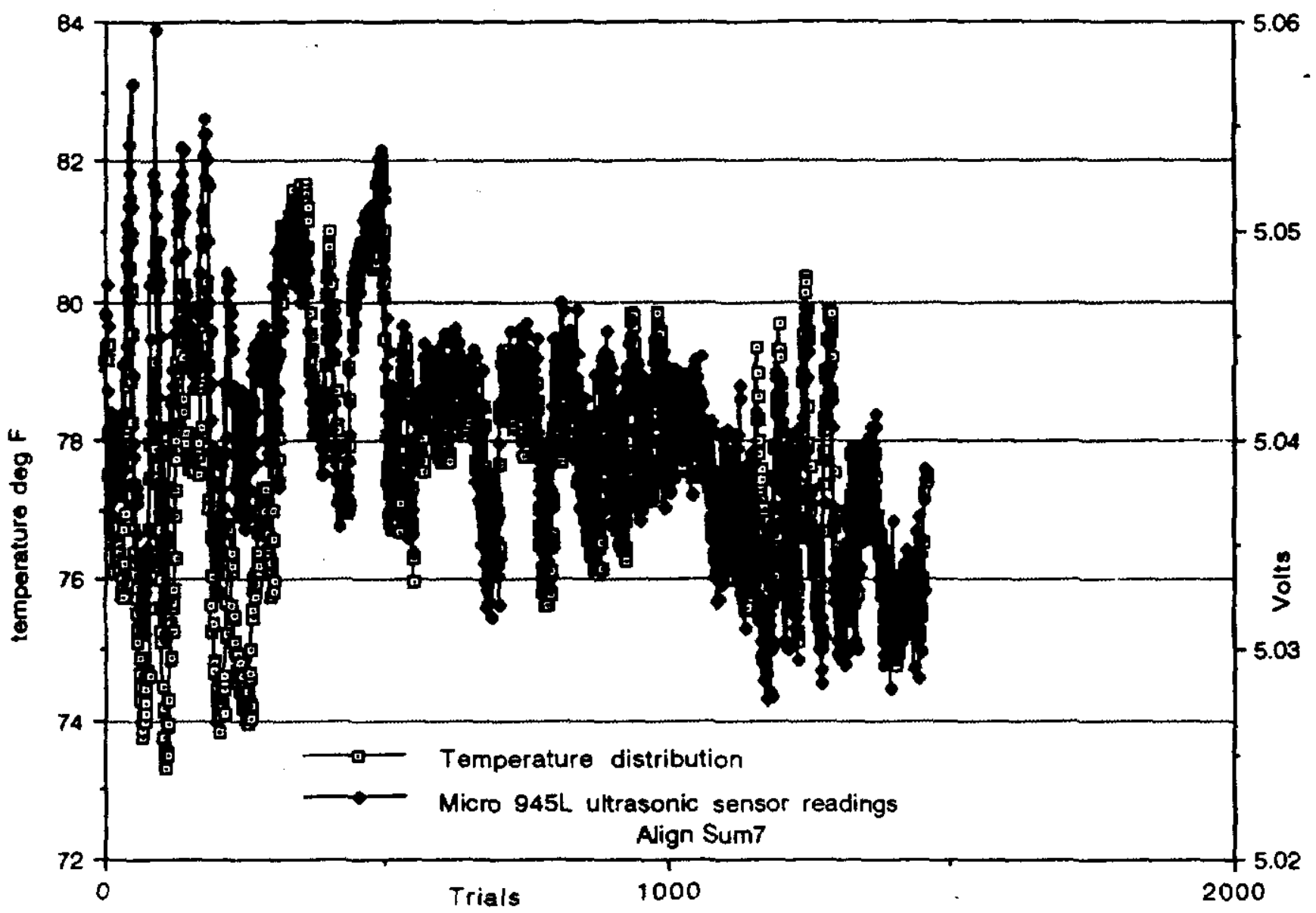

Figure 14. Long term runsum readings for the Microswitch ultrasonic distance detector on a fixed target as compared to the corresponding temperature distribution. 


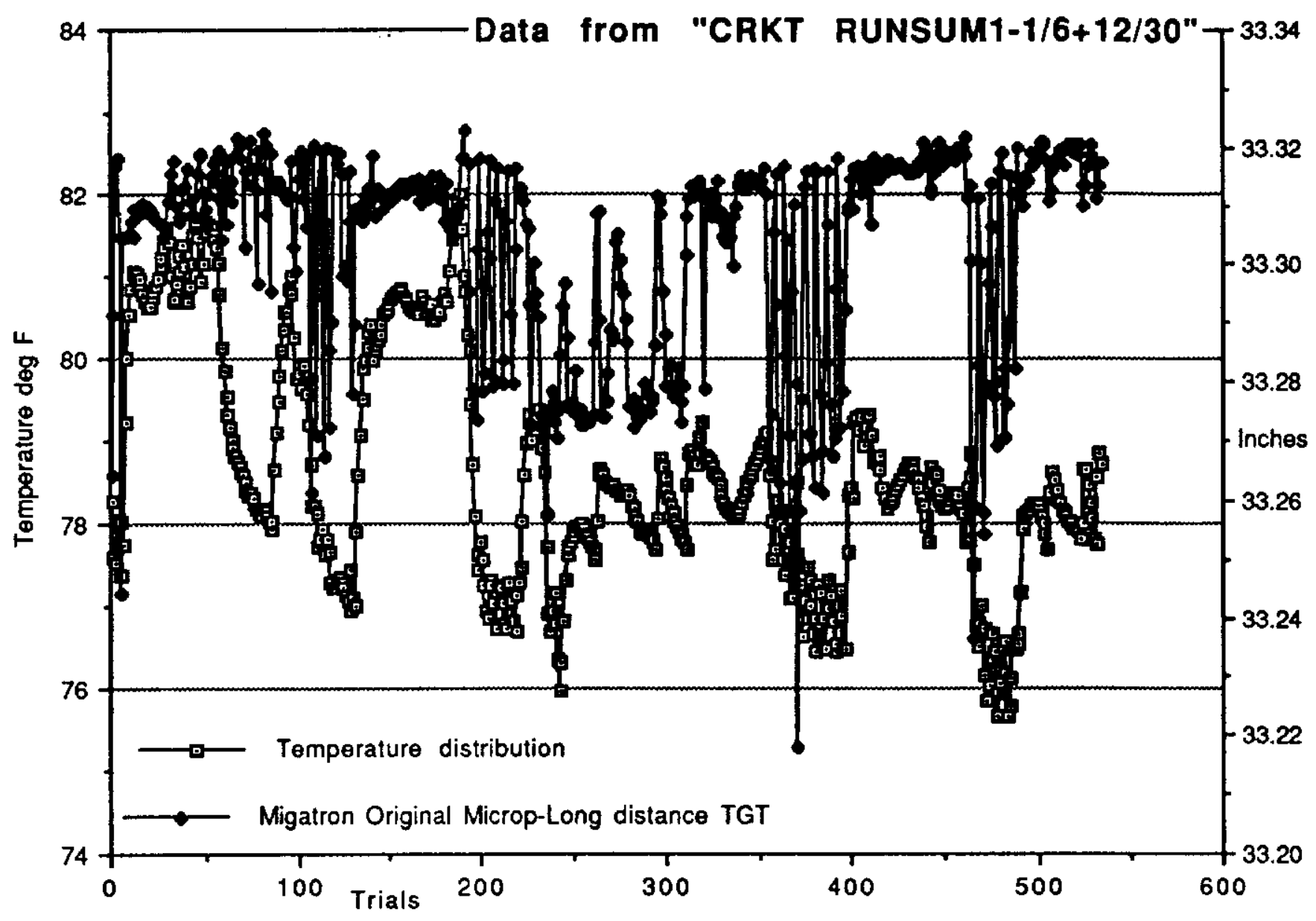

Figure 15. Long term readings of the original Migatron RPS- 8800 ultrasonic distance detector on a distant fixed target compared to the corresponding temperature distribution. For large temperature excursions there are microprocessor instabilities. 


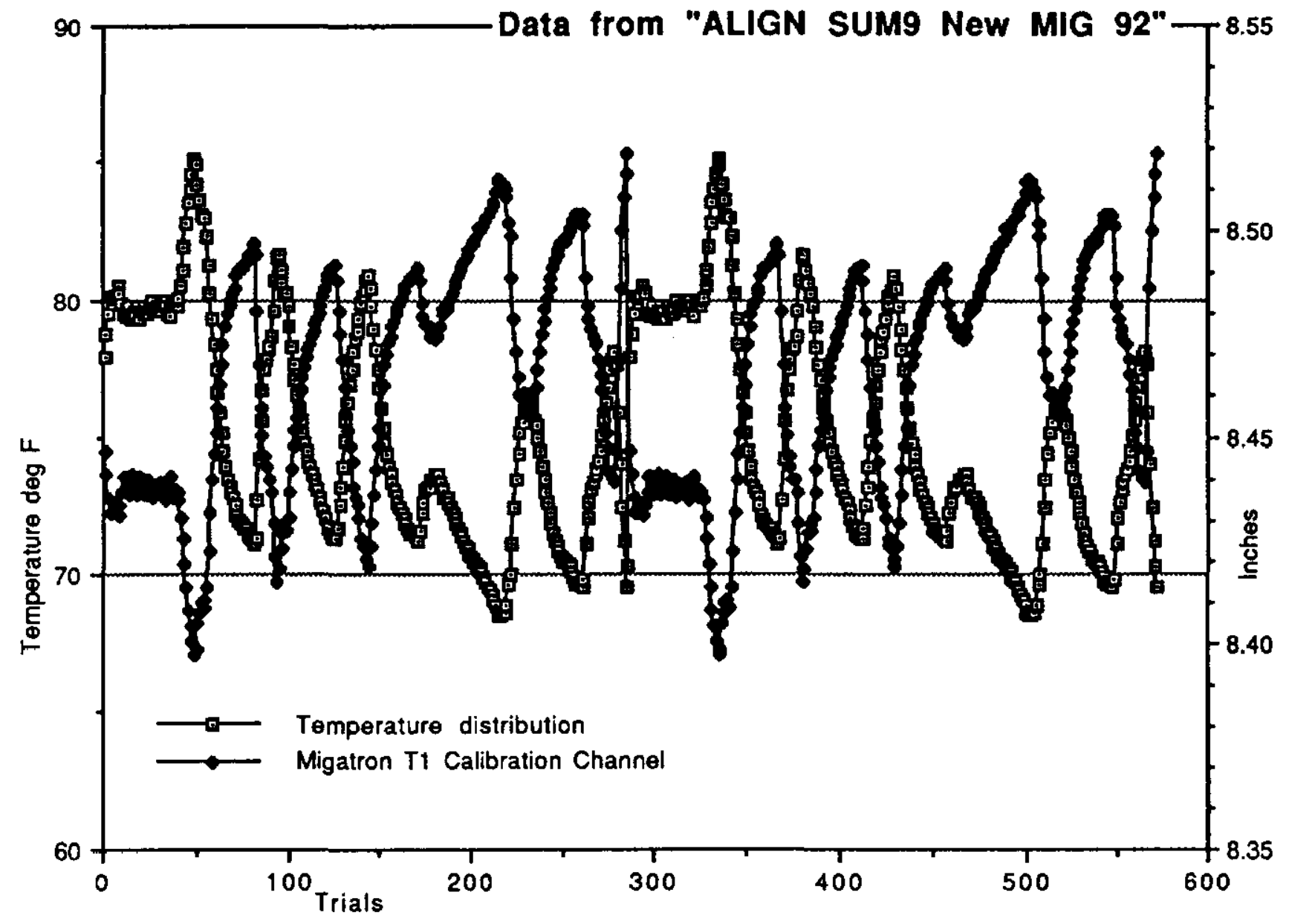

Figure 16a. Long term readings of the RPS-8800 raw calibration channel for the new Migatron microprocessor compared to the corresponding temperature distribution. 


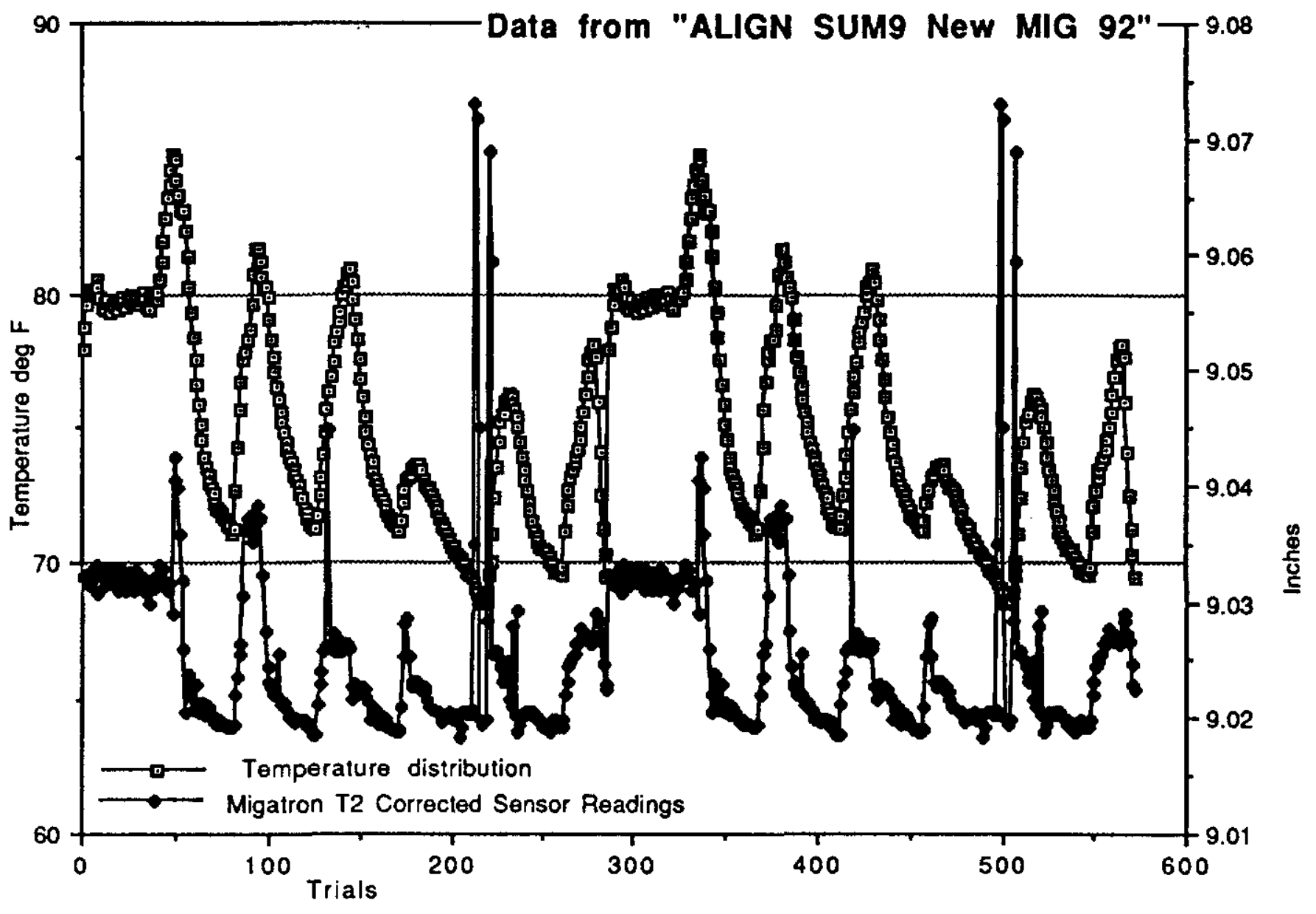

Figure 16b. Long term readings of the new RPS -8800 ultrasonic distance detector for a corrected channel T2 on a near fixed target compared to the temperature distribution. There are still instabilities. 


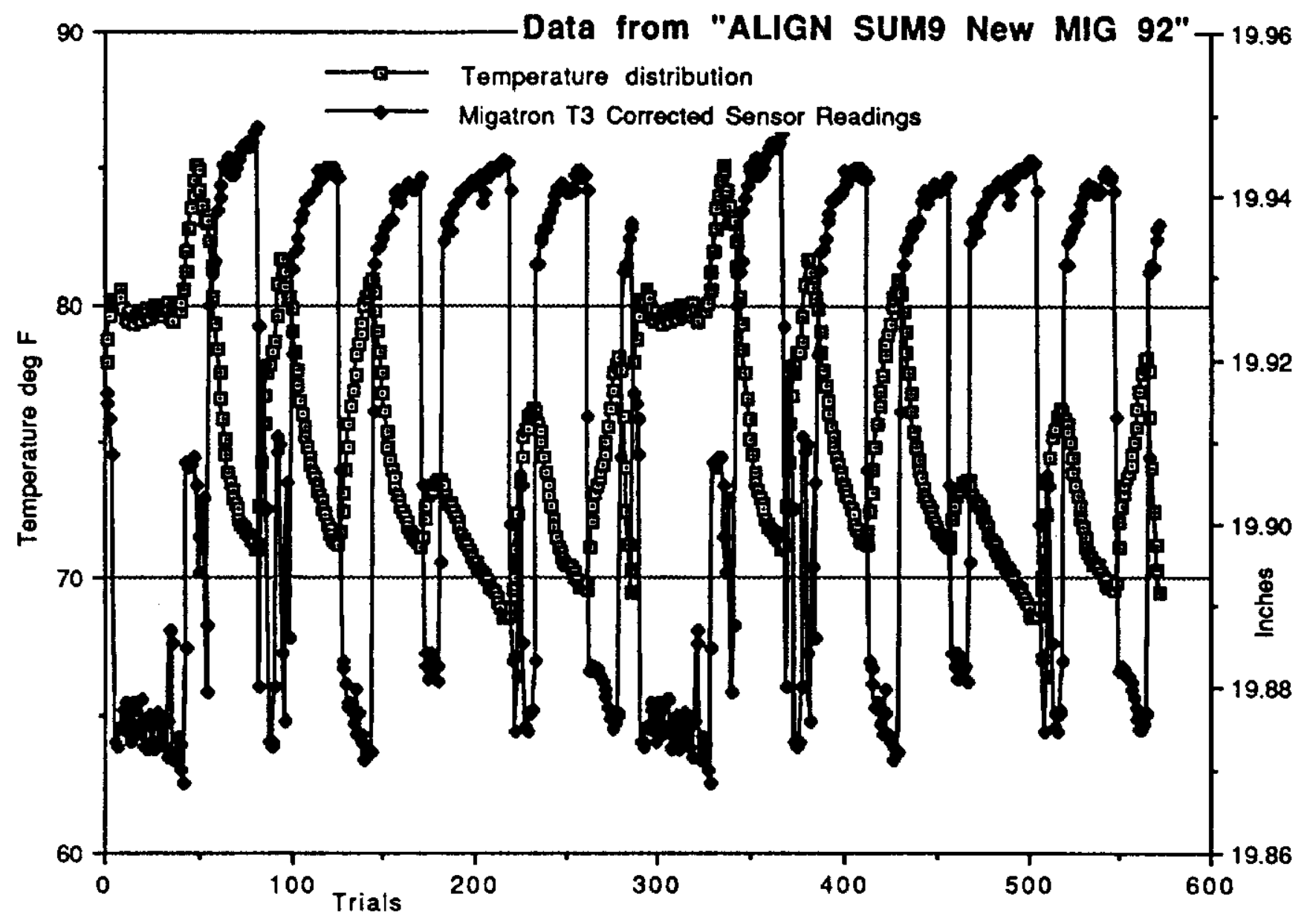

Figure 16c. Long term readings of the new RPS-8800 ultrasonic distance detector for a corrected channel T3 on a far fixed target compared to the temperature distribution. Data points are 30 minutes apart. 
Figure 17. Schematic outline of the Keyence laser diode distance measuring detector.

OPERATING PRINCIPLE

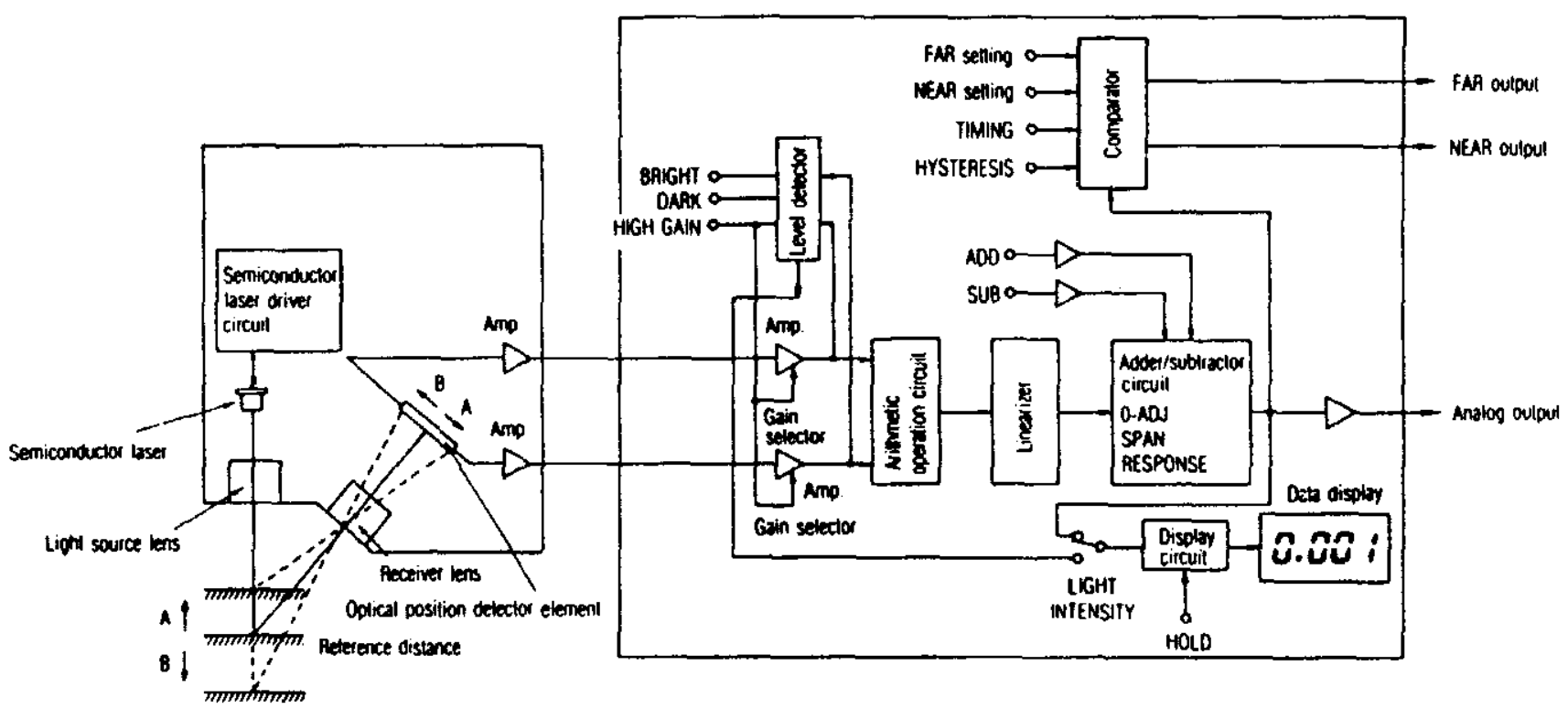

The light beam emitted from the laser is converged through the light source lenses and thrown on the object to be detected. When the light beam is reflected from the object, however, it is diffused. The diffused light beam is converged again by the receiver lenses and cast on the optical position detector element as a small spot. When the object is displaced, the light spot is accordingly moved. The optical position detector element in turn encodes the amount of the movement into an electric signal. An arithmetic operation circuit provided in the controlter outputs the electric signal that indicates the displacement of the object. The magnitude of this output signal is independent of the reflection factor of the cetected object. 


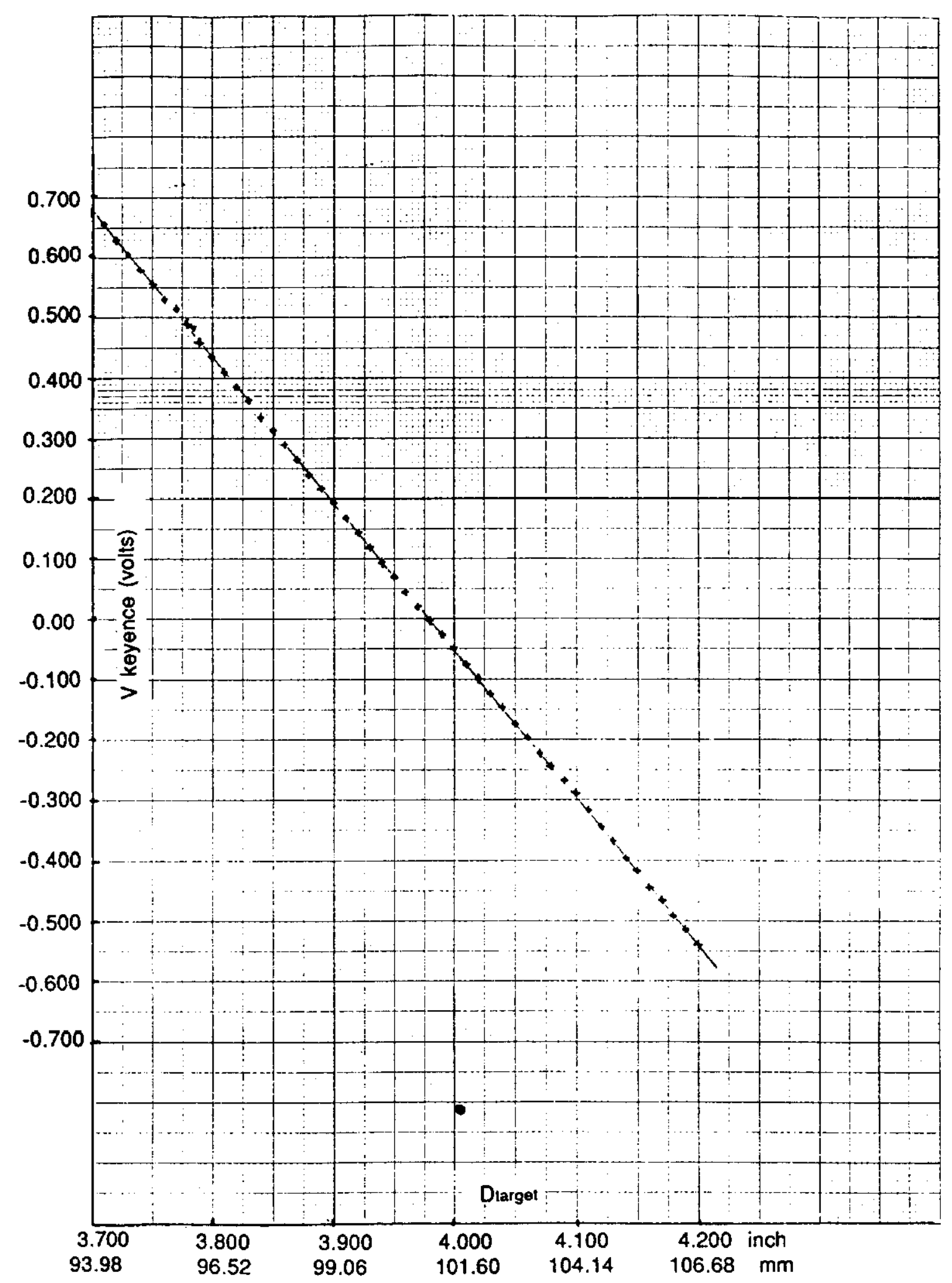

Figure 18. Measured resolution of the Keyence optical distance measuring system over a micrometer support stage range. 


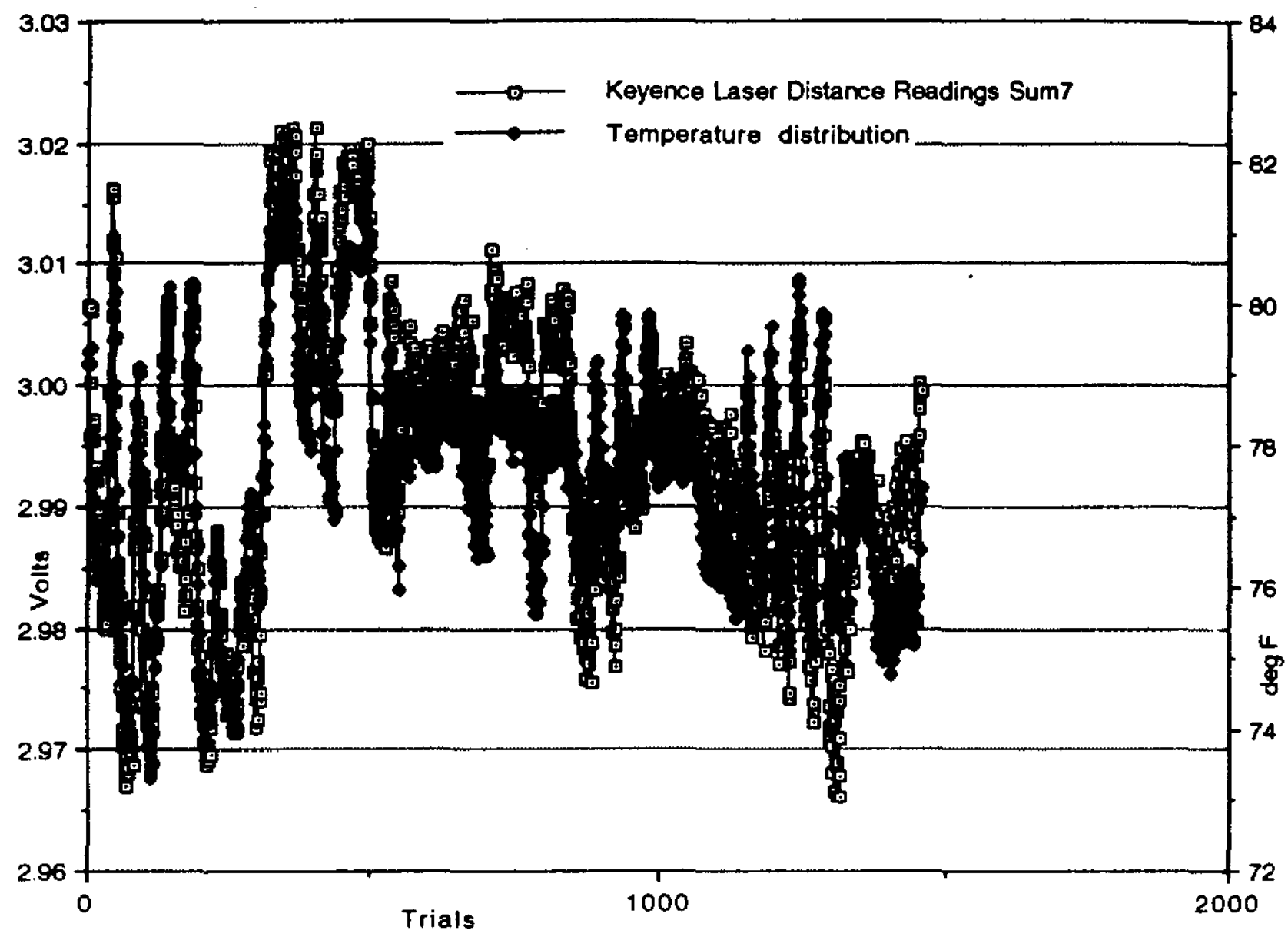

Figure 19. Long term readings of the Keyence distance measuring device on at fixed target at a $130 \mathrm{~mm}$ distance compared to the corresponding temperature distribution. Data points are 30 minutes apart. 

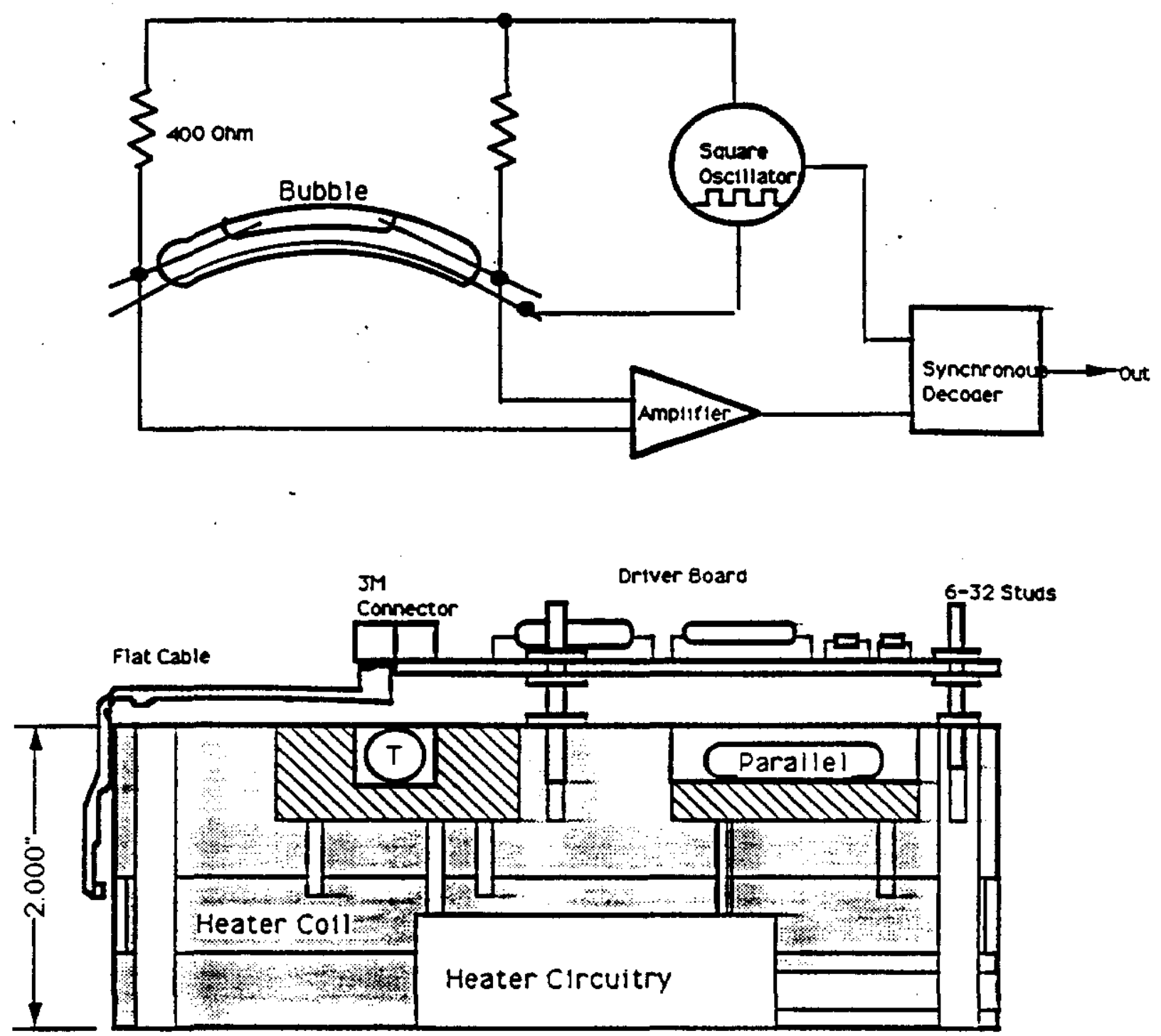

Figure 20. Schematic of dual bubble inclinometer block and detector. For our tests, both bubbles were transverse in each block. The block is thermally stabilized with a heater and insulation. 


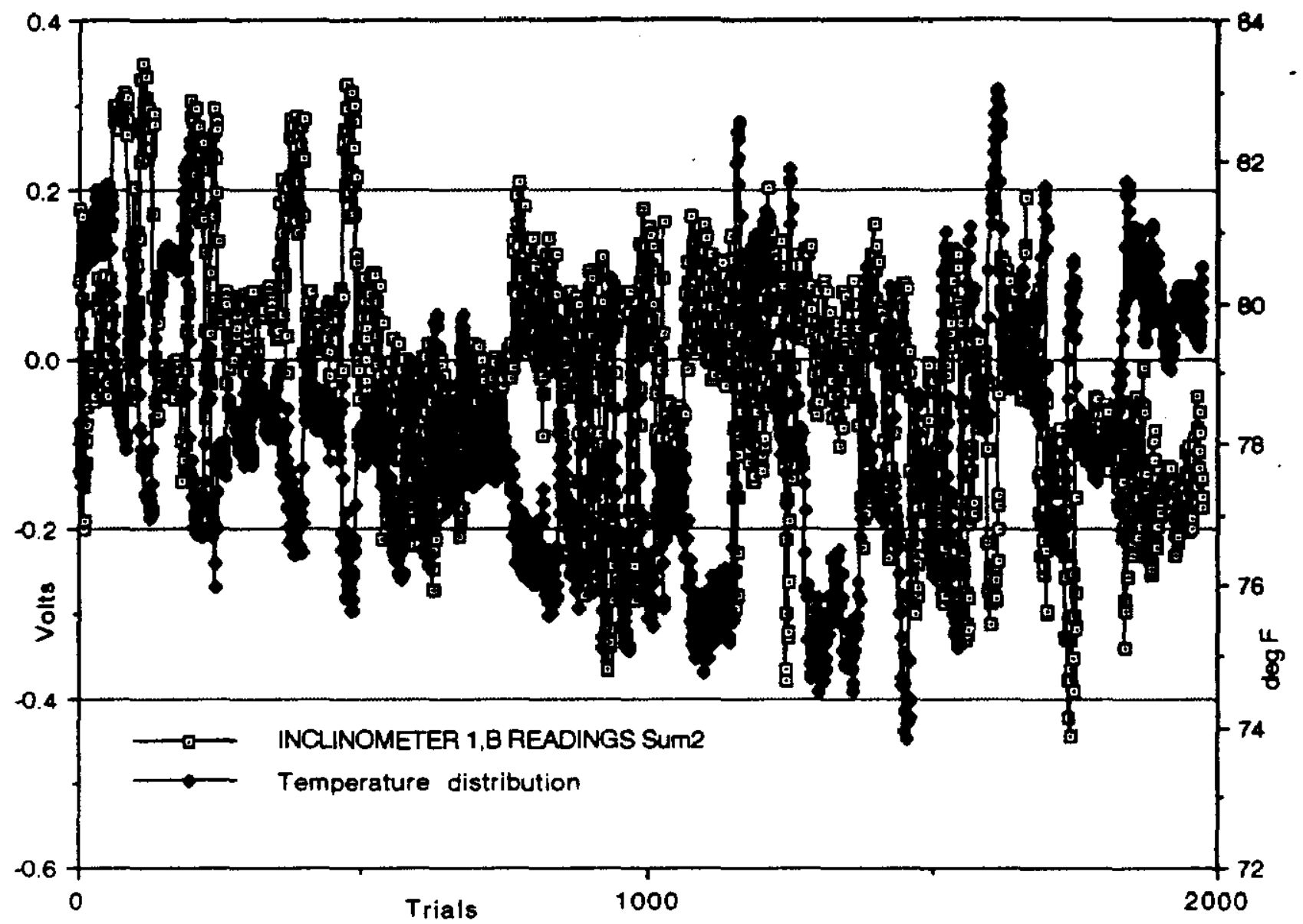

Figure 21. Long term readings on Inclinometer 1, channel B compared to the corresponding ambient temperature distribution. There are physical fluctuations of the support base correlated with temperature fluctuations. Data points are 30 minutes apart. 


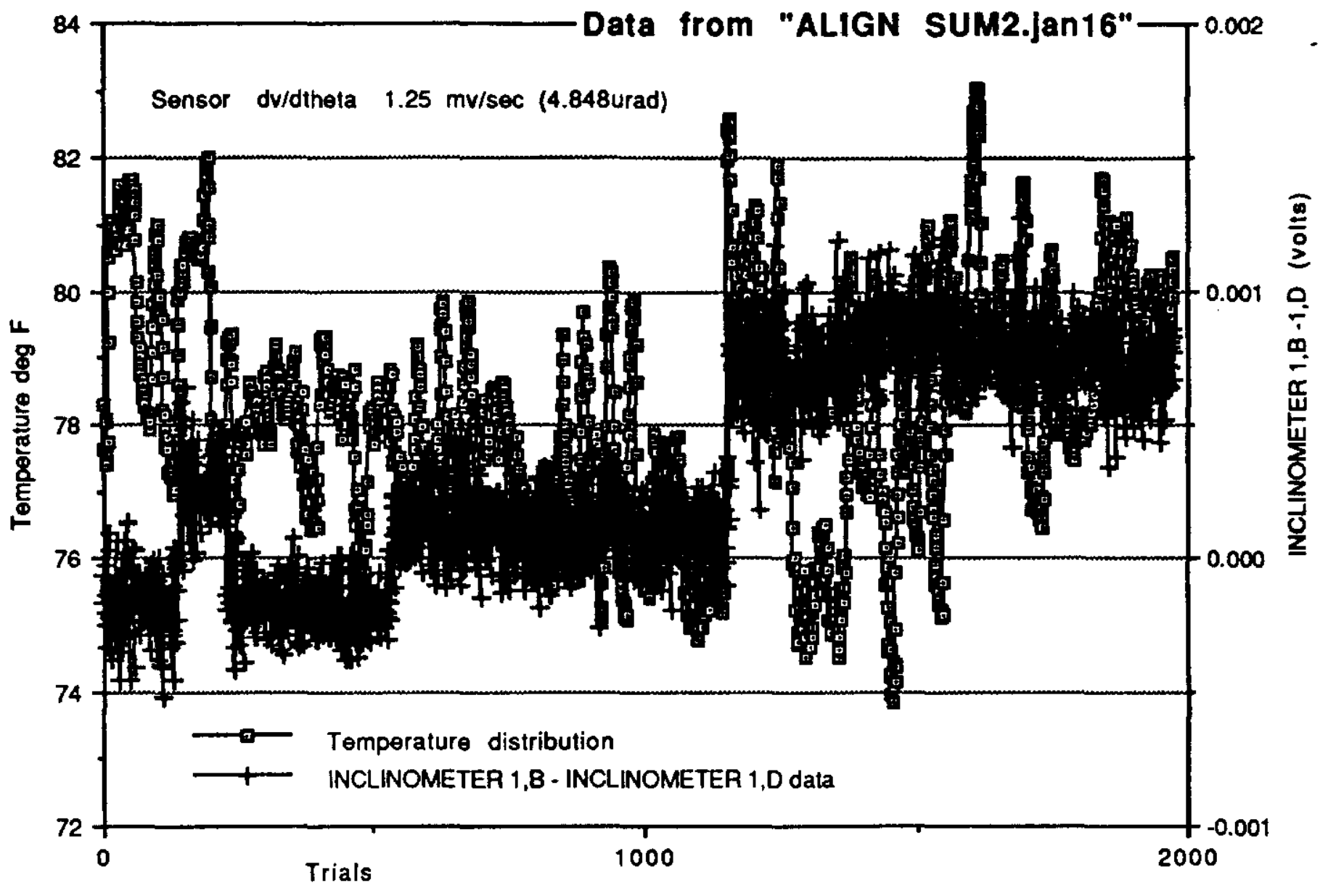

Figure 22. Long term reading difference of Inclinometer 1, channel B and 1 , channel $D$ compared to the corresponding temperature distribution. Here the small shifts for extended time periods are uncorrelated with temperature fluctuations. 


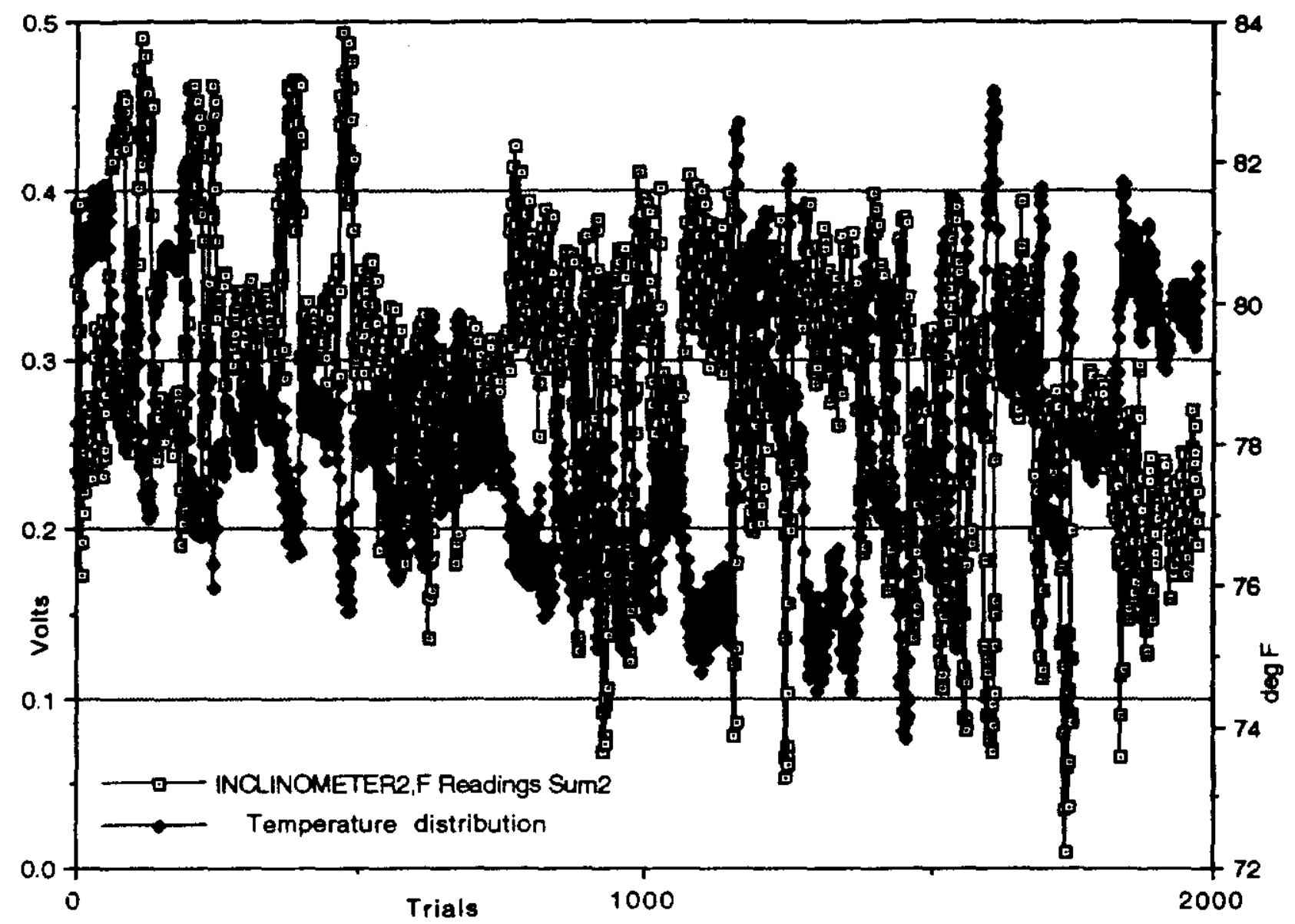

Figure 23. Long term readings on Inclinometer 2, channel $F$ compared to the corresponding ambient temperature distribution. The physical fluctuations are comparable to Inclinometer 1. Data points are 30 minutes apart. 


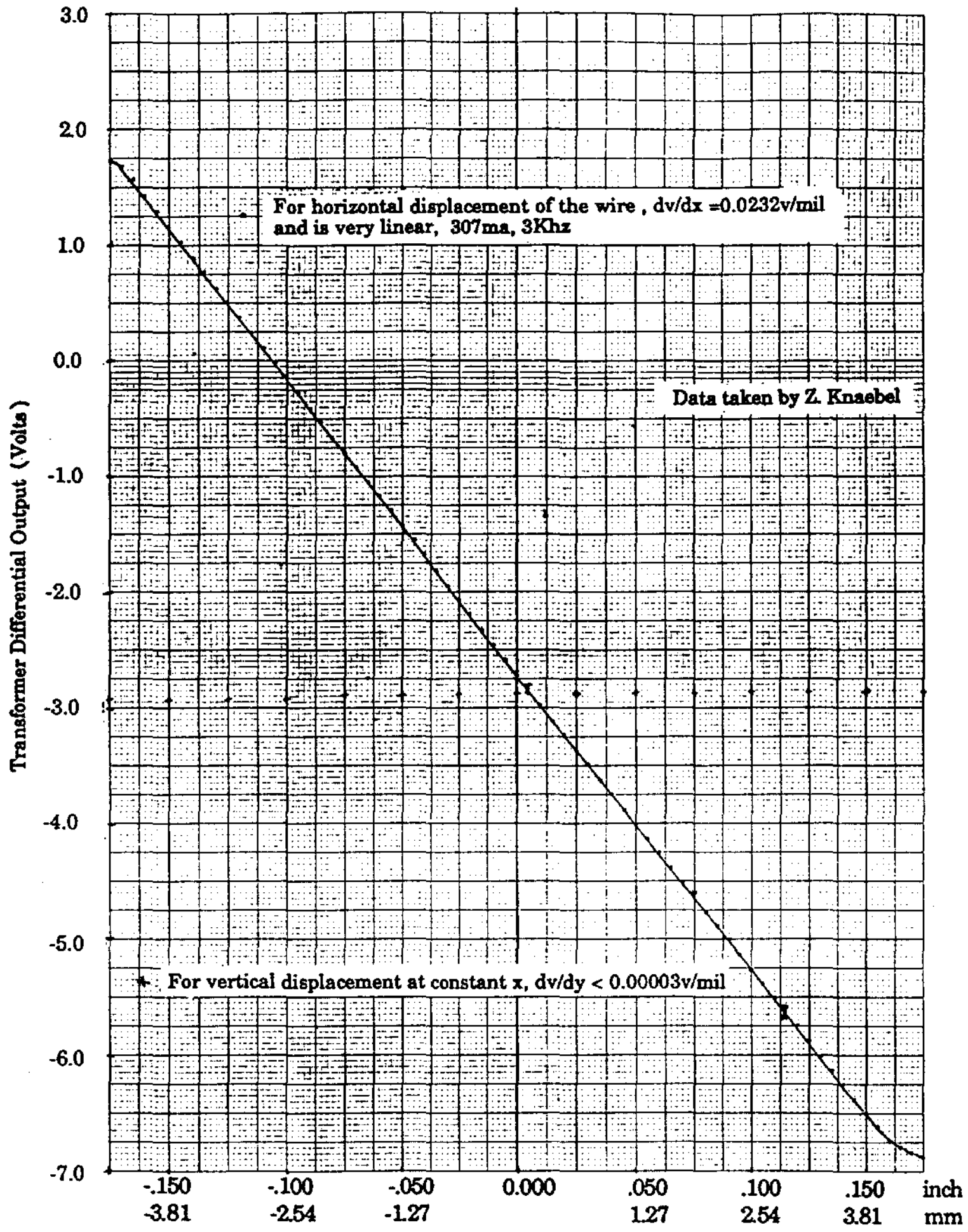

Figure 24. Transformer-electronics difference voltage output for displacement of the source wire (307ma, 3Khz) inside the transformer. The two vertical legs of the transformer have bucking coils. There is a very small vertical gradient of the difference output. 
Figure 25. The small vertical gradient of the difference voltage output for vertical motion of the source wire inside the transformer.

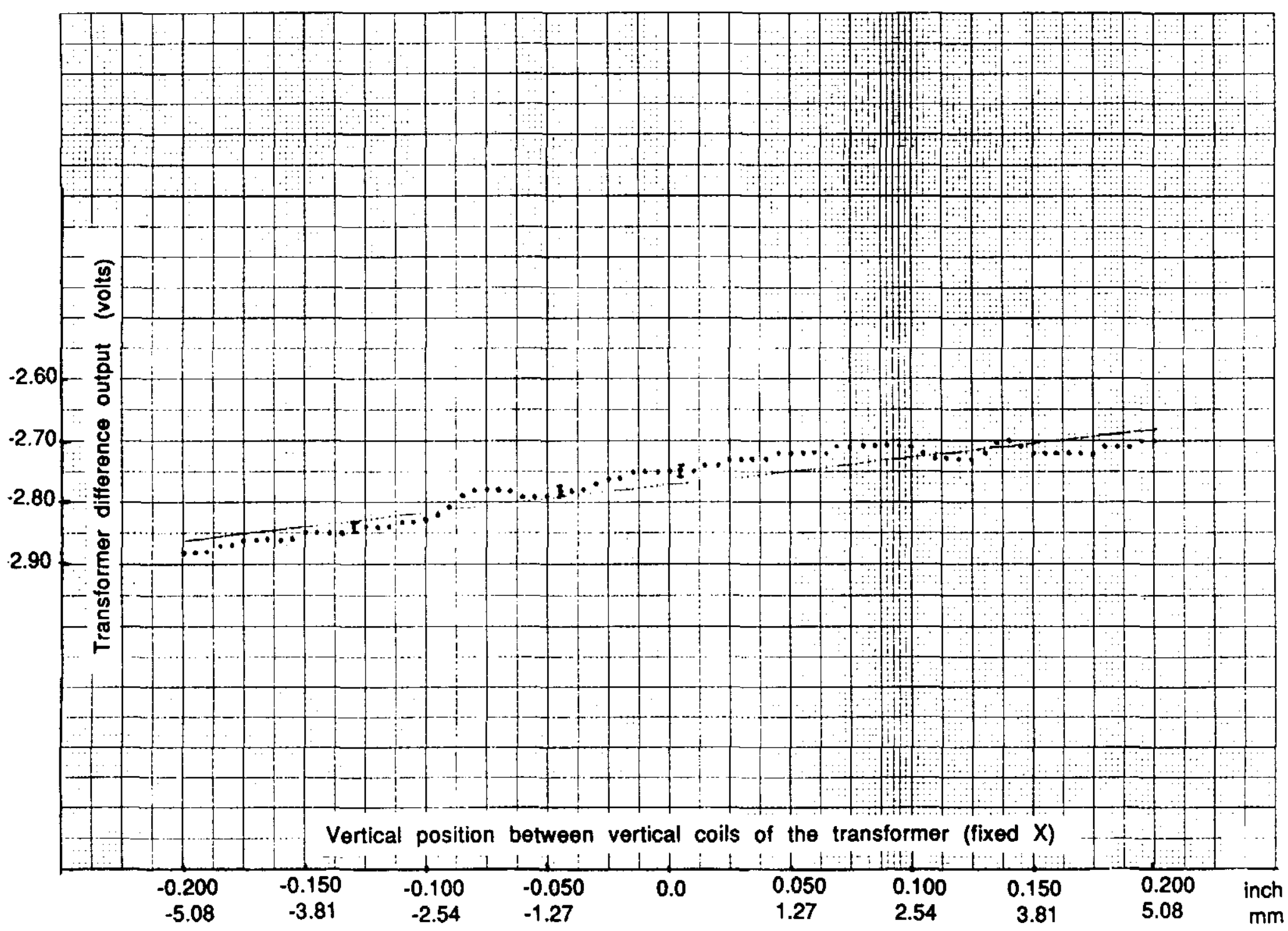




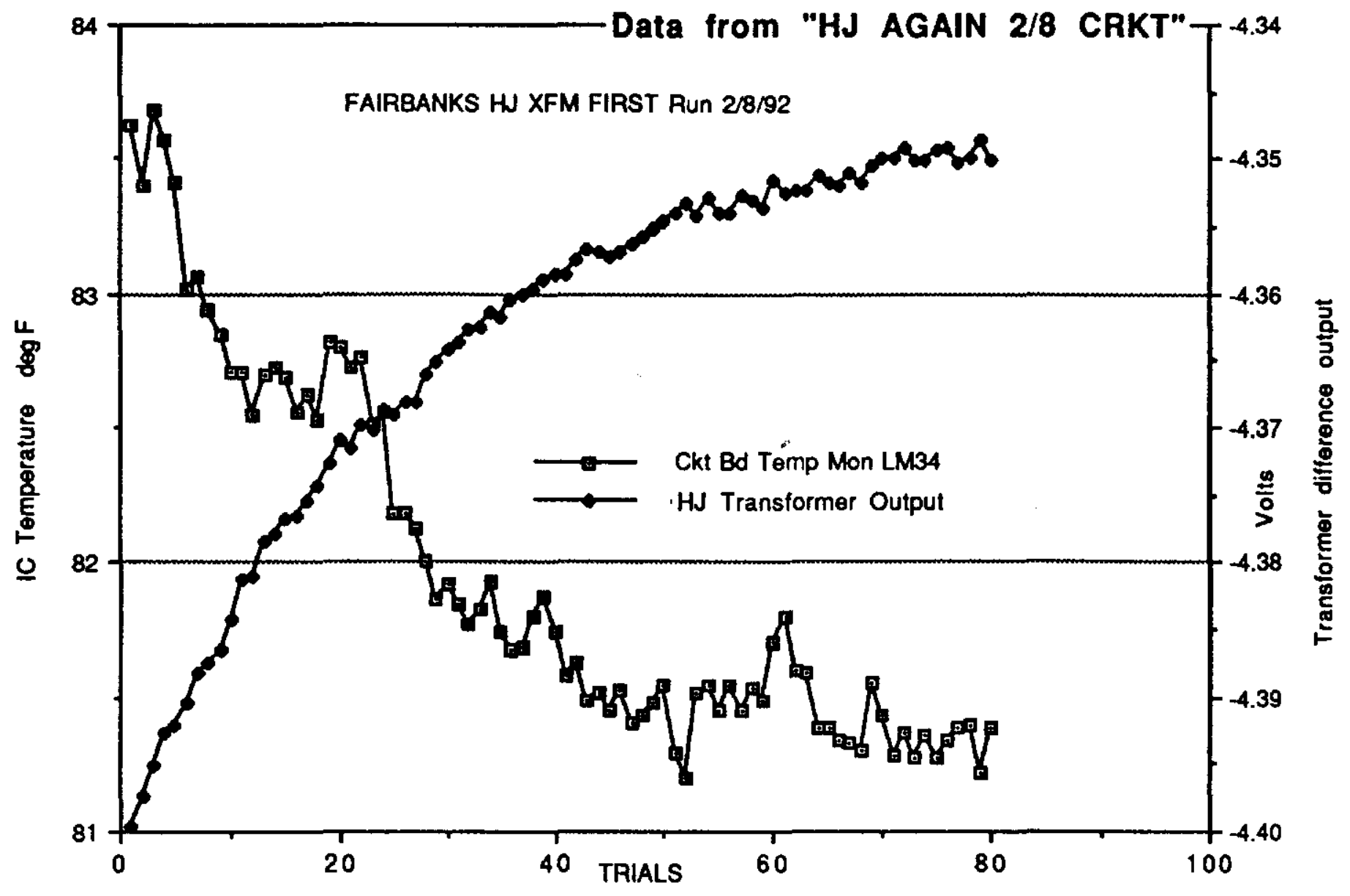

Figure 26. Short term readings of the transformer difference output compared to the corresponding temperature distribution of the electronics. 


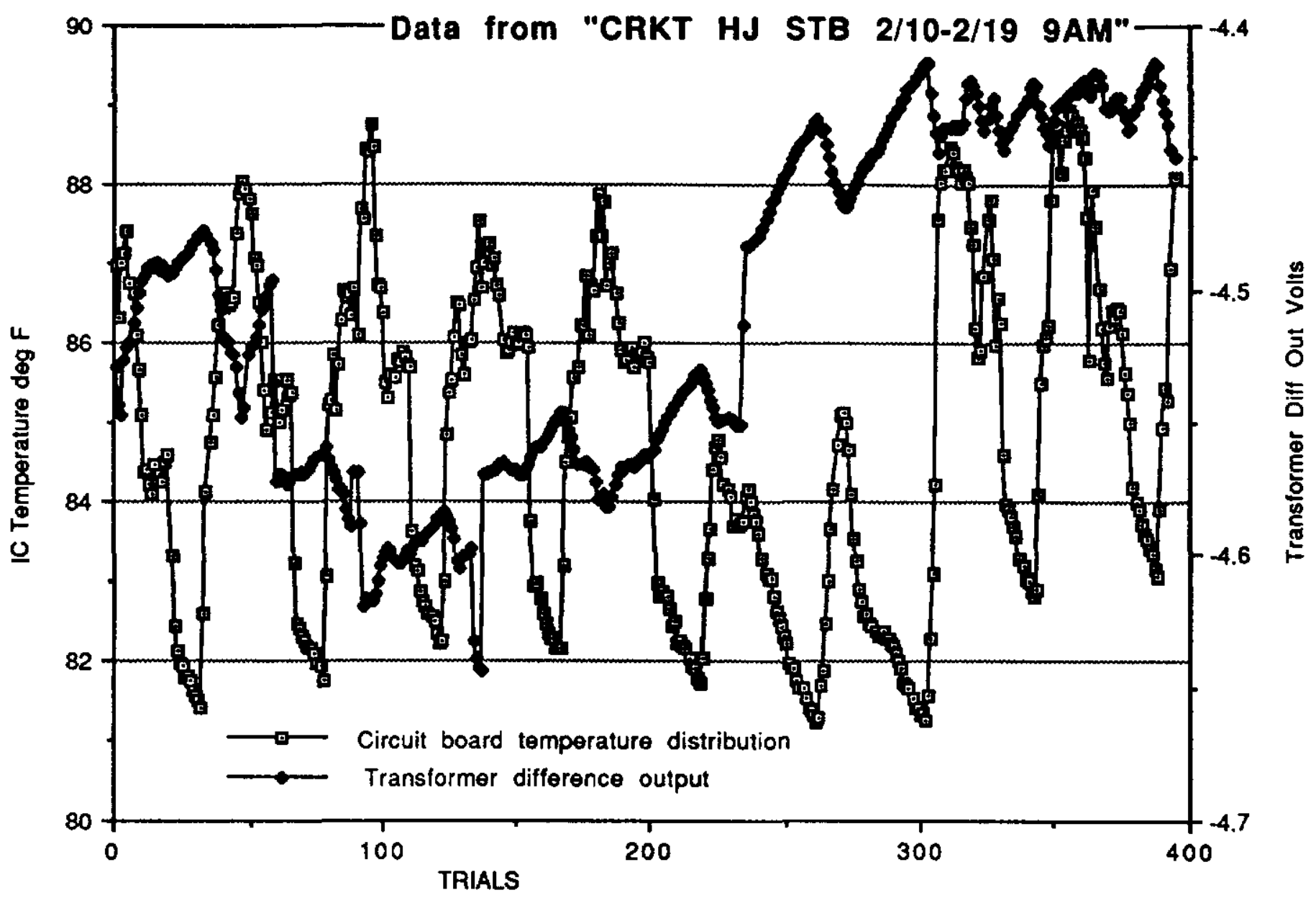

Figure 27. First long term stability test on the transformerelectronics difference output compared to the corresponding circuit temperature distribution. There is a shift of the data curve that may represent a shift of the input current on the wire or amplifier gain. New LVDT circuitry is being implemented. 


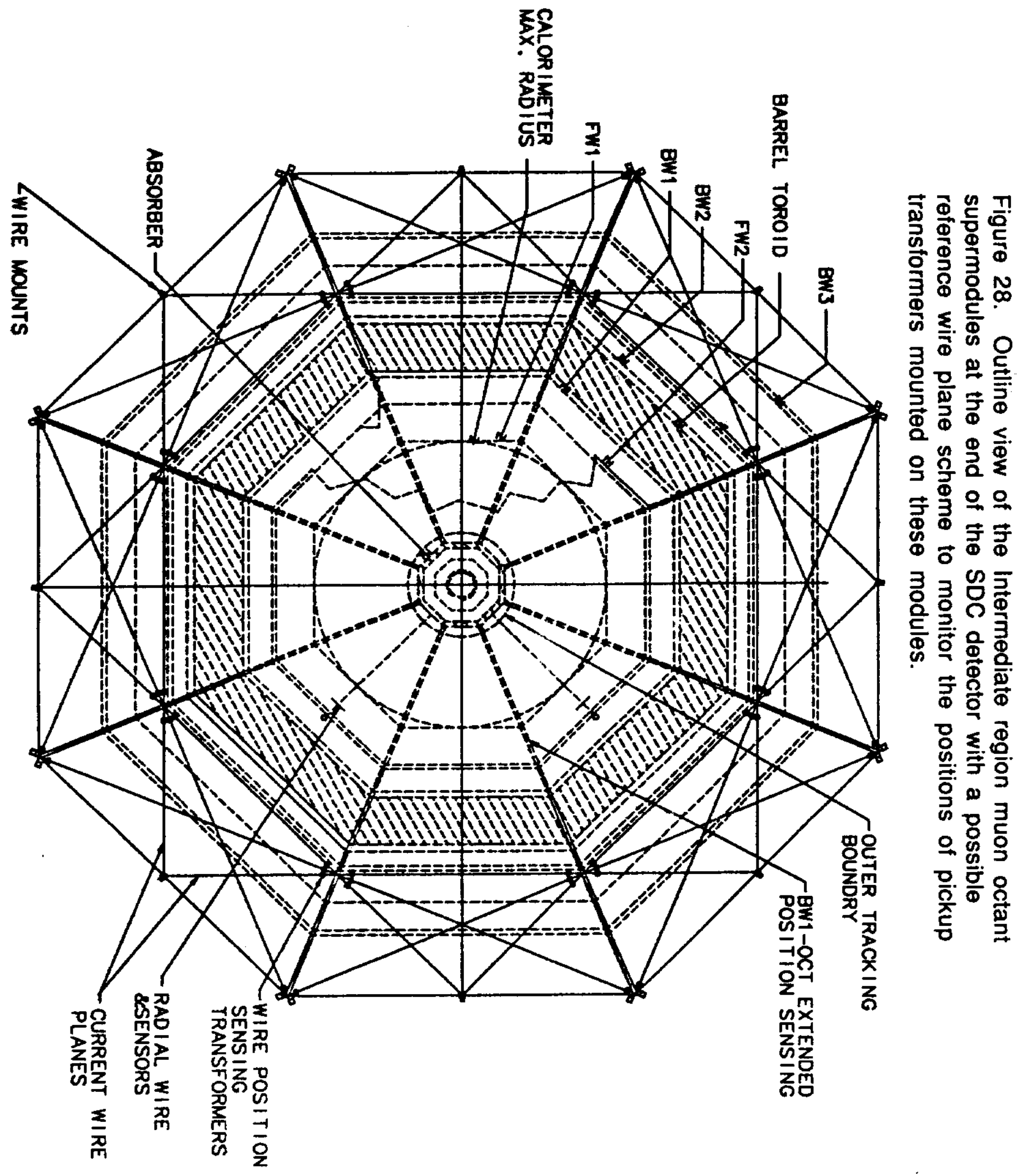

